RICE UNIVERSITY

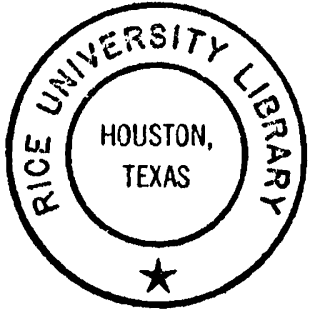

PREDICTION-OF BINARY CRITICAL LOCI

BY CUBIC EQUATIONS OF STATE

by

ROBERT M. PALENCHAR

A THESIS SUBMITTED

IN PARTIAL FULFILLMENT OF THE

REQUIREMENTS FOR THE DEGREE

MASTER OF SCIENCE

APPROVED, THESIS COMMITTEE:

T.W. telace
T.W. Leland, Director
Professor of Chemical Engineering

Clavens A.Molé

Clarence A. Miller

Professor of Chemical Engineering

Merh A. Rokert

Mark A. Robert

Assistant Professor of

Chemical Engineering

Houston, Texas

May, 1985

31272002890653 


\section{ABSTRACT \\ PREDICTION OF BINARY CRITICAL LOCI \\ BY CUBIC EQUATIONS OF STATE}

bY ROBERT M. PALENCHAR

The equations of state by Redlich Kwong, Soave, Peng and Robinson, Adachi, and Teja generated the critical loci of four class 1 and four class 2 binary mixtures. Two unlike pair parameters were used to fit the equations to a single experimental critical point in the mixture. The Teja equation was the most accurate for class 1 mixtures with a $0.9 \%$ deviation in predicting critical temperatures and a 2.6\% deviation in predicting critical pressures. The Peng and Robinson equation was least accurate with errors of $1.9 \%$ and $4.5 \%$ respectively. For class 2 systems, none of the equations were quantitatively correct in generating the critical curves. The Soave equation was the only one to at least qualitatively predict the critical lines for all the mixtures. All of the equations were incapable of accurately predicting the critical volumes of the mixtures. 


\section{ACKNOWLEDGEMENTS}

I would like to thank Dr. Thomas W. Leland for serving as my research advisor. He gave me many ideas while I was working on my thesis.

I would also like to thank $\mathrm{Dr}$. Clarence Miller and $\mathrm{Dr}$. Mark Robert for serving on my committee and for providing helpful comments after reading my thesis.

I wish to acknowledge the financial support of the Gas Research Institute (GRI) which made this study possible.

This thesis is dedicated to my parents. 


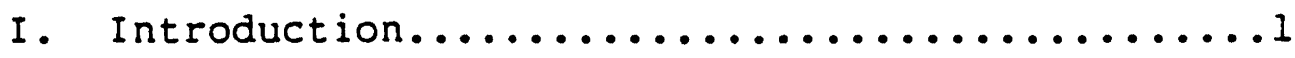

II. Thermodynamics of the Critical Point.........6

III. Equations of State..................

A. The Redlich Kwong Equation of State......10

B. The Soave Equation of State...........11

C. The Peng and Robinson Equation of State...12

D. The Adachi Equation of State...........13

E. The Teja Equation of State............14

F. Mixture Rules for Equations of State.....16

G. Calculation of the Critical Point.......17

IV. Results and Discussion............... 19

A. Class 1 Critical Loci.................

1. The Propane - Hexane System........22

2. The Methane - Carbon Dioxide System...35

3. The Butane - Carbon Dioxide System...44

4. The Decane - Carbon Dioxide System....57 
B. Class 2 Critical Loci.................59

5. The Benzene - Water System.........59

6. The Water - Carbon Dioxide System....63

7. The Methane - Hexane System.......67

8. The Methane - Heptane System.......70

C. Critical Volume Prediction............75

v. Conclusion........................

References..............................80

Appendices

A. Derivation of the Free Energy Equations in terms of $P, V$, and $x \ldots \ldots \ldots \ldots \ldots \ldots \ldots \ldots \ldots$ 


\section{LIST OF TABLES}

Number

Page

1. Average Percent Error in Predicting Binary Critical Loci by Cubic Equations of State.....20

2. Values of Fitted Parameters $\lambda_{12}$ and $\zeta_{12}$ for each Cubic Equation of state............21

3. Comparison of Calculating the Critical Loci of the Propane - Hexane System with and

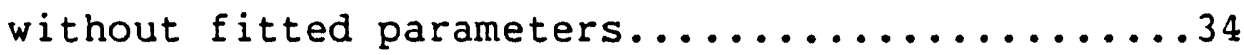

4. Comparison of Methods for Predicting

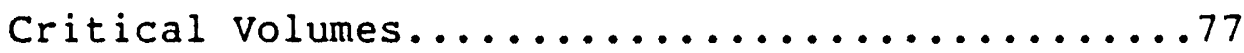




\section{LIST OF FIGURES}

Number

$\underline{\text { Page }}$

1. Critical Temperature of Propane - Hexane System

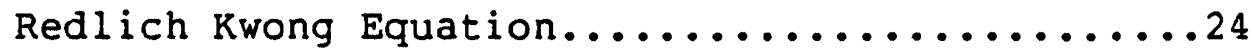

2. Critical Pressure of Propane - Hexane System Redlich Kwong Equation....................24

3. Critical Loci of Propane - Hexane System

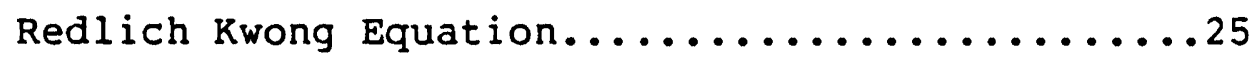

4. Critical Volume of Propane - Hexane System

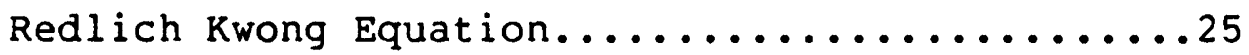

5. Critical Temperature of Propane - Hexane System

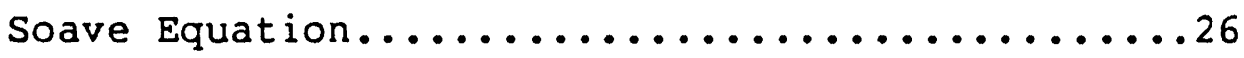

6. Critical Pressure of Propane - Hexane System

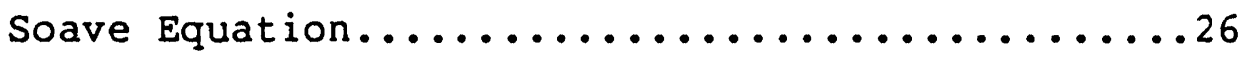

7. Critical Loci of Propane - Hexane System Soave Equation ( $f$ itted and unfitted curve) ....27

8. Critical Volume of Propane - Hexane System

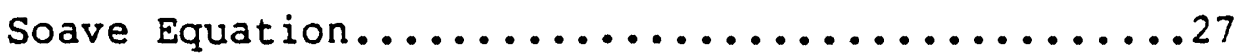

9. Critical Temperature of Propane - Hexane System

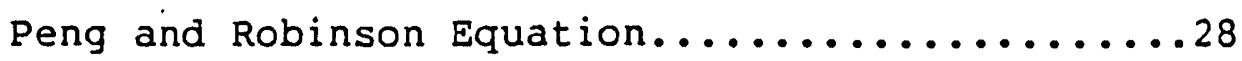


10. Critical Pressure of Propane - Hexane System Peng and Robinson Equation...............28

11. Critical Loci of Propane - Hexane System Peng and Robinson Equation (fitted and unfitted curves)..............29

12. Critical Volume of Propane - Hexane System Peng and Robinson Equation..................29

13. Critical Temperature of Propane - Hexane System

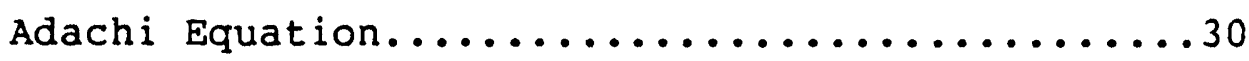

14. Critical Pressure of Propane - Hexane System

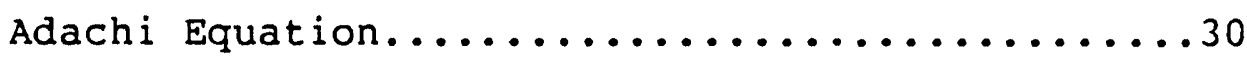

15. Critical Loci of Propane - Hexane System Adachi Equation (fitted and unfitted curves)....31

16. Critical Volume of Propane - Hexane System

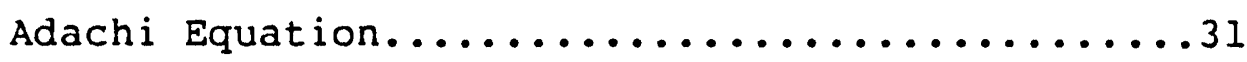

17. Critical Temperature of Propane - Hexane System

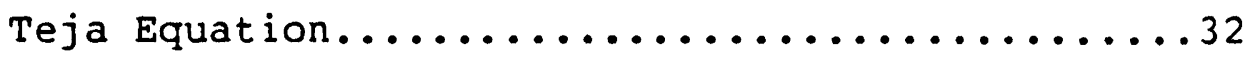

18. Critical Pressure of Propane - Hexane System

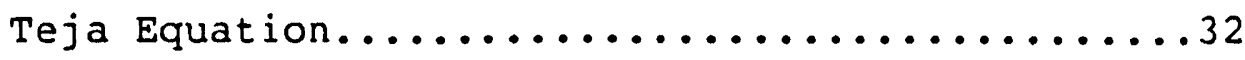

19. Critical Loci of Propane - Hexane System Teja Equation (fitted and unfitted curves).....33 
20. Critical Volume of Propane - Hexane System

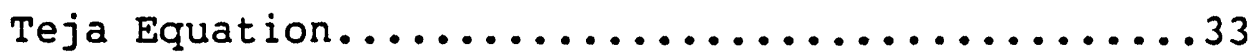

21. Critical Temperature of Methane - $\mathrm{CO}_{2}$ System Redlich Kwong Equation.....................

22. Critical Pressure of Methane $-\mathrm{CO}_{2}$ System

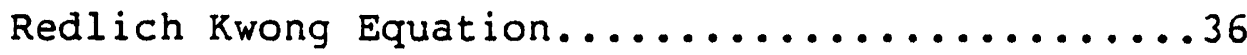

23. Critical Loci of Methane - $\mathrm{CO}_{2}$ System Redlich kwong Equation.......................

24. Critical Loci of Methane - $\mathrm{CO}_{2}$ System

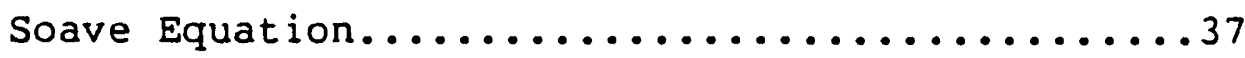

25. Critical Temperature of Methane $-\mathrm{CO}_{2}$ System Soave Equation..........................

26. Critical Pressure of Methane - $\mathrm{CO}_{2}$ System Soave Equation.........................

27. Critical Temperature of Methane - $\mathrm{CO}_{2}$ System Peng and Robinson Equation...................

28. Critical Pressure of Methane $-\mathrm{CO}_{2}$ System Peng and Robinson Equation...................

29. Critical Loci of Methane - $\mathrm{CO}_{2}$ System Peng and Robinson Equation...............40 
30. Critical Loci of Methane - $\mathrm{CO}_{2}$ System Adachi Equation....................40

31. Critical Temperature of Methane $-\mathrm{CO}_{2}$ System Adachi Equation......................41

32. Critical Pressure of Methane $-\mathrm{CO}_{2}$ System Adachi Equation........................

33. Critical Temperature of Methane $-\mathrm{CO}_{2}$ System Teja Equation......................42

34. Critical Pressure of Methane $-\mathrm{CO}_{2}$ System Teja Equation........................

35. Critical Loci of Methane $-\mathrm{CO}_{2}$ System Teja Equation........................

36. Critical Temperature of Butane $-\mathrm{CO}_{2}$ System Redlich Kwong Equation.................. 46

37. Critical Pressure of Butane - $\mathrm{CO}_{2}$ System Redlich Kwong Equation..................46

38. Critical Loci of Butane - $\mathrm{CO}_{2}$ System Redlich Kwong Equation................47

39. Critical Volume of Butane $-\mathrm{CO}_{2}$ System Redlich Kwong Equation................. 
40. Critical Temperature of Butane $-\mathrm{CO}_{2}$ System Soave Equation.....................48

41. Critical Pressure of Butane - $\mathrm{CO}_{2}$ System Soave Equation......................48

42. Critical Loci of Butane $-\mathrm{CO}_{2}$ System Soave Equation.......................49

43. Critical volume of Butane $-\mathrm{CO}_{2}$ System Soave Equation.......................49

44. Critical Temperature of Butane $-\mathrm{CO}_{2}$ System Peng and Robinson Equation................. 50

45. Critical Pressure of Butane $-\mathrm{CO}_{2}$ System Peng and Robinson Equation................. 50

46. Critical Loci of Butane $-\mathrm{CO}_{2}$ System Peng and Robinson Equation................ 51

47. Critical Volume of Butane - $\mathrm{CO}_{2}$ System Peng and Robinson Equation.................

48. Critical Temperature of Butane $-\mathrm{CO}_{2}$ System

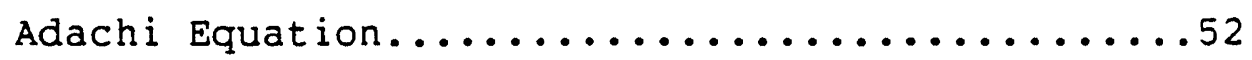

49. Critical Pressure of Butane - $\mathrm{CO}_{2}$ System Adachi Equation....................... 52 
50. Critical Loci of Butane $-\mathrm{CO}_{2}$ System

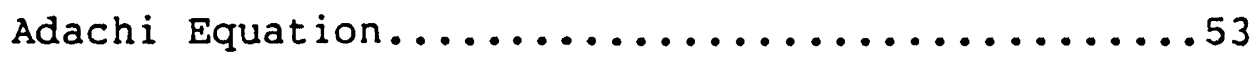

51. Critical Volume of Butane - $\mathrm{CO}_{2}$ System

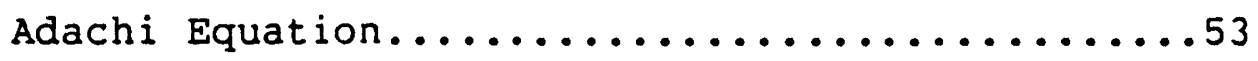

52. Critical Temperature of Butane $-\mathrm{CO}_{2}$ System Teja Equation...................... 54

53. Critical Pressure of Butane - $\mathrm{CO}_{2}$ System Teja Equation.........................

54. Critical Loci of Butane $-\mathrm{CO}_{2}$ System

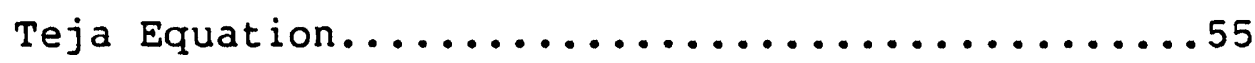

55. Critical Volume of Butane $-\mathrm{CO}_{2}$ System

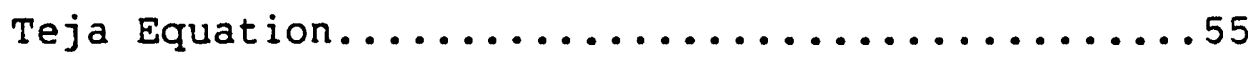

56. Critical Pressure of Butane $-\mathrm{CO}_{2}$ System Redlich Kwong Equation (fitted and unfitted)...56

57. Critical Loci of Decane - $\mathrm{CO}_{2}$ System

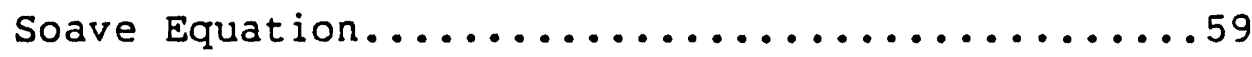

58. Critical Loci of Benzene - Water System Redlich kwong Equation.................61

59. Critical Loci of Benzene - Water System Soave Equation......................62 
60. Critical Loci of Water $-\mathrm{CO}_{2}$ System Redlich Kwong Equation.................64

61. Critical Loci of Water $-\mathrm{CO}_{2}$ System Soave Equation.......................65

62. Critical Loci of Water $-\mathrm{CO}_{2}$ System Teja Equation......................66

63. Critical Loci of Methane - Hexane System Soave Equation....................68

64. Critical Loci of Methane - Hexane System Teja Equation.......................69

65. Critical Loci of Methane - Heptane System Soave Equation.....................

66. Critical Loci of Methane - Heptane System

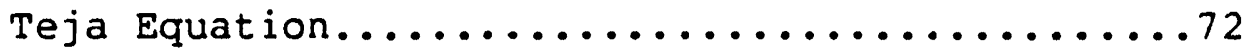

67. Critical Loci of Methane - Heptane System Near Methane Critical Point Soave Equation.......................73

68. Critical Loci of Methane - Heptane System Near Methane Critical Point

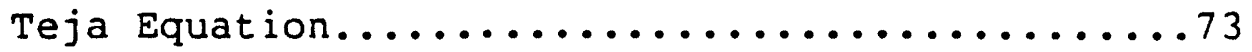

69. Comparison of Critical Volume Prediction in Propane - Hexane System..................75 


\section{LIST OF SYMBOLS}

\begin{tabular}{|c|c|}
\hline $\mathrm{b}_{12}$ & Unlike pair parameter for equation of \\
\hline $\mathrm{C}_{1}$ & Critical point of component 1 \\
\hline $\mathrm{C}_{2}$ & Critical point of component 2 \\
\hline $\mathrm{C}_{\mathrm{m}}$ & Critical point at infinite pressure \\
\hline $\mathrm{f}$ & fugacity \\
\hline $\mathbf{P}$ & Pressure \\
\hline$P_{C}$ & Critical pressure \\
\hline $\mathbf{R}$ & Gas constant \\
\hline $\mathbf{T}$ & Temperature \\
\hline $\mathrm{T}_{\mathrm{C}}$ & Critical temperature \\
\hline $\mathbf{T}_{\mathbf{r}}$ & Reduced temperature \\
\hline $\mathrm{V}$ & Volume \\
\hline $\mathrm{V}_{\mathrm{C}}$ & Critical volume \\
\hline $\mathrm{x}_{1}$ & Mole fraction of component 1 \\
\hline & Mole fraction of compo \\
\hline
\end{tabular}


$\mathrm{Z}_{\mathrm{C}} \quad$ Critical compressibility factor

for Teja equation

$\zeta 12$ Fitted binary interaction parameter

$\lambda_{12}$ Fitted binary interaction parameter

$\omega$

Pitzer acentric factor 


\section{Chapter I}

\section{INTRODUCTION}

The critical state of multicomponent mixtures is important from both a theoretical and practical point of view. The critical point is a key point in the construction of phase diagrams since at this point liquid and vapor phases have identical properties. Critical properties of mixtures are required in petroleum and gas engineering and for the accurate design of separation equipment and reactors at high pressure. Many interesting physical phenomena occur in the critical region. The isothermal compressiblity of a pure fluid, which is usually finite, becomes infinite at the critical point. The heat capacity at constant pressure, $C_{p}$, also diverges at the critical point. Retrograde condensation, the phenomenon of condensation progressing on increase of temperature or decrease in pressure, has its boundaries at the critical locus of the mixture. Recently it has been shown (Chang, Sengers) that scaled equations of state diverge when used to predict the critical point of mixtures. These as well as other reasons make it essential to have available methods for estimating the critical points of mixtures. This thesis examines the ability of five cubic equa- 
tions of state in predicting the critical locus of binary hydrocarbon and non-hydrocarbon mixtures. Much of the data cited below is drawn from van Konynenburg (1968).

In the last twenty years considerable work has been done in the study and prediction of binary critical loci (Joffe, Spear, Hissong, Peng, Teja). Using the Van Der Waals equation, van Konynenburg has qualitatively predicted nine different types of binary critical loci. He distinguished these different types of critical behavior by the shapes of their critical locus projections on a pressure temperature diagram.

In general, the critical curve of a binary mixture begins or ends at the critical point of one of the components in the mixture, $C_{1}$ or $C_{2}$, or at a critical endpoint. A critical endpoint is the thermodynamic state of a system which is at a critical point of phase separation and, simultaneously, is in equilibrium with a noncritical phase (Robert). There are two types of critical endpoints. An upper critical endpoint (UCEP) occurs when two of the phases in a heterogeneous (usually two liquid phases and a gas phase) system become homogeneous when the temperature is raised. In a lower critical endpoint (LCEP) this occurs when the temperature is decreased.

An azeotropic point, where vapor and Iiquid composition are identical, is another distinguishing characteristic on 
the critical curve. Systems exhibiting negative azeotropy show a maximum temperature point on the critical curve. A minimum temperature point on the critical line is characteristic of systems with positive azeotropy.

The nine different binary critical loci behavior catagorized by van Konynenburg are:

\section{Class 1}

I. One gas - liquid critical line connecting the two pure component critical points $\left(C_{1}-C_{2}\right)$.

I-A. The same as I, with the addition of a negative azeotrope.

II. Two critical lines: $C_{1}-C_{2}$ and a liquid - liquid critical line originating from the critical point at infinite pressure $\left(C_{m}\right)$ to an UCEP.

II-A. The same as II, with the addition of a positive azeotrope.

\section{Class 2}

III-HA. Two critical lines: $C_{1}$ to UCEP, $C_{m}$ to $C_{2}$. A three phase line runs from the UCEP to $P=0, T=0$ at lower temperatures than the one component vaporpressure curves, producing 'heteroazeotropic' behavior. 
III. The same as III-HA except that the three phase line lies between the two one-component vapor-pressure curves.

IV. Three critical lines: $C_{1}$ to UCEP, LCEP to $C_{2}$, and $C_{m}$ to UCEP.

V. Two critical lines: $C_{1}$ to UCEP, LCEP to $\mathrm{C}_{2}$.

V-A. The same as $V$, with the addition of a negative azeotrope.

In addition, there are class 3 binary systems which have very complex critical behavior. The phase behavior of these mixtures results from strong specific interactions between the two components which lead to a high degree of order in the liquid mixture. Such systems cannot be represented by cubic equations of state such as the van der wals equation and therefore van Konynenburg did not study them.

Eight mixtures were studied which correspond to six of the nine types of critical loci discovered by Van Konynenberg. These mixtures are:

1. propane - hexane (type I)

2. methane - carbon dioxide (type I)

3. butane - carbon dioxide (type I)

4. decane - carbon dioxide (type II)

5. benzene - water (type II I-HAm) 
6. water - carbon dioxide (type III)

7. methane - hexane (type $V$ )

8. methane - heptane (type V)

The five cubic equations of state which were used to predict the critical curves of the above mixtures are:

1. Redlich Kwong Equation of State

2. Soave Equation of State

3. Peng and Robinson Equation of State

4. Adachi Equation of State

5. Teja Equation of State

These equations were first checked to see if they qualitatively generated the correct shapes of the critical curve. Then further analysis was performed to determine the quantitative accuracy of the prediction. 


\section{Chapter II}

\section{THERMODYNAMICS OF THE CRITICAL POINT}

The critical state of a mixture may be defined as the point where the differences in properties between two coexisting phases vanish. The thermodynamic condition for the existence of a critical point was first derived by Gibbs more than a hundred years ago. For a pure component, the gas-liquid critical point must obey the following equation:

$$
\begin{aligned}
& \left(\frac{\partial P}{\partial V}\right)_{t}=0 \\
& \left(\frac{\partial^{2} P}{\partial V^{2}}\right)_{t}=0
\end{aligned}
$$

For the case of a binary mixture, the defining equations are most easily written in terms of the molar Gibbs free energy as: 


$$
\begin{aligned}
& \left(\frac{\partial^{2} G}{\partial x_{1}^{2}}\right)_{p, t}=0 \\
& \left(\frac{\partial^{3} G}{\partial x_{1}^{3}}\right)_{p, t}=0
\end{aligned}
$$

When working with pressure explicit equations of state, such as the cubic equations of state studied in this report, it is more convenient to express the above equations in terms of the measured variables $P, V, T$, and $x$. Using straightforward thermodynamic relationships (see appendix A), the critical point equations become (Redlich and Kister):

$$
\begin{aligned}
\left(\frac{\partial^{2} G}{\partial x_{1}{ }^{2}}\right)_{p, t} & =\frac{R T}{x_{1} x_{2}}+\int_{v}^{\infty}\left(\frac{\partial^{2} P}{\partial x_{I}{ }^{2}}\right)_{v, t} d V \\
& -\left(\frac{\partial P}{\partial x_{I}}\right)_{v, t}\left(\frac{\partial V}{\partial x_{1}}\right)_{p, t}=0
\end{aligned}
$$




$$
\begin{aligned}
& \left(\frac{\partial^{3} G}{\partial x_{1}^{3}}\right)_{p, t}=\frac{R T\left(x_{1}-x_{2}\right)}{x_{1}{ }^{2} x_{2}^{2}}+\int_{v}^{\infty}\left(\frac{\partial^{3} P}{\partial x_{1}^{3}}\right)_{v, t} d V \\
& -\left(\frac{\partial P}{\partial x_{1}}\right)_{v, t}\left(\frac{\partial^{2} V}{\partial x_{1}^{2}}\right)_{p, t}-\left(\frac{\partial V}{\partial x_{1}}\right)_{p, t}^{2}\left(\frac{\partial^{2} P}{\partial V \partial x_{1}}\right)_{t} \\
& -2\left(\frac{\partial V}{\partial x_{1}}\right)_{p, t}\left(\frac{\partial^{2} P}{\partial x_{1}^{2}}\right)_{v, t}=0
\end{aligned}
$$

The above equations contain partial derivatives of volume with respect to mole fraction. To calculate these derivatives with pressure explicit equations of state some mathematical identities must be used. Appendix A lists these identities and the final form of the critical loci equations.

Equations 2.1 and 2.2 define a single critical point in the two-dimensional $T, V$, space appropriate for a one-component system. On the other hand, the binary mixture equa-. tions, equations 2.3 and 2.4 , define a critical line in the three dimensional space $T, P, X$, appropriate for a binary mixture. Thus there is a critical temperature $T_{C}$ for each fixed pressure, or a critical pressure $P_{C}$ for each fixed temperature $(S \cot t)$. 


\section{Chapter II I}

\section{EQUATIONS OF STATE}

The thermodynamic properties of liquid mixtures can be described by many alternative theoretical approaches. Corresponding states theory is the oldest method and seems to show the greatest promise for the quantitative interpretation of the properties of dense fluids. :an der wals was first to apply the principles of corresponding states by assuming that mixtures can be represented by a 'single-fluid' equation if the appropriate reduced variables and mixture rules are chosen. In particular he tied all his predictions and theories to his famous equation:

$$
P=\frac{R T}{V-b}-\frac{a}{V^{2}}
$$

The parameter $a$ is a measure of the attractive forces between the molecules and thus lowers the overall pressure. The parameter $b$ is a measure of the size (intrinsic volume) of the molecules and increases the total pressure in the equation. If the conditions for the pure-fluid critical 
point, equations 2.1 and 2.2, are applied to the van der Waals equation then the parameters $a$ and $b$ can be obtained as a function of the critical temperature and critical pressure:

$$
\begin{aligned}
& a=27 \cdot R^{2} \cdot T_{C}{ }^{2} /\left(64 \cdot P_{C}\right) \\
& b=R \cdot T_{C} /\left(8 \cdot P_{C}\right)
\end{aligned}
$$

The attraction term in the van der Waals equation is rather simple in form with no temperature dependence. Because of this, more complex two and three parameter cubic equations of state have been suggested as a model for the phase behavior of fluids and fluid mixtures.

\subsection{REDLICH KWONG EQUATION OF STATE}

The Redlich-Kwong equation is an improvement over the van de waals equation and is one of the most widely used equations for engineering calculations. It is has the form:

$$
\begin{aligned}
& P=\frac{R T}{V-b}-\frac{a}{T^{0.5} V(V+b)} \\
& a=0.4278 \cdot R^{2} \cdot T_{C}^{2.5} / P_{C} \\
& b=0.0867 \cdot R \cdot T_{C} / P_{C}
\end{aligned}
$$


Unlike the van der Waals equation, equation 3.4 contains the temperature dependent term $\mathrm{T}^{-1 / 2}$ in the attraction term. According to the authors the form of this equation was "by no means rigorous and its justification rests mainly on the degree of approximation obtained by comparatively simple means". At the time it was published, the RedlichKwong equation was the best two parameter equation available.

\subsection{SOAVE EQUATION OF STATE}

Although the Redlich-Kwong equation predicts $P-V-T$ with relatively good accuracy, its application to pure and multicomponent vapor-liquid equilibrium does not produce satisfactory results (Wilkinson). The Soave equation of state is an attempt to improve the equation by assuming a more general temperature dependence for the a parameter:

$$
\begin{aligned}
& P=\frac{R T}{V-b}-\frac{a(T)}{V(V+b)} \\
& a(T)=0.42747 \cdot \alpha(T) \cdot R^{2} \cdot T_{C}{ }^{2} / P_{C} \\
& b=0.08664 \cdot R \cdot T_{C} / P_{C} \\
& \alpha(T)=\left\{1+m\left(1-T^{0.5}\right)\right\}^{2} \\
& m=0.480+1.574 \omega-0.176 \omega^{2}
\end{aligned}
$$


As can be seen above, the Soave equation includes the fugacity of the pure component as one of the correlation parameters. Soave found that his equation worked well for mixtures of hydrocarbons. Greater deviations were obtained, however, for mixtures containing hydrogen, carbon dioxide, hydrogen sulfide, and polar compounds.

\subsection{PENG AND ROBINSON EQUATION OF STATE}

The last of the two parameter cubic equation of state tested in this work is that proposed by Peng and Robinson. It has the same repulsion form as the Soave equation but a more complex attraction term:

$$
\begin{aligned}
& P=\frac{R T}{V-b}-\frac{a(T)}{V(V+b)+b(V-b)} \\
& a(T)=0.45724 \cdot \alpha(T) \cdot R^{2} \cdot T_{C}{ }^{2} / P_{C} \\
& b=0.07780 \cdot R \cdot T_{C} / P_{C} \\
& \alpha(T)=\left\{1+K\left(1-T r^{0.5}\right)\right\}^{2} \\
& K=0.37464+1.54226 \omega-0.26992 \omega^{2}
\end{aligned}
$$

The Peng and Robinson equation also contains the pure component fugacity as a correlation parameter. However, the 
authors found that equation 3.12 predicts thermodynamic properties of substances more accurately than the Soave equation.

\subsection{ADACHI EQUATION OF STATE}

When an equation of state is applied to represent saturation properties for pure components, it is desirable to satisfy the following three equations at equilibrium:

$$
\begin{aligned}
& \mathrm{v}_{\text {calc }}^{\mathrm{v}}=\mathrm{V}^{\mathrm{v}} \exp \\
& \mathrm{v}^{1} \text { calc }=\mathrm{V}^{1} \exp \\
& \mathrm{f}^{\mathrm{v}} \text { calc }=\mathrm{f}^{1}{ }_{\text {calc }}
\end{aligned}
$$

With this in mind, Adachi proposed an equation of state that contained a third parameter $c$, in addition to the parameters $a$ and $b$. The equation of state by Adachi has the following form:

$$
\begin{aligned}
& P=\frac{R T}{V-b}-\frac{a(T)}{V(V+C)} \\
& a(T)=A_{O} \cdot Z_{C}\left\{1+\alpha\left(1-T r^{0.5}\right)\right\}^{2} R^{2} \cdot T_{C}{ }^{2} / P_{C} \\
& b=B \cdot Z_{C} \cdot R \cdot T_{C} / P_{C}
\end{aligned}
$$




$$
\begin{aligned}
C=C \cdot Z_{C} \cdot R \cdot T_{C} / P_{C} \\
\alpha=0.479817+1.55553 \omega-0.287787 \omega^{2} \\
A_{O}=B \cdot(1+C)^{3} /(1-B)^{3} \\
B=0.260796-0.0682692 \omega-0.367338 \omega^{2} \\
C=\left\{(4 / B-3)^{0.5}-3\right\} / 2 \\
z_{C}=\left\{1 /(1-B)-A_{O} /(1+C)\right\}
\end{aligned}
$$

In his paper, Adachi compared four different forms for the repulsion term and four different forms for the attraction term before deciding on equation 3.20 as the best equation. Equation 3.20 is rather simple compared to the supporting equations for calculating the constants $a, b$, and $c$ which are relatively complex functions of the pure component critical temperature and pressure and the fugacity coefficient.

\subsection{TEJA EQUATION OF STATE}

The last equation of state studied in this thesis is the Teja equation of state. Like the Adachi equation, it contains three parameters $a, b$, and c. However, the attraction term is more complex than the corresponding term in the Adachi equation. The Teja equation of state is:

$$
P=\frac{R T}{V-b}-\frac{a(T)}{V(V+b)+c(V-b)}
$$




$$
\begin{aligned}
& \mathrm{a}(\mathrm{T})=\Omega_{\mathrm{a}} \cdot \alpha(\mathrm{T}) \cdot \mathrm{R}^{2} \cdot \mathrm{T}_{\mathrm{C}}{ }^{2} / \mathrm{P}_{\mathrm{C}} \\
& \mathrm{b}=\Omega_{\mathrm{b}} \cdot \mathrm{R} \cdot \mathrm{T}_{\mathrm{C}} / \mathrm{P}_{\mathrm{C}} \\
& \mathrm{C}=\Omega_{\mathrm{C}} \cdot \mathrm{R} \cdot \mathrm{T}_{\mathrm{C}} / \mathrm{P}_{\mathrm{C}} \\
& \Omega_{\mathrm{a}}=3 \mathrm{Z}_{\mathrm{C}}{ }^{2}+3\left(1-2 \mathrm{Z}_{\mathrm{C}}\right) \Omega_{\mathrm{b}}+\Omega_{\mathrm{b}}{ }^{2}+1-3 \mathrm{Z}_{\mathrm{C}} \\
& \Omega_{\mathrm{b}} \text { equals the smallest positive root of }: \\
& \quad \Omega_{\mathrm{b}}{ }^{3}+\left(2-3 \mathrm{Z}_{\mathrm{C}}\right) \Omega_{\mathrm{b}}{ }^{2}+3 \mathrm{Z}_{\mathrm{C}}{ }^{2} \Omega_{\mathrm{b}}-\mathrm{Z}_{\mathrm{C}}{ }^{3}=0 \\
& \Omega_{\mathrm{C}}=1-3 \mathrm{Z}_{\mathrm{C}} \\
& \mathrm{Z}_{\mathrm{C}}=0.329032-0.076799 \omega+0.0211947 \omega^{2} \\
& \alpha(\mathrm{T})=\left\{1+\mathrm{F}\left(1-\mathrm{Tr} \mathrm{r}^{0.5}\right)\right\}^{2} \\
& \mathrm{~F}=0.452413+1.30982 \omega-0.295937 \omega^{2}
\end{aligned}
$$

This equation, unlike the other four state equations which predict a fixed value for the critical compressibility, contains a variable critical compressiblity factor $z_{C}$. Teja fitted $z_{C}$ for a number of substances and then correlated the values against the accentric factor to produce equation 3.36 .

\subsection{MIXTURE RULES FOR EQUATIONS OF STATE}

In applying equations of state to the prediction of thermodynamic properties of mixtures, it is necessary to relate the mixture parameters $a_{m}, b_{m}$, and $c_{m}$, to the properties of the individual components. In this study, the mixture constants $a_{m}, b_{m}$, and $c_{m}$ for the equations of state were calculated with the following mixture rules: 


$$
\begin{aligned}
& a_{m}=a_{11} x_{1}{ }^{2}+2 a_{12} x_{1} x_{2}+a_{22} x_{2}{ }^{2} \\
& b_{m}=b_{11} x_{1}{ }^{2}+2 b_{12} x_{1} x_{2}+b_{22} x_{2}{ }^{2} \\
& c_{m}=c_{11} x_{1}+c_{22} x_{2}
\end{aligned}
$$

The parameters $a_{11}$ and $a_{22}$ are measures of the attractive forces between pairs of molecules of the pure components 1 and 2, respectively. The interaction parameter, a 12 is a measure of the force that exsist between unlike pairs of molecules. $b_{11}, b_{22}$, and $b_{12}$ are size parameters (proportional to volume) for the pure components and for the mixed pairs. For their evaluation, the interaction parameters, $a_{12}$ and $b_{12}$, were calculated from pure component data according to the following equations:

$$
\begin{aligned}
& a_{12}=\zeta_{12} \cdot\left(a_{11} a_{22}\right)^{0.5} \\
& b_{12}=\lambda_{12} \cdot\left(b_{11}+b_{22}\right) / 2
\end{aligned}
$$

Where $\zeta_{12}$ and $\lambda_{12}$ are adjustable parameters which are fit to experimental data. Equations 3.39 and 3.40 implies random mixing of the two components when $\zeta_{12}$ and $\lambda_{12}$ are set equal to one (van Konynenburg). This approximation has been shown to be approximately true in the case of non-polar, non- 
reacting components. These approximations will be poorest when there are large differences between critical temperatures and between the molecular sizes of the pure components and when there is significant molecular orientation in the mixture or in one of the pure components. Thus $\zeta_{12}$ and $\lambda_{12}$ can be viewed as a measure of the 'randomness' of the system.

\subsection{CALCULATION OF THE CRITICAL POINT}

Equations 2.5 and 2.6 , together with an equation of state make up a system of three non-linear equations in three unknowns: $T_{C}, P_{C}$, and $V_{C}$. Initially, the interaction parameters $\zeta 12$ and $\lambda_{12}$ were set equal to one. Then, for a given composition, the free energy equations were solved for the critical temperature and critical volume of the system. A program package solved the equations using a modification of the Powell hybrid method. The critical pressure was then determined from the equation of state using the critical volume and critical temperature obtained from the free energy equations. To calculate the optimum values for $\lambda_{12}$ and $\zeta_{12}$, the following functions were calculated at $x_{1}=$ 0.50 : 


$$
\begin{aligned}
& F_{1}=\left|T_{C} \exp -T_{C} c a l c\right| \\
& F_{2}=\left|P_{c} \exp -P_{C} c a l c\right|
\end{aligned}
$$

If the experimental data at $x_{1}=0.50$ was unavailable, then the closest experimental value to $x_{I}=0.50$ was used. New values of $\lambda_{12}$ and $\zeta_{12}$ were selected, using a damped Newton Rapson method, until the absolute values of the functions $F_{1}$ and $F_{2}$ were less than 0.0005 . Once the optimum values of $\zeta_{12}$ and $\lambda_{12}$ were calculated in this manner, they were used to calculate the entire critical locus from $x_{1}=0.0$ to $x_{1}=$ 1.0. All of the calculations were carried out on a VAX -. 11/750 digital computer. 


\section{Chapter IV}

\section{RESULTS AND DISCUSSION}

The critical loci of eight binary systems have been calculated with the five cubic equations of state mentioned in chapter 3. The predicted critical curves of these systems, which represent six of the nine different types of critical behavior discussed by Van Konynenberg, are compared to experimental data. No single equation of state was clearly the best in predicting the critical values of the systems studied. Table I summarizes the average deviation from experimental data of the five equations in predicting the critical constants of the binary systems tested. Table 2 lists the optimum values for the fitted parameters $\lambda_{12}$ and $\zeta 12$ for each equation of state.

\subsection{CLASS 1 CRITICAL LOCI}

The different types of critical loci are grouped into different classes according to their projections on a pressure - temperature diagram. The simplest types of critical behavior that have been observed experimentally belong to class 1. Class 1 type binary mixtures are characterized by a continuous critical line connecting the critical points of 
Table 1

Average Percent Error in Predicting Binary

Critical Loci by Cubic Equations of State

\begin{tabular}{|lrrrrrr|}
\hline system & $\begin{array}{c}\text { Redlich } \\
\text { Kwong }\end{array}$ & Soave & Adachi & $\begin{array}{c}\text { Peng and } \\
\text { Robinson }\end{array}$ & Teja \\
\hline propane/ & $(1)$ & 0.37 & 0.08 & 0.14 & 0.80 & 0.05 \\
hexane & $(2)$ & 1.09 & 0.49 & 0.73 & 2.52 & 0.33 \\
(3) 18.31 & 19.51 & 16.78 & 7.70 & 16.78 \\
methane/ & 2.53 & 2.18 & 2.88 & 3.64 & 2.16 \\
OO$_{2}$ & 6.32 & 5.86 & 7.99 & 8.58 & 5.82 \\
butane/ & 0.77 & 0.54 & 1.18 & 1.28 & 0.51 \\
CO2 & 2.62 & 1.77 & 2.96 & 2.47 & 1.56 \\
decane/ & 17.00 & 20.96 & 28.06 & 7.99 & 13.38 \\
CO2 & - & 1.67 & - & - & - \\
benzene/ & - & 9.61 & - & - & - \\
water & 1.61 & 2.69 & - & - & - \\
water/ & 18.94 & 30.89 & - & - & - \\
CO2 & 1.38 & 1.14 & - & - & 2.02 \\
methane/ & 21.66 & 16.62 & - & - & 27.70 \\
hexane & - & 4.91 & - & - & 6.14 \\
methane/ & - & 19.42 & - & - & 22.67 \\
heptane & - & 2.43 & - & - & 4.90 \\
& - & 3.39 & - & - & 8.30 \\
& - & 18.89 & - & - & 22.23 \\
\hline
\end{tabular}

(1) percent error critical temperature prediction

(2) percent error critical pressure prediction

(3) percent error critical volume prediction (if available)

- equation failed to generate critical loci 
Table 2

Values of fitted parameters $\lambda_{12}$ and

$\zeta 12$ for each Cubic Equation of State

\begin{tabular}{|lcccccc|}
\hline system & $\begin{array}{c}\text { Redlich } \\
\text { Kwong }\end{array}$ & Soave & Adachi & $\begin{array}{c}\text { Peng and } \\
\text { Robinson }\end{array}$ & Teja \\
\hline propane/ & $(1) \quad 0.9244$ & 1.0097 & 0.9094 & 0.8320 & 0.9897 \\
hexane & $(2)$ & 0.9111 & 0.9734 & 0.8846 & 0.8245 & 0.9771 \\
methane/ & 0.9558 & 1.0524 & 1.0990 & 0.7476 & 1.0465 \\
OO$_{2}$ & 0.8765 & 0.9222 & 0.8871 & 0.7893 & 0.9250 \\
butane/ & 0.9182 & 0.9990 & 1.2607 & 0.6600 & 0.9578 \\
CO2 & 0.7567 & 0.8390 & 0.9713 & 0.7475 & 0.8294 \\
decane/ & - & 1.3268 & - & - & - \\
CO2 & - & 0.9352 & - & - & - \\
benzene/ & 0.8015 & 0.8019 & - & - & - \\
water & 0.6556 & 0.5980 & - & - & - \\
water/ & 1.0546 & 1.0446 & - & - & 1.2307 \\
CO2 & 0.8828 & 1.0407 & - & - & 1.2927 \\
methane/ & - & 1.1310 & - & - & 1.0682 \\
hexane & - & 1.1441 & - & - & 0.9661 \\
methane/ & - & 1.0237 & - & - & 0.8861 \\
heptane & - & 0.9661 & - & - & 0.7446 \\
\hline
\end{tabular}

(1) Calculated value for $\lambda_{12}$

(2) Calculated value for $\zeta 12$

- equation failed to generate critical loci 
the pure components. The critical lines are loci of critical points which are most easily viewed as gas-liquid ones, although the distinction is one of convenience only. Mixtures of two components with similar gas-liquid critical temperatures (usually $\mathrm{TC}_{1} / \mathrm{TC}_{2} \leq 2$ ) display this type of behavior (van konynenburg). The four class 1 binary mixtures studied in this investigation are:

(1) propane - hexane (Kay)

(2) methane - carbon dioxide (Donnelly)

(3) butane - carbon dioxide (Olds)

(4) decane - carbon dioxide (Reamer)

\subsubsection{Propane - Hexane System}

Figures 1 - 20 compare the calculated critical curves of the propane - hexane system with experimental data. This system is a type I mixture because there is a single critical line connecting the pure critical points. The agreement between calculated and experimental values is very good for the critical temperature and pressure. This is to be expected because propane and hexane have relatively similar 
critical temperatures, $666.1^{\circ} \mathrm{R}$ and $914.2^{\circ} \mathrm{R}$ respectively, and are similar in molecular size. The critical temperature curve decreases monatomically while the critical pressure curve has a local maximum. This experimentally verified behavior is a characteristic of hydrocarbon systems as well as other systems. The Teja equation of state was the best overall with a $0.05 \%$ deviation in predicting the critical temperatures and a $0.33 \%$ deviation for the critical pressures. These values are well within the experimental error of the data points as reported by Kay. The Peng and Robinson equation was the least accurate of the five. It predicted critical temperatures with a $0.80 \%$ accuracy and critical pressures with an accuracy of $2.52 \%$. However even these values may be within the experimental accuracy of the data used.

Table 3 compares the predicted critical loci of the propane - hexane system when the optimum values of $\zeta 12$ and $\lambda_{12}$ are used and when they are set equal to one. The need for using the fitted parameters is evident because the accuracy of the prediction improves dramatically when the optimum values are used. Figures 3,7,11,15, and 19 also show this comparison graphically.

Unlike the critical pressures and temperatures, the critical volume curve of the propane - hexane system was predicted with much less accuracy. The Peng and Robinson 
equation was the best with an average deviation of $7.7 \%$ and the Soave equation was poorest with a $19.5 \%$ deviation from experimental data. These values are definitely greater than the experimental error and represent a problem with predicting critical volumes with cubic equations of state. The reasons for this will be discussed later in this chapter. 
FIGURE 1

CRITICAL TEMPERATURE OF PROPANE - HEXANE SYSTEM

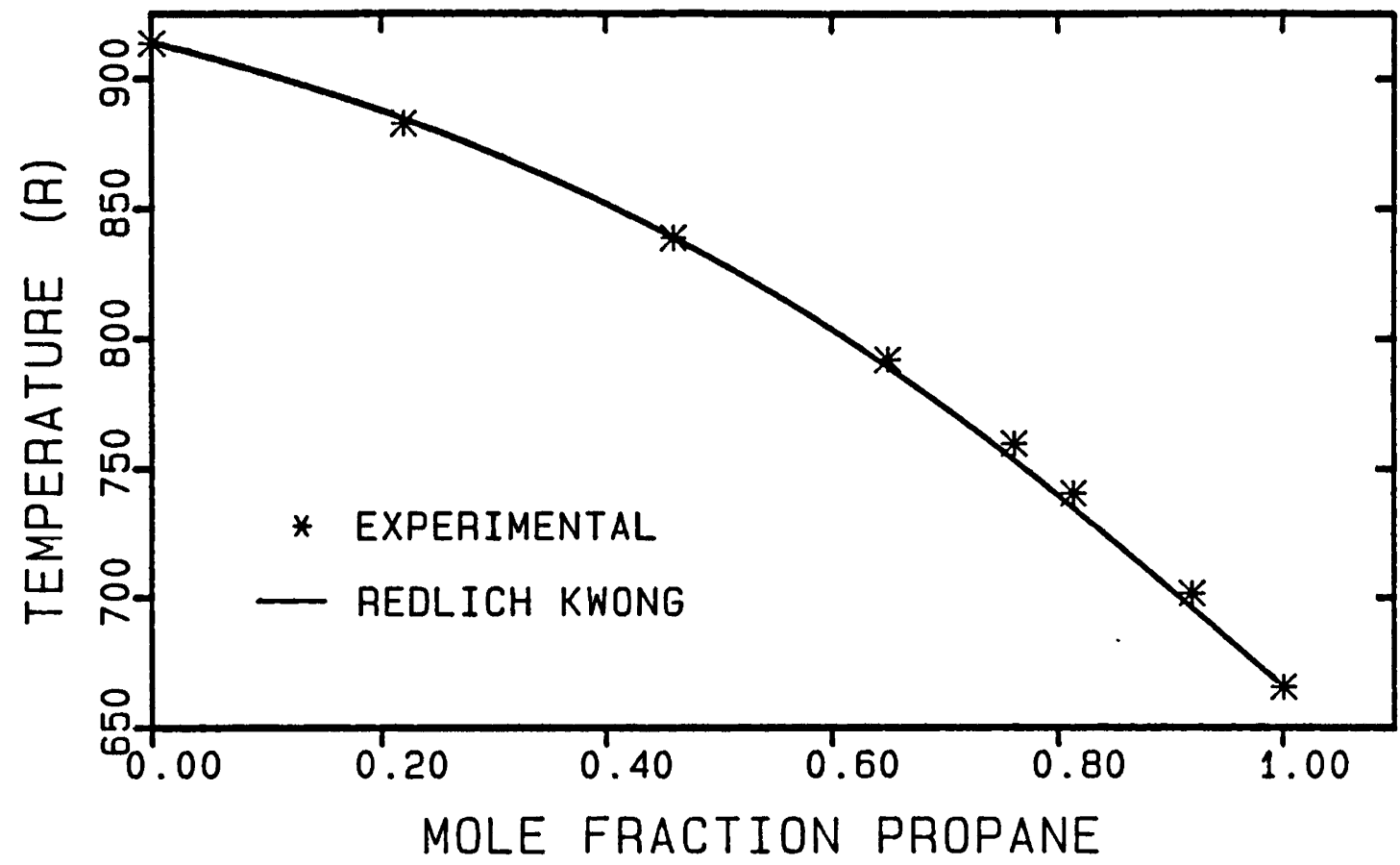

FIGURE 2

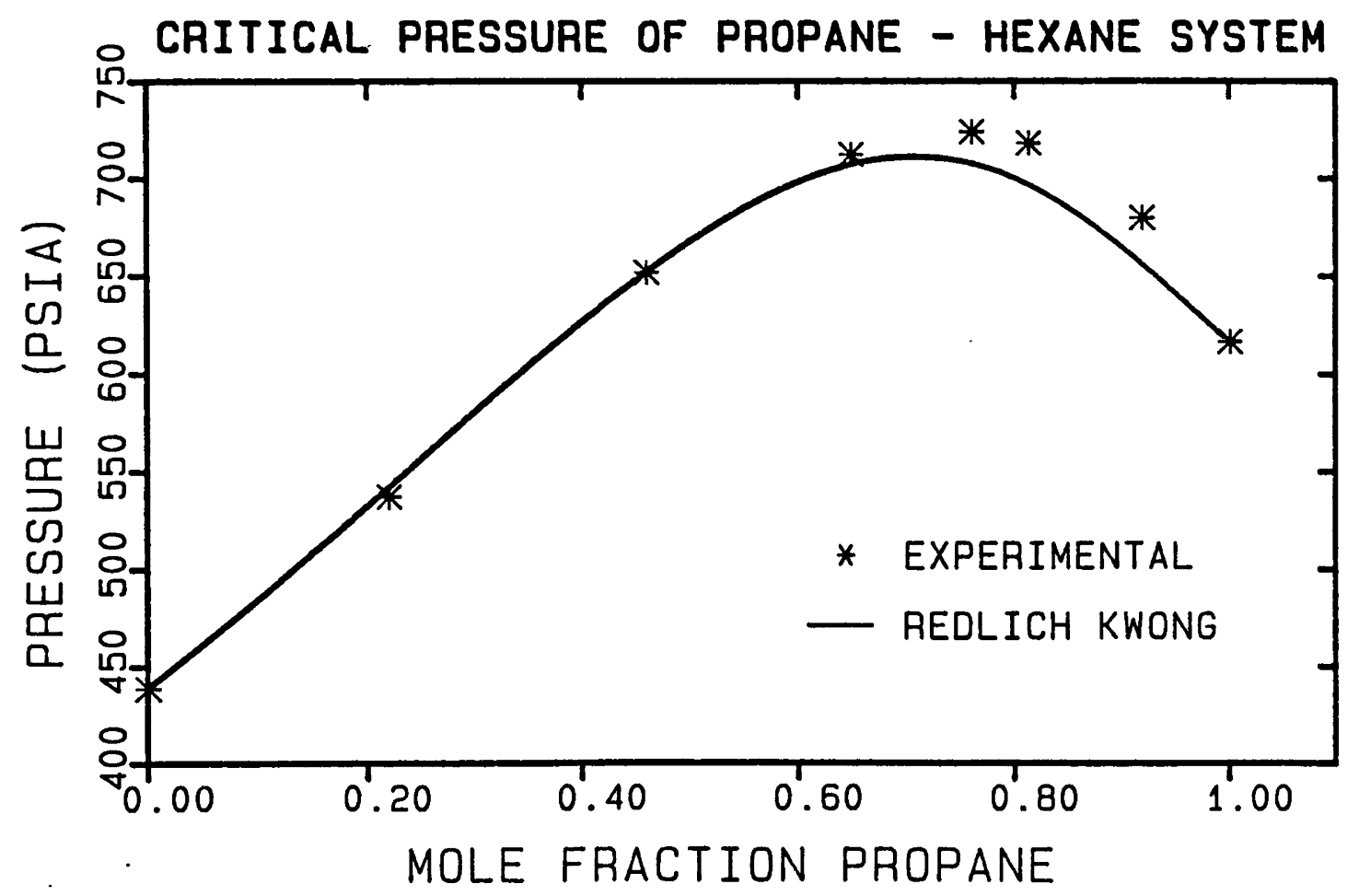


FIGURE 3

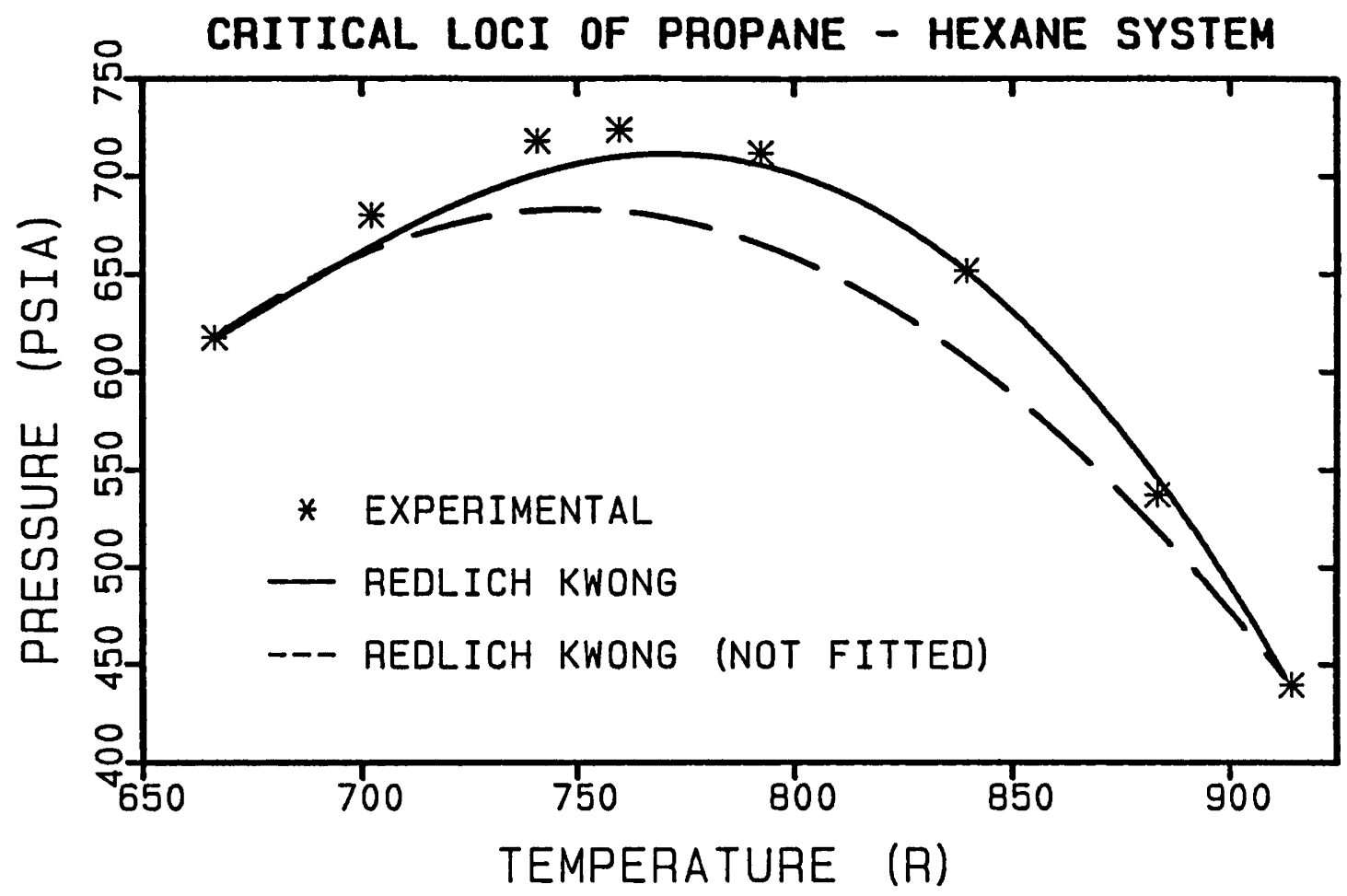

FIGURE 4

CRItical Volume of propane - hexane system

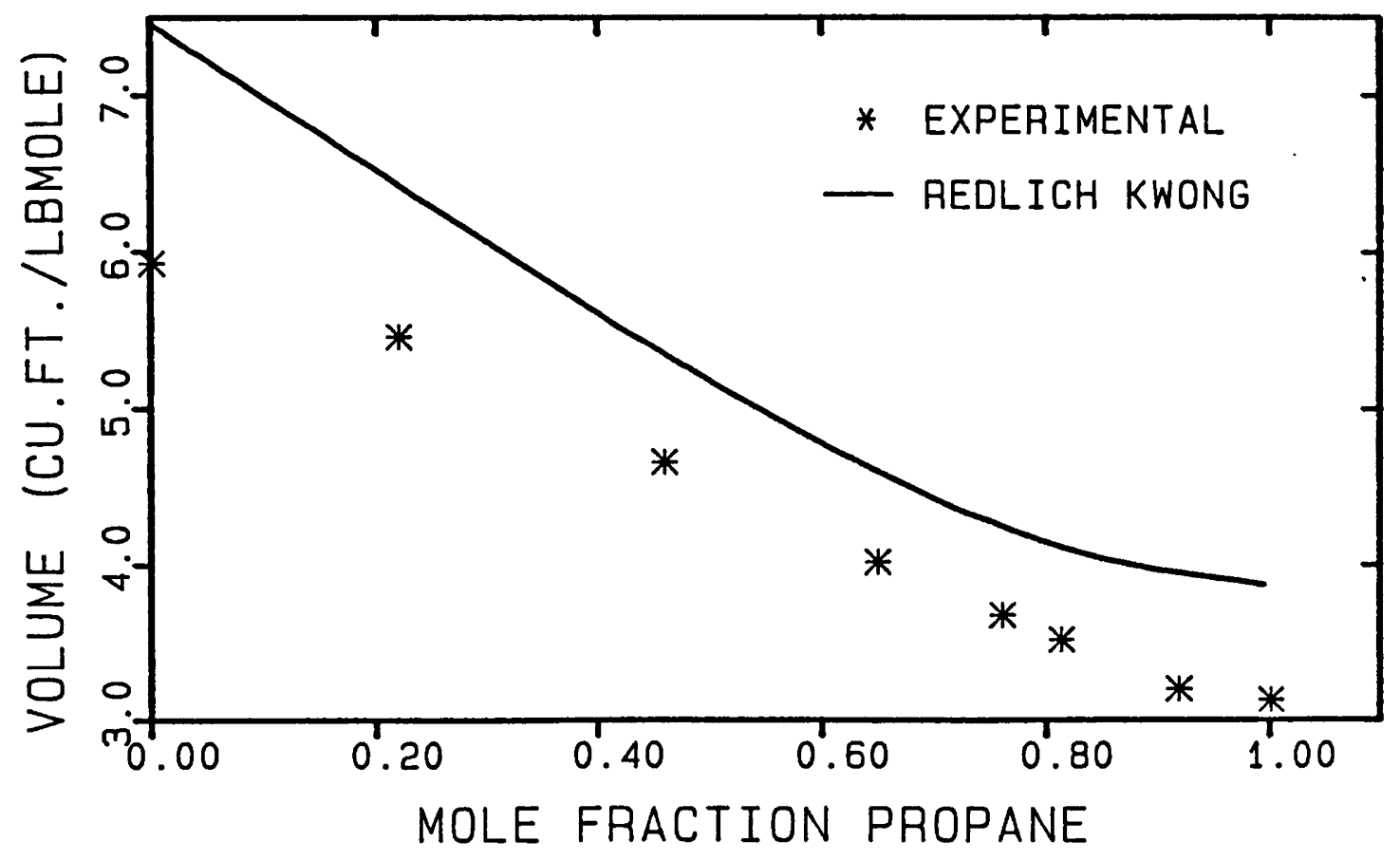


FIGURE 5

CRITICAL TEMPERATURE OF PROPANE - HEXANE SYSTEM

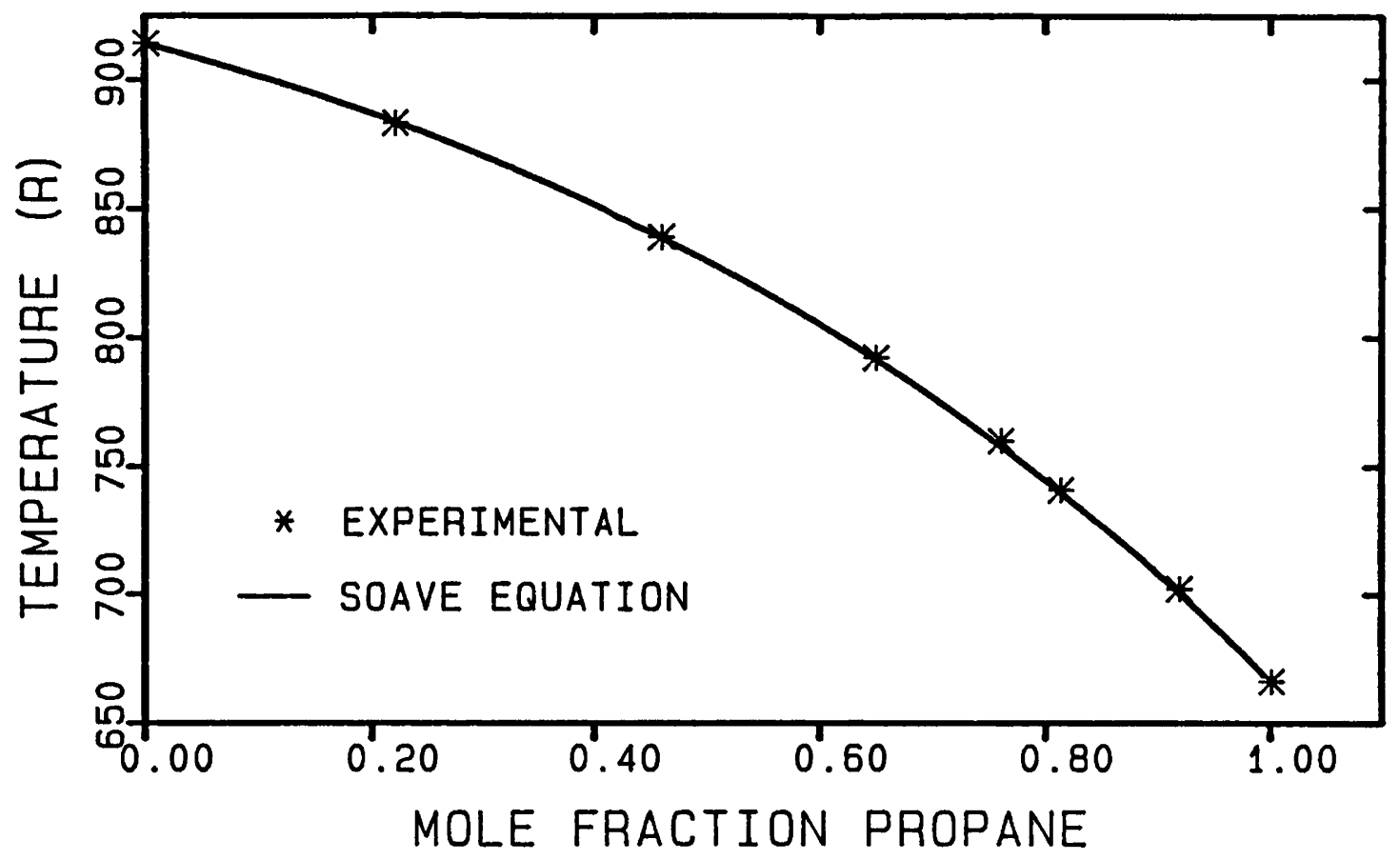

FIGURE 6

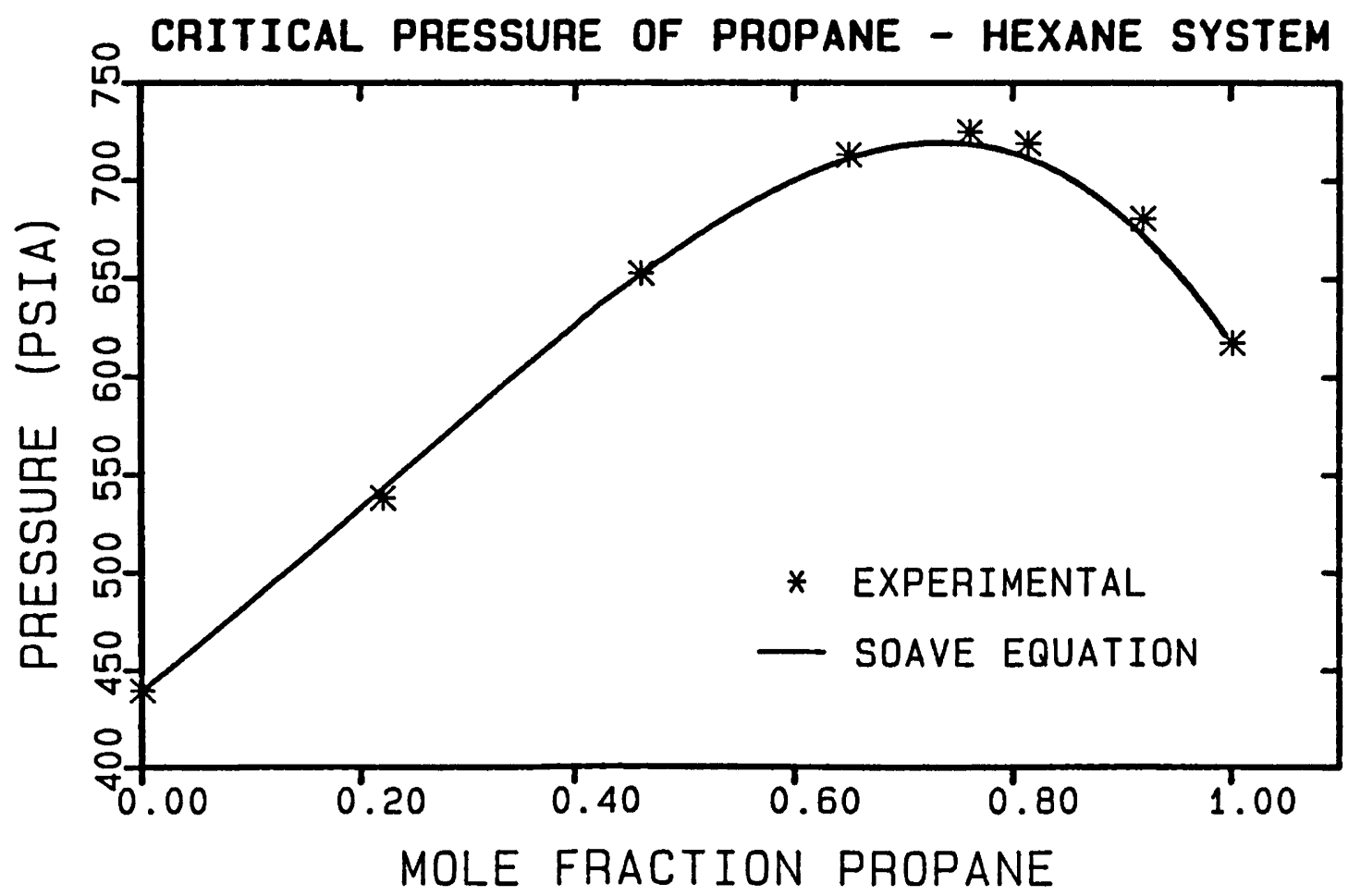


FIGURE 7

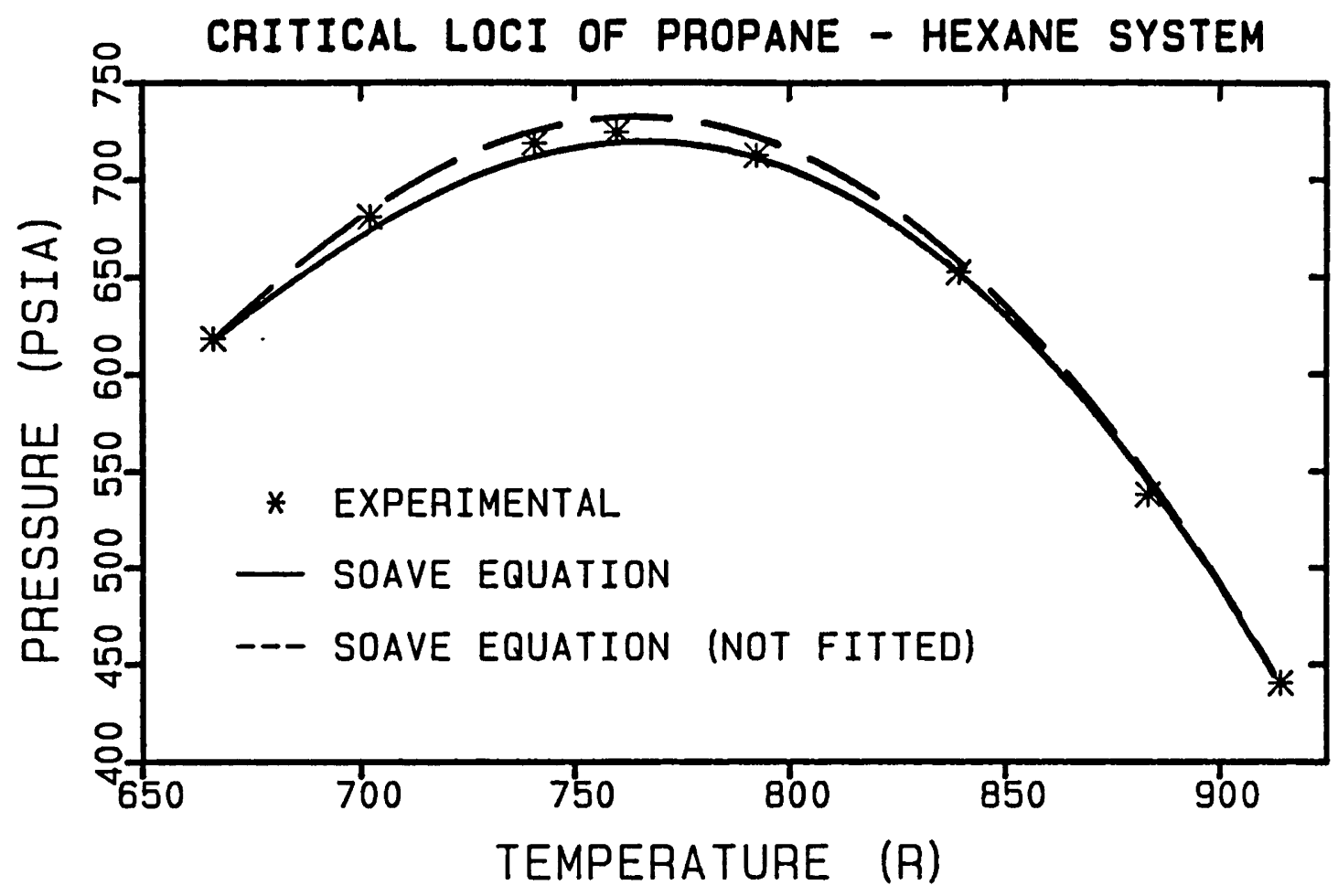

FIGURE 8

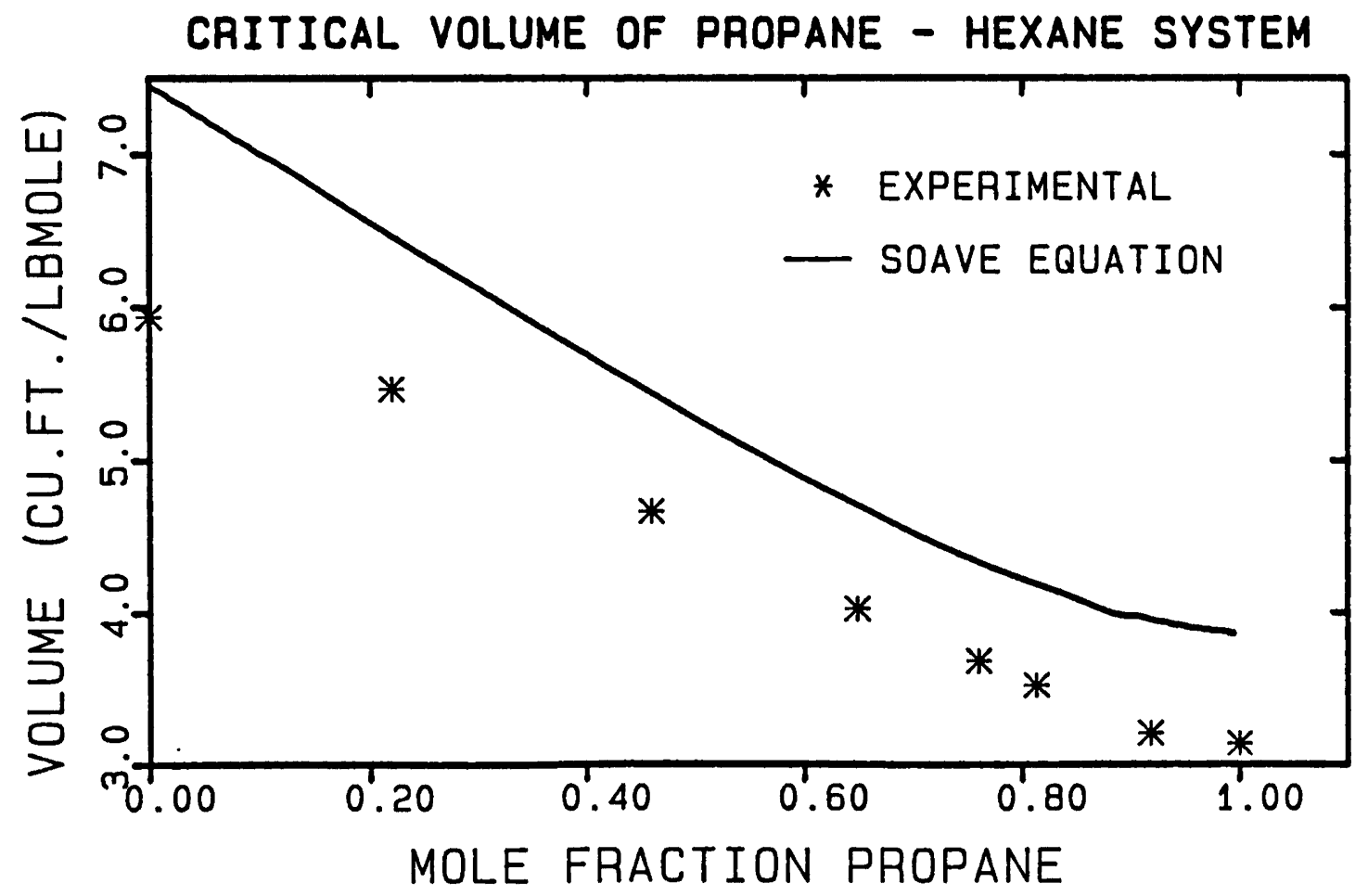


FIGUAE 9

CRITICAL TEMPERATURE OF PROPANE - HEXANE SYSTEM

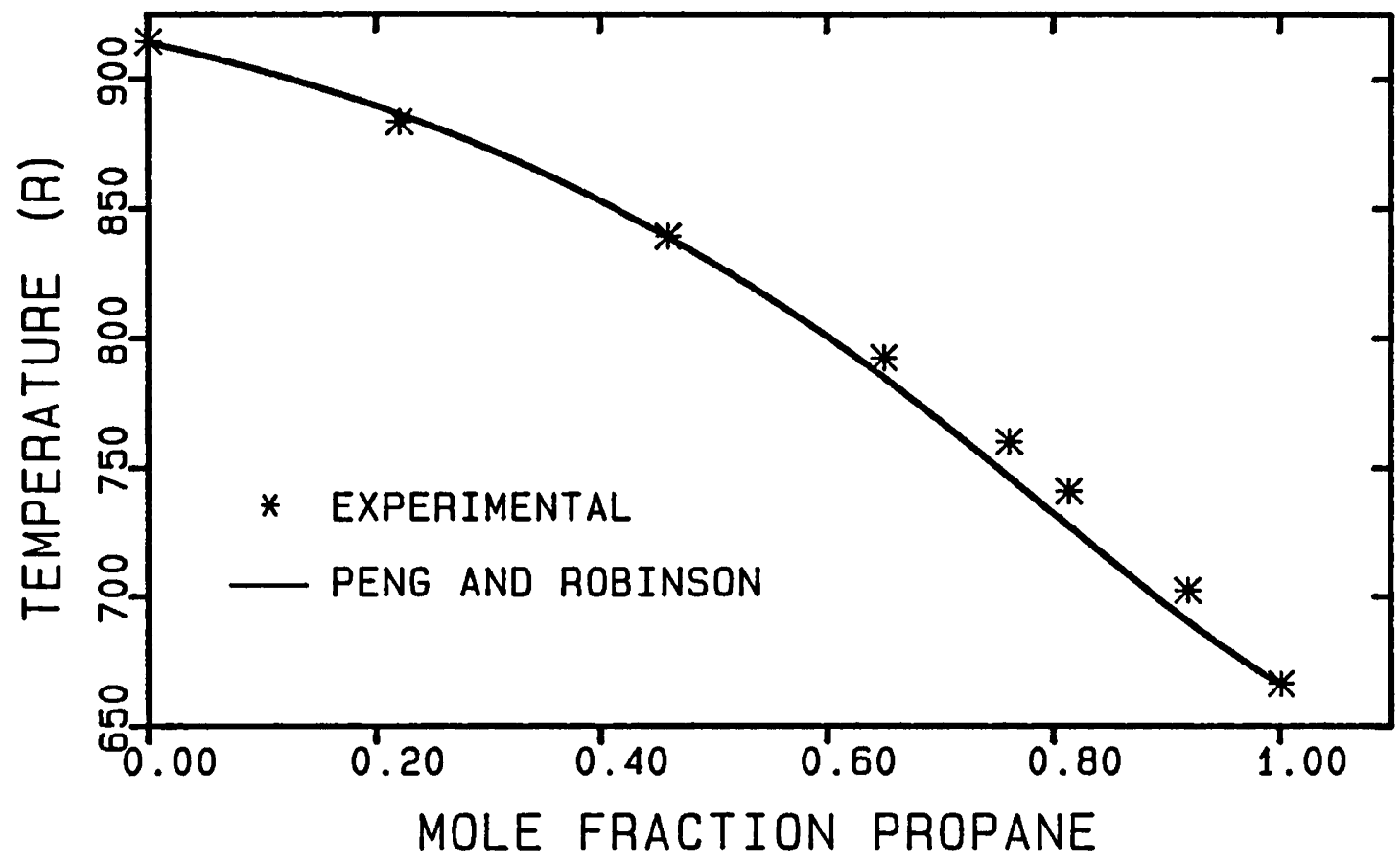

F I GURE 10

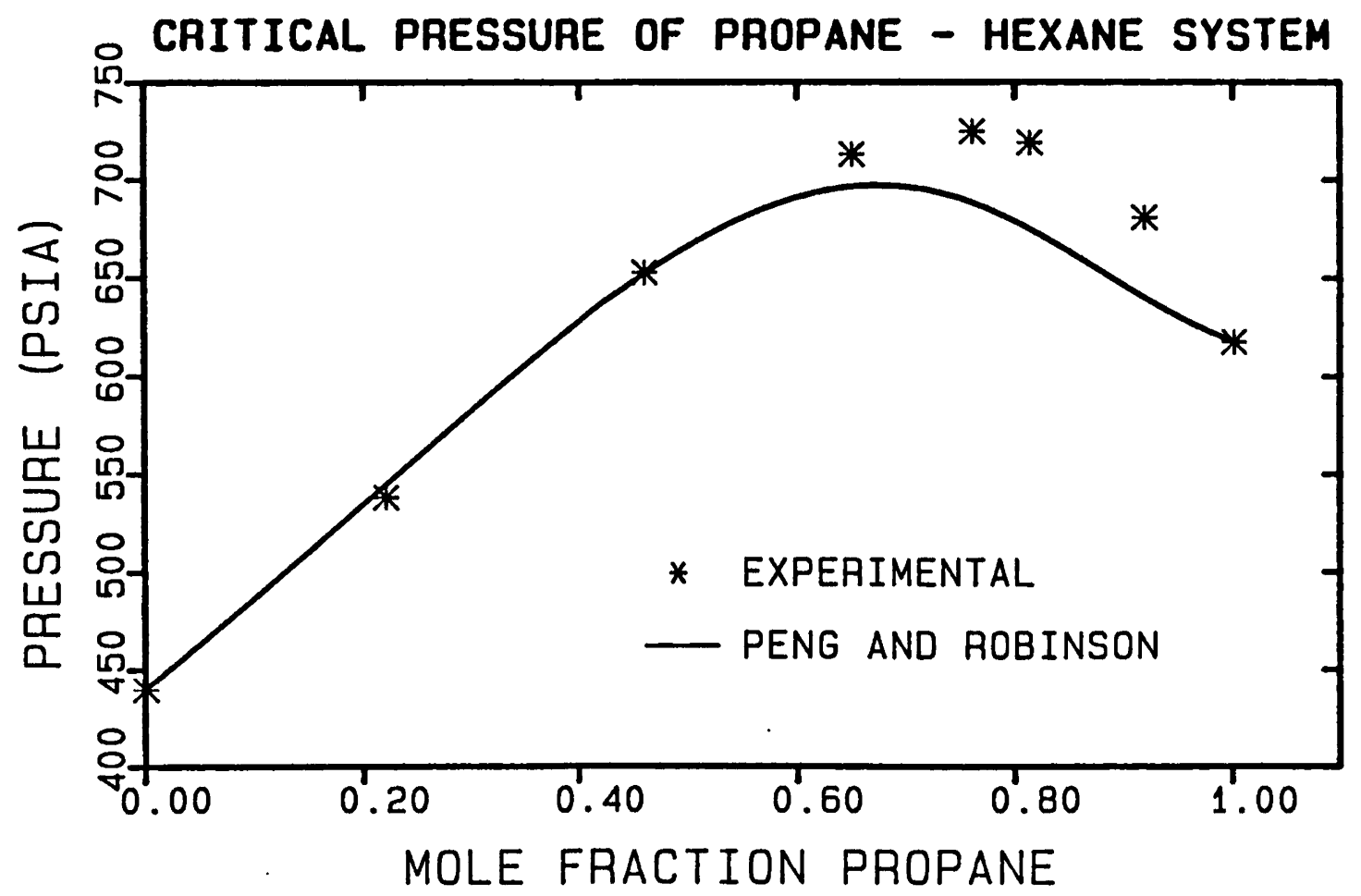


FIGURE 11

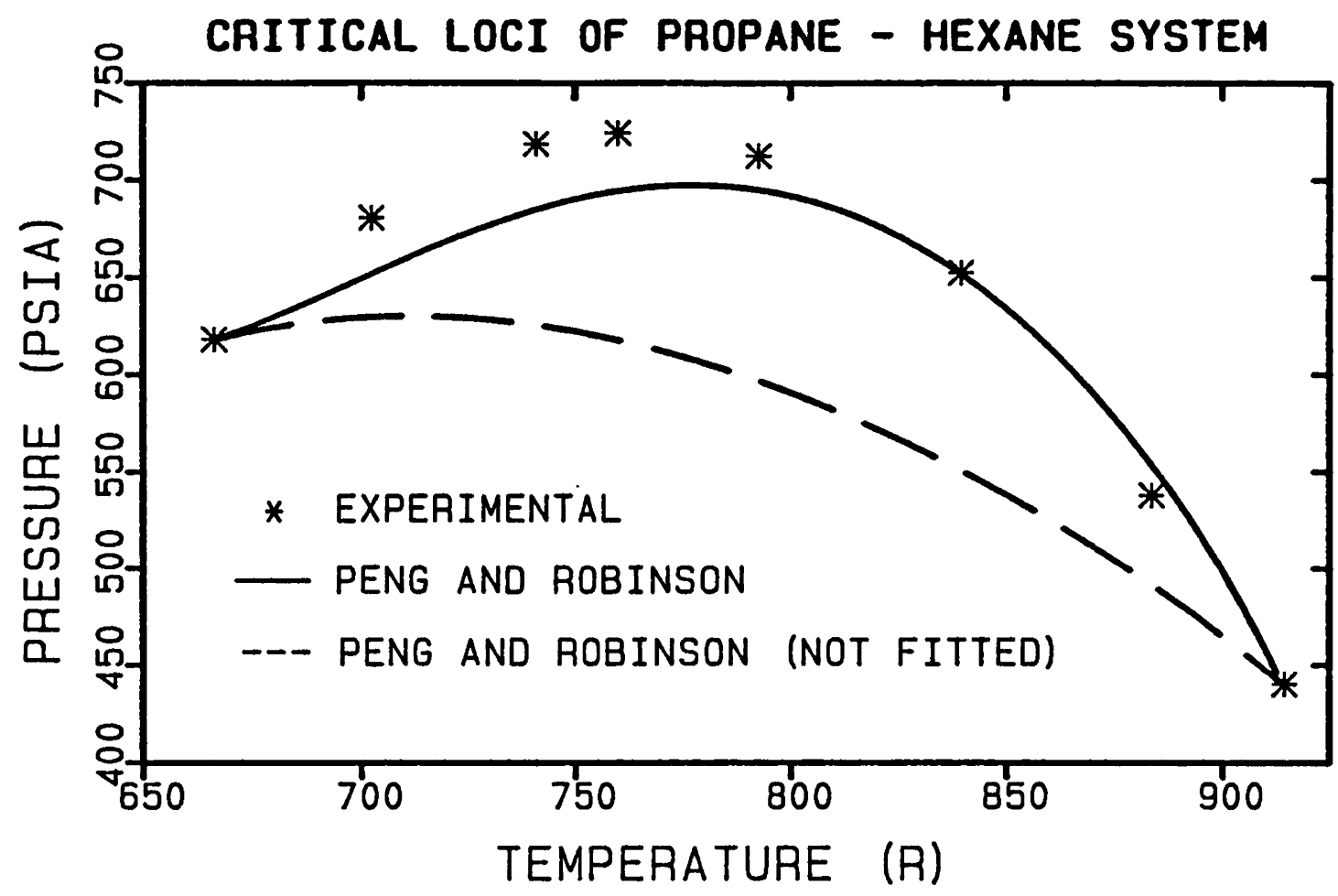

FIGURE 12

○ CRItical volume of propane - heXane system

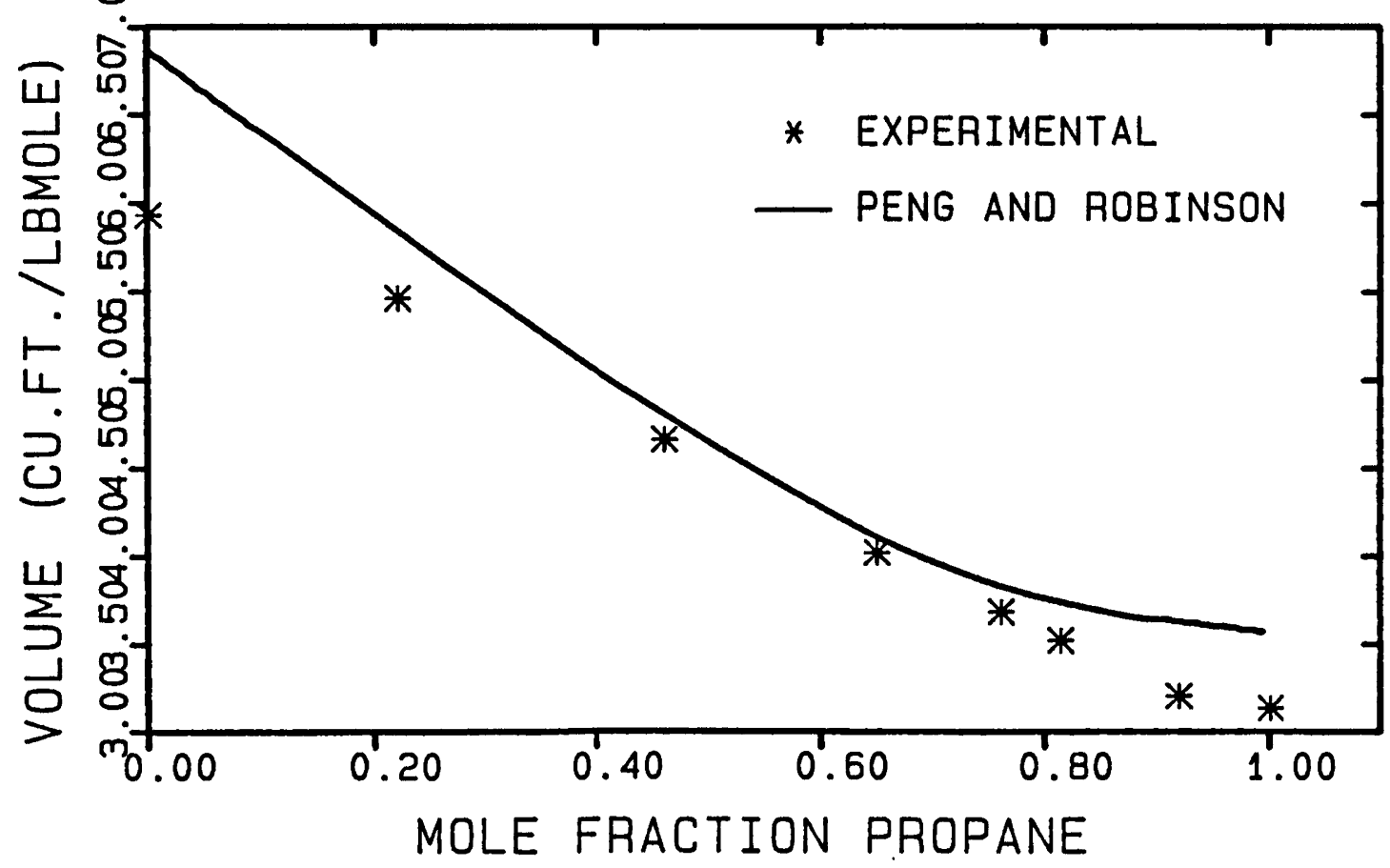


FIGURE 13

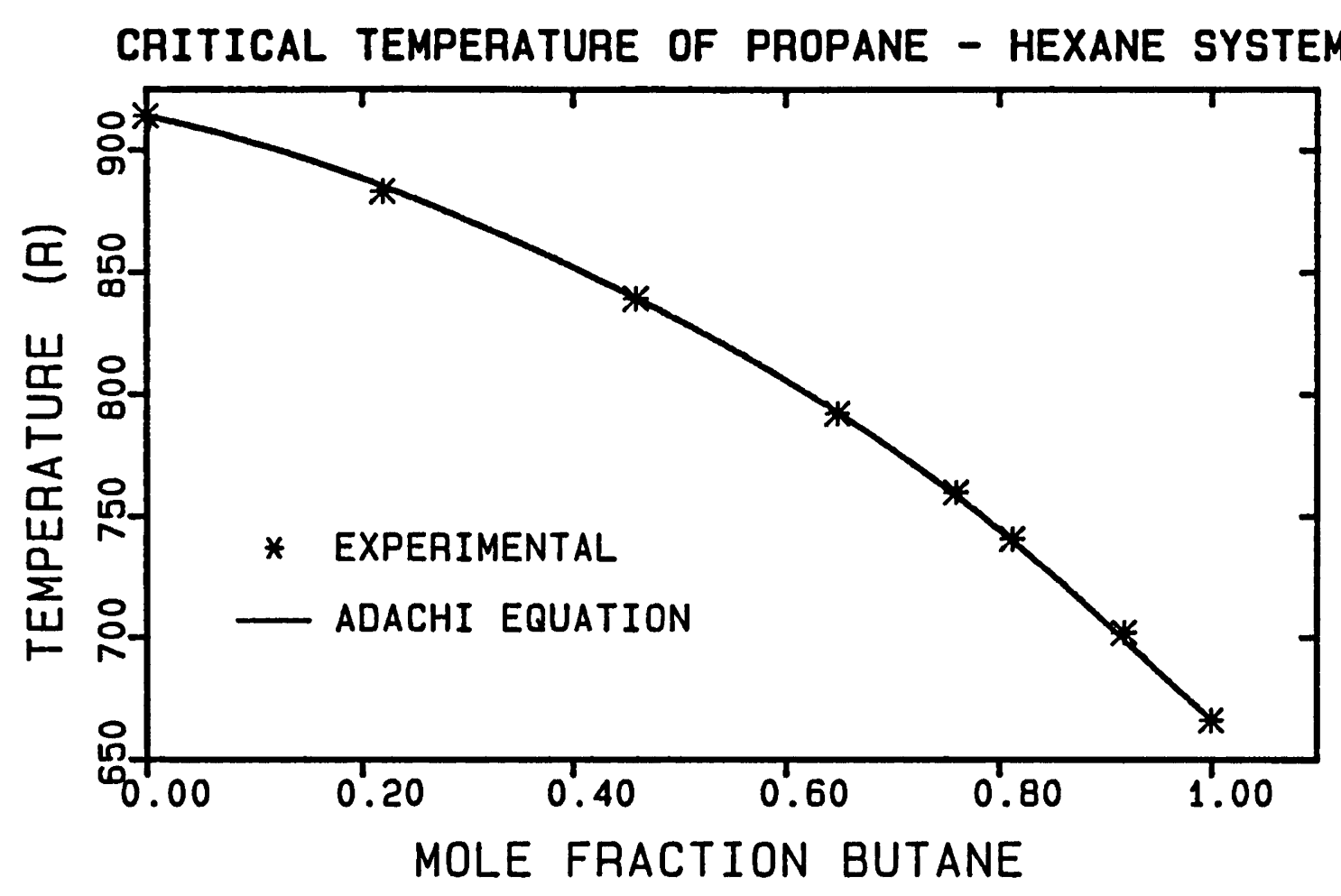

FIGURE 14

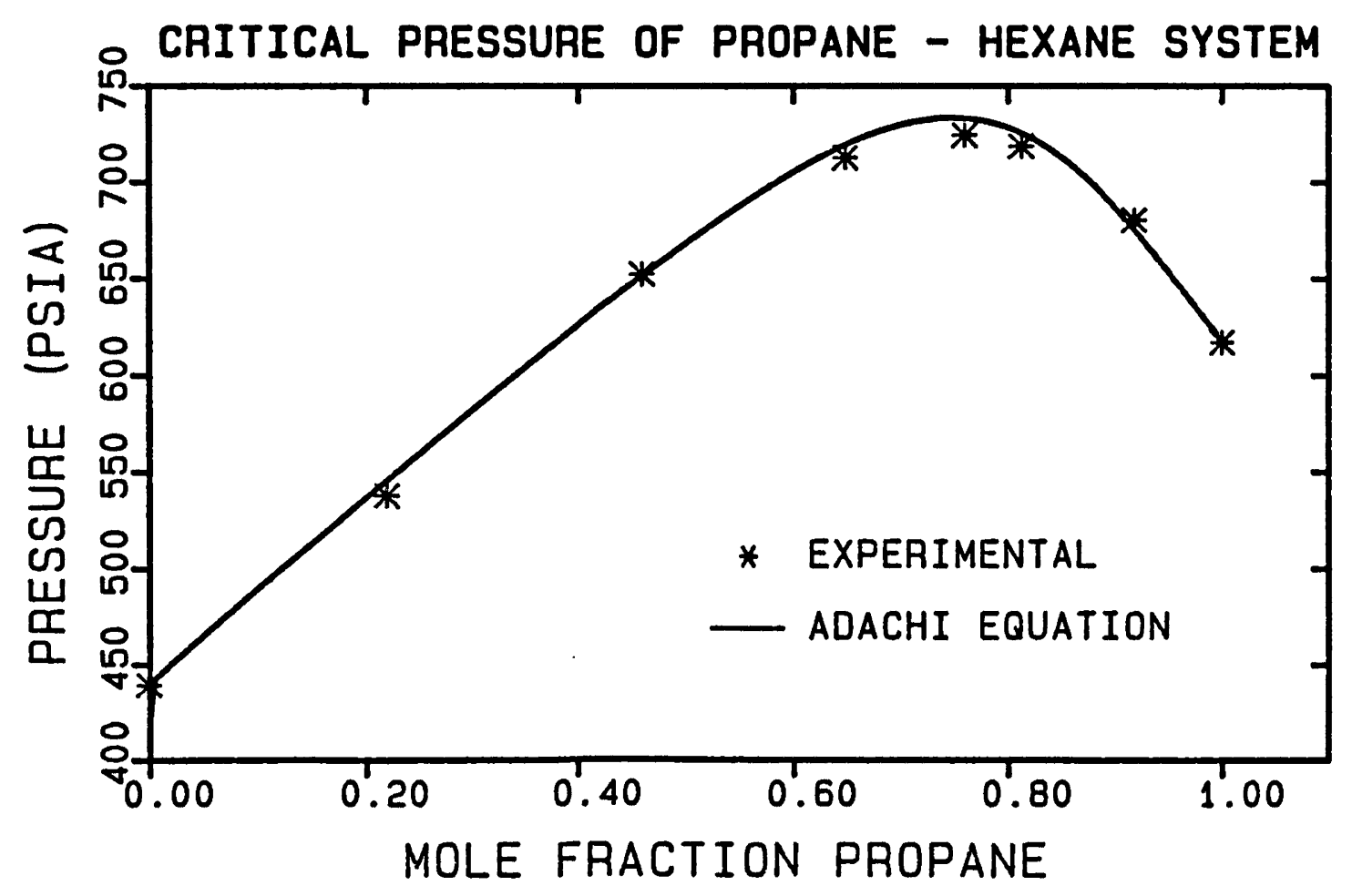


FIGURE 15

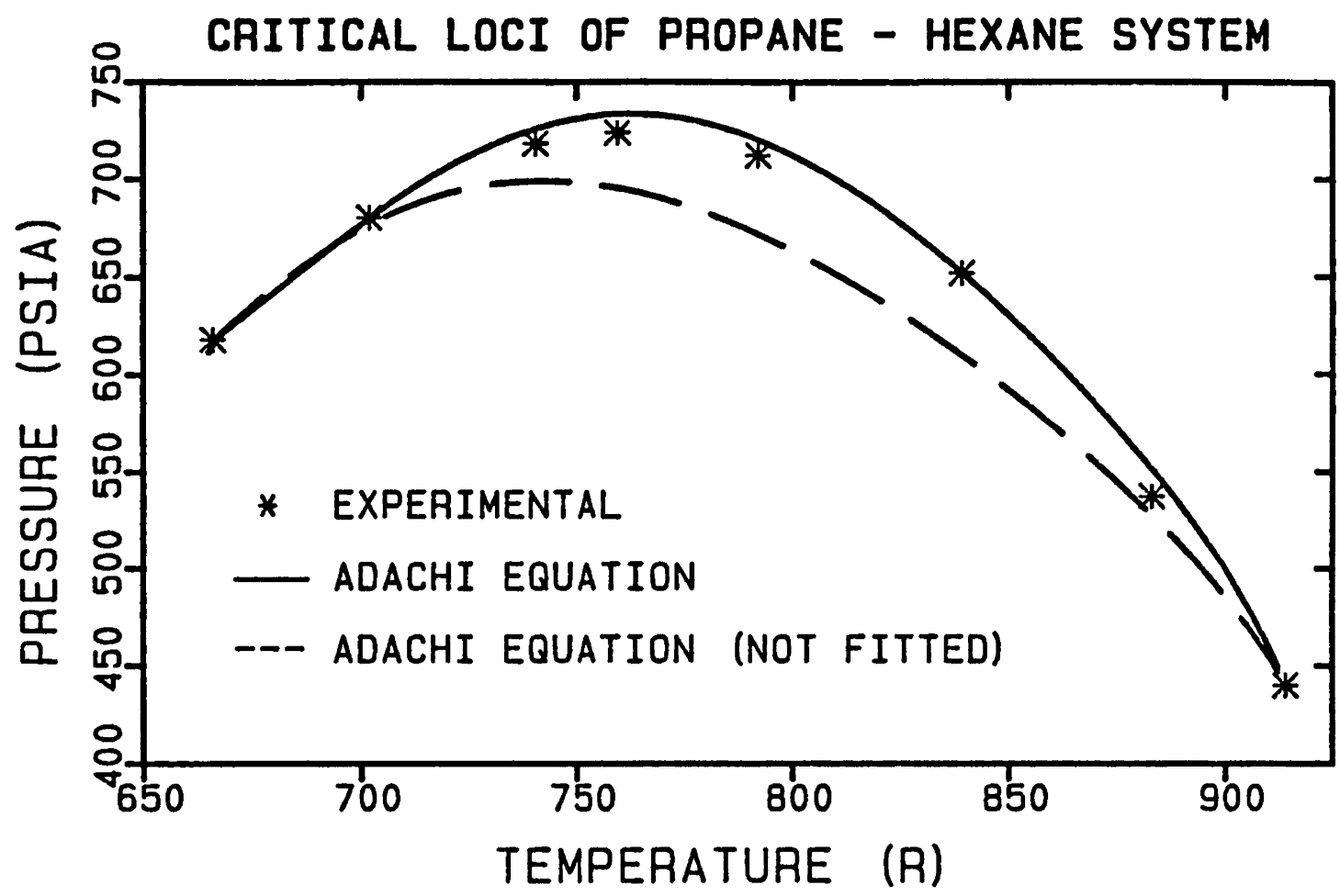

FIGURE 16

CRITICAL VOLUME OF PROPANE - HEXANE SYSTEM

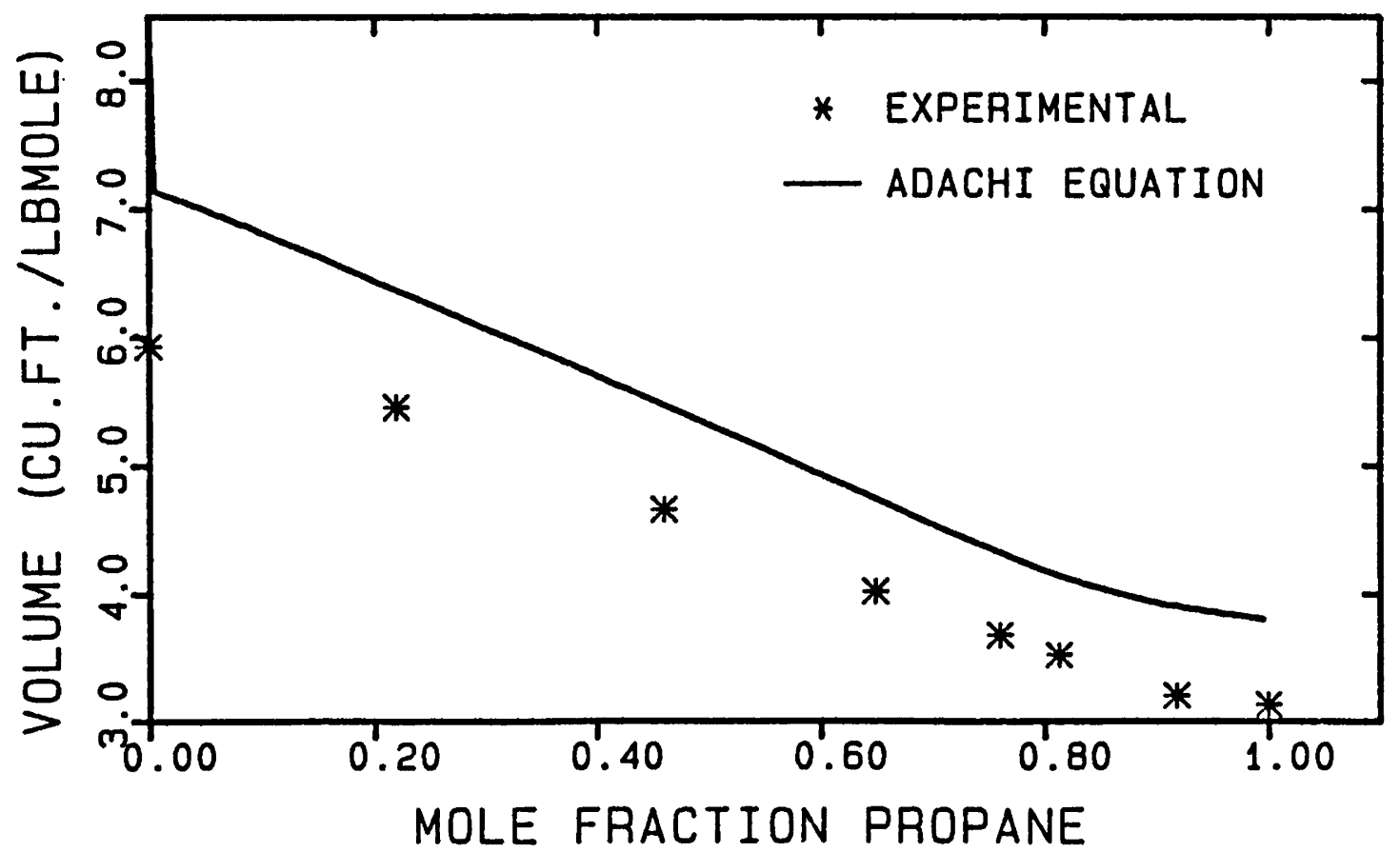


FIGURE 17

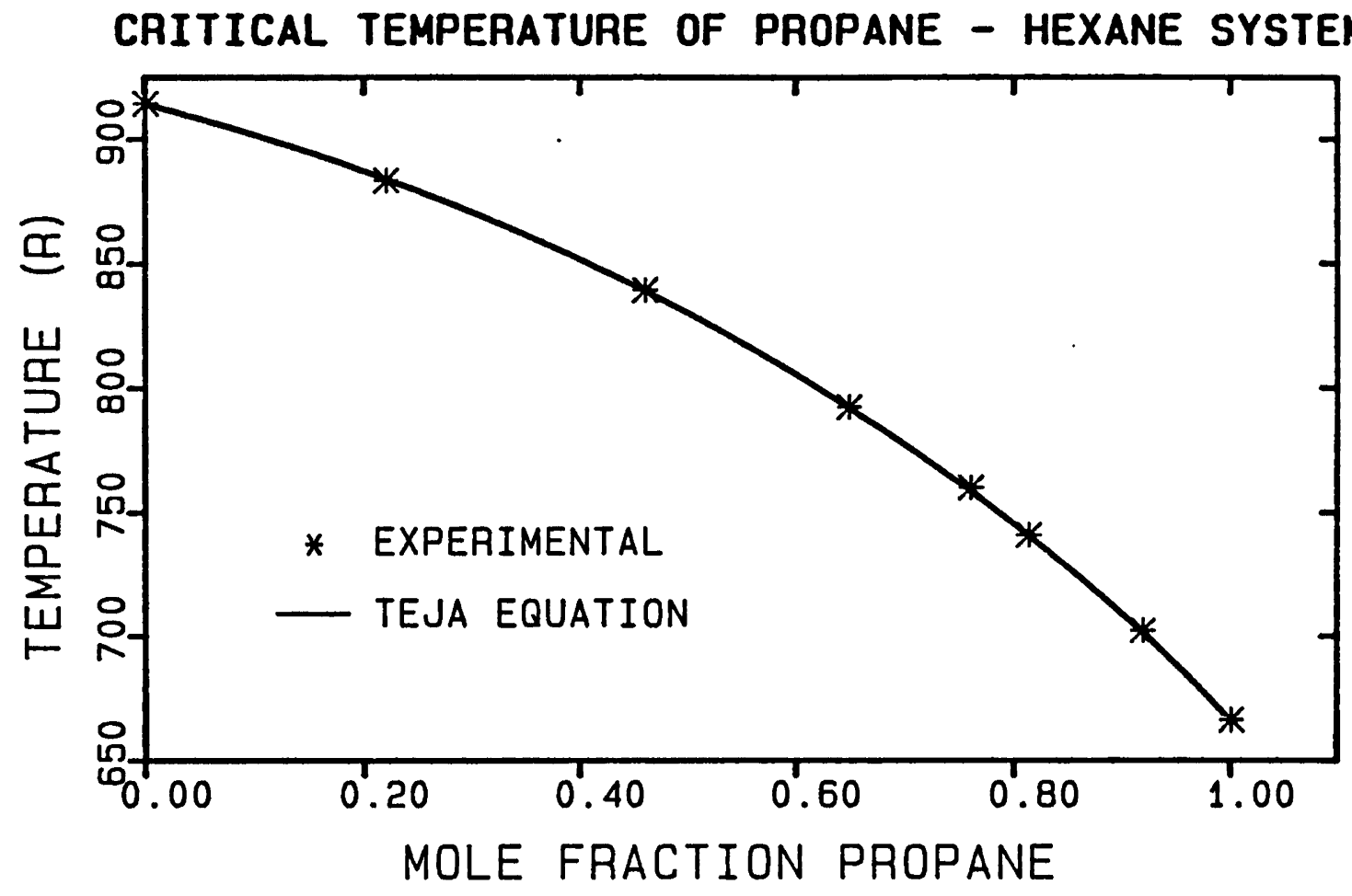

FIGURE 18

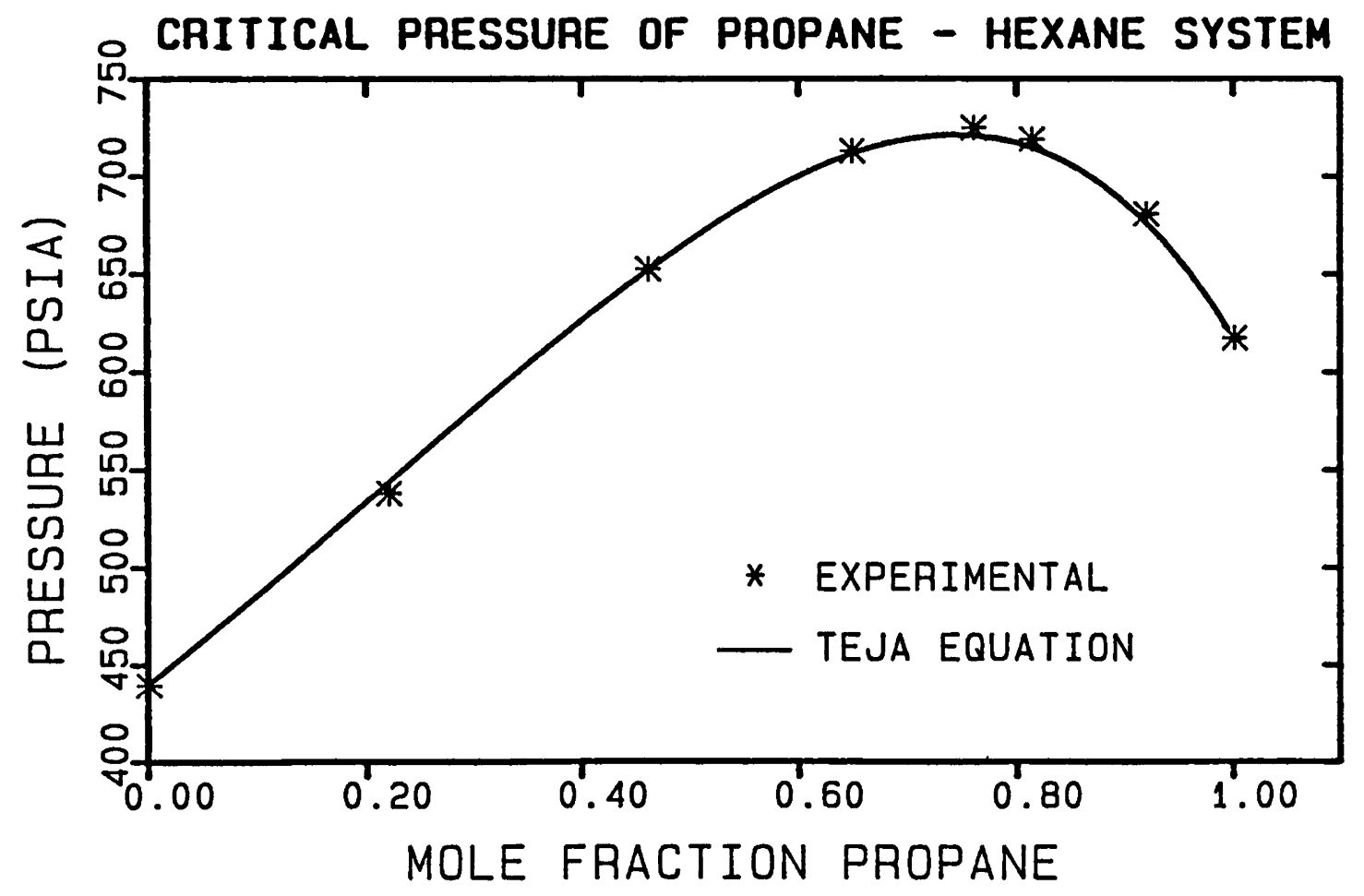


FIGURE 19

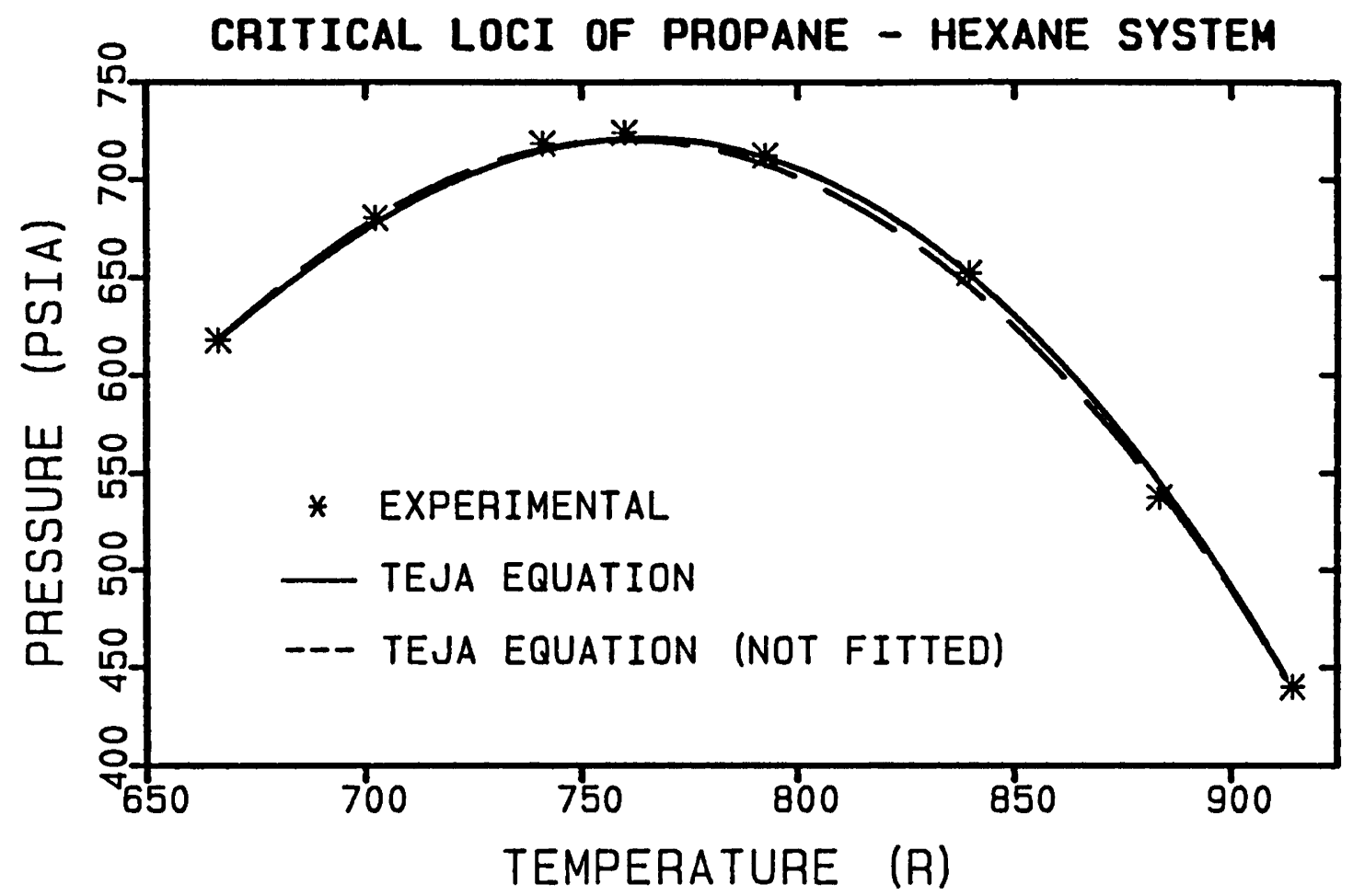

FIGURE 20

\& CRItical VOLUME OF PROPANE - hexANE SYSTEM

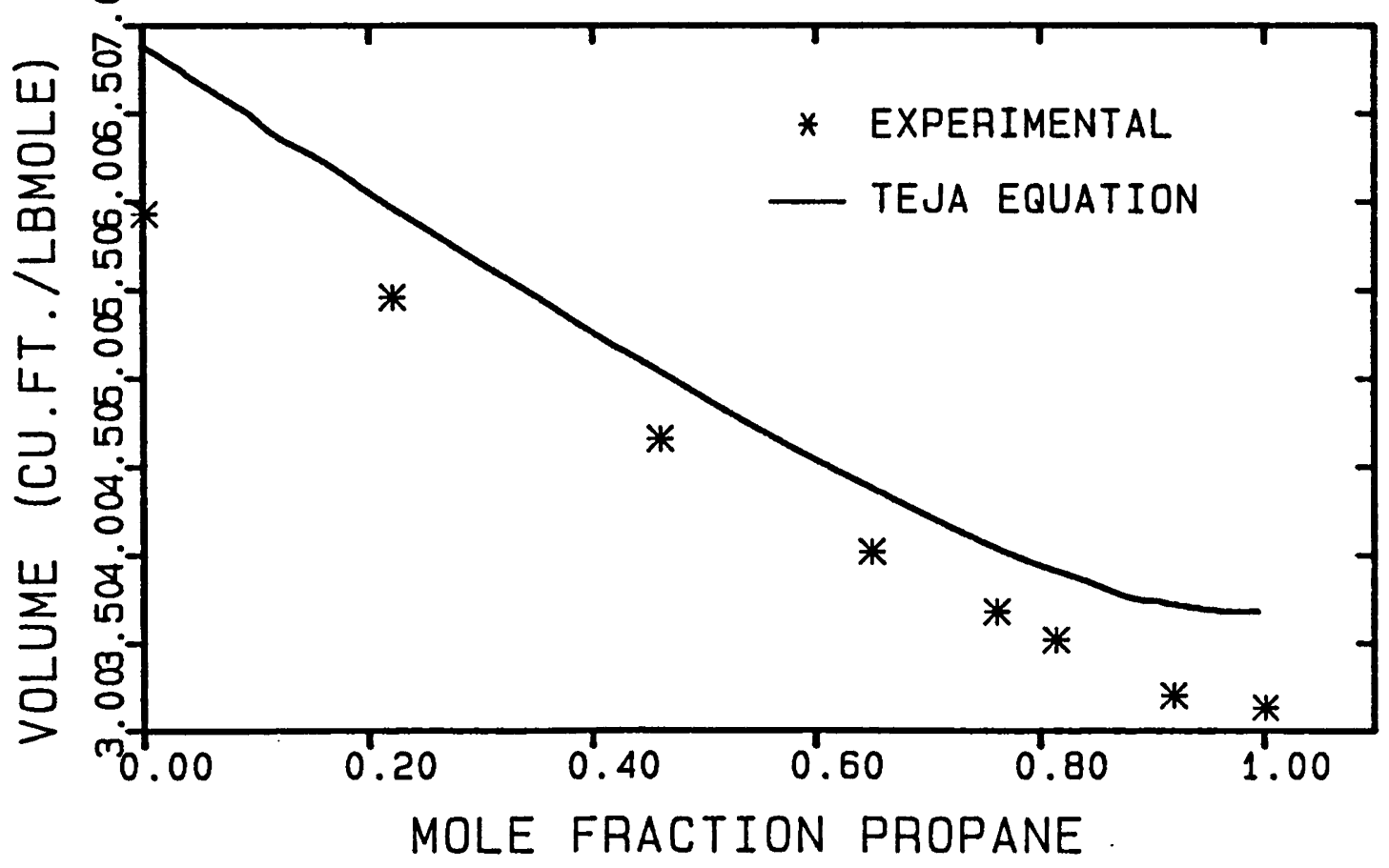


Table 3

Comparison of Calculating the Critical Loci of the Propane - Hexane System with and without Fitted Parameters

\begin{tabular}{|lcccccc|}
\hline $\begin{array}{l}\text { percent } \\
\text { error }\end{array}$ & $\begin{array}{c}\text { Redlich } \\
\text { Kwong }\end{array}$ & Soave & Adachi & $\begin{array}{l}\text { Peng and } \\
\text { Robinson }\end{array}$ & Teja \\
\hline Critical & $(1)$ & 1.09 & 0.49 & 2.52 & 2.52 & 0.33 \\
pressure & $(2)$ & 3.59 & 0.72 & 2.63 & 10.17 & 0.43 \\
critical & 0.37 & 0.08 & 0.14 & 0.80 & 0.05 \\
temperature & 0.20 & 0.51 & 0.22 & 1.25 & 0.20 \\
Critical & 18.31 & 19.51 & 16.78 & 7.7 & 11.61 \\
volume & 21.75 & 19.63 & 20.88 & 14.51 & 12.18 \\
\hline
\end{tabular}

percent error critical loci prediction: (1) with optimum values of $\zeta_{12}$ and $\lambda_{12}$.

(2) with $\zeta_{12}$ and $\lambda_{12}$ set equal to one. 


\subsubsection{Methane - Carbon Dioxide System}

Figures 21 - 35 compare the predicted versus experimental critical curves for the methane - carbon dioxide system. This is an important system because carbon dioxide occurs in varying quantities in most natural gases and gas condensate well effluents. The critical temperatures and pressures were predicted with good accuracy considering that mixtures containing carbon dioxide are difficult to model. This may be due to carbon dioxide's relatively high fugacity coefficient of 0.255 and relatively low critical temperature of $547.5^{\circ} \mathrm{R}$. Again the Teja equation was the best in predictirg the critical temperatures and pressures with $2.16 \%$ and $5.82 \%$ deviation respectively. The Peng and Robinson equation was the least accurate with a $3.64 \%$ deviation for the critical temperatures and an $8.58 \%$ deviation for the pressures. The critical volume data for this system were not available so no volume comparison could be made. 
FIGURE 21

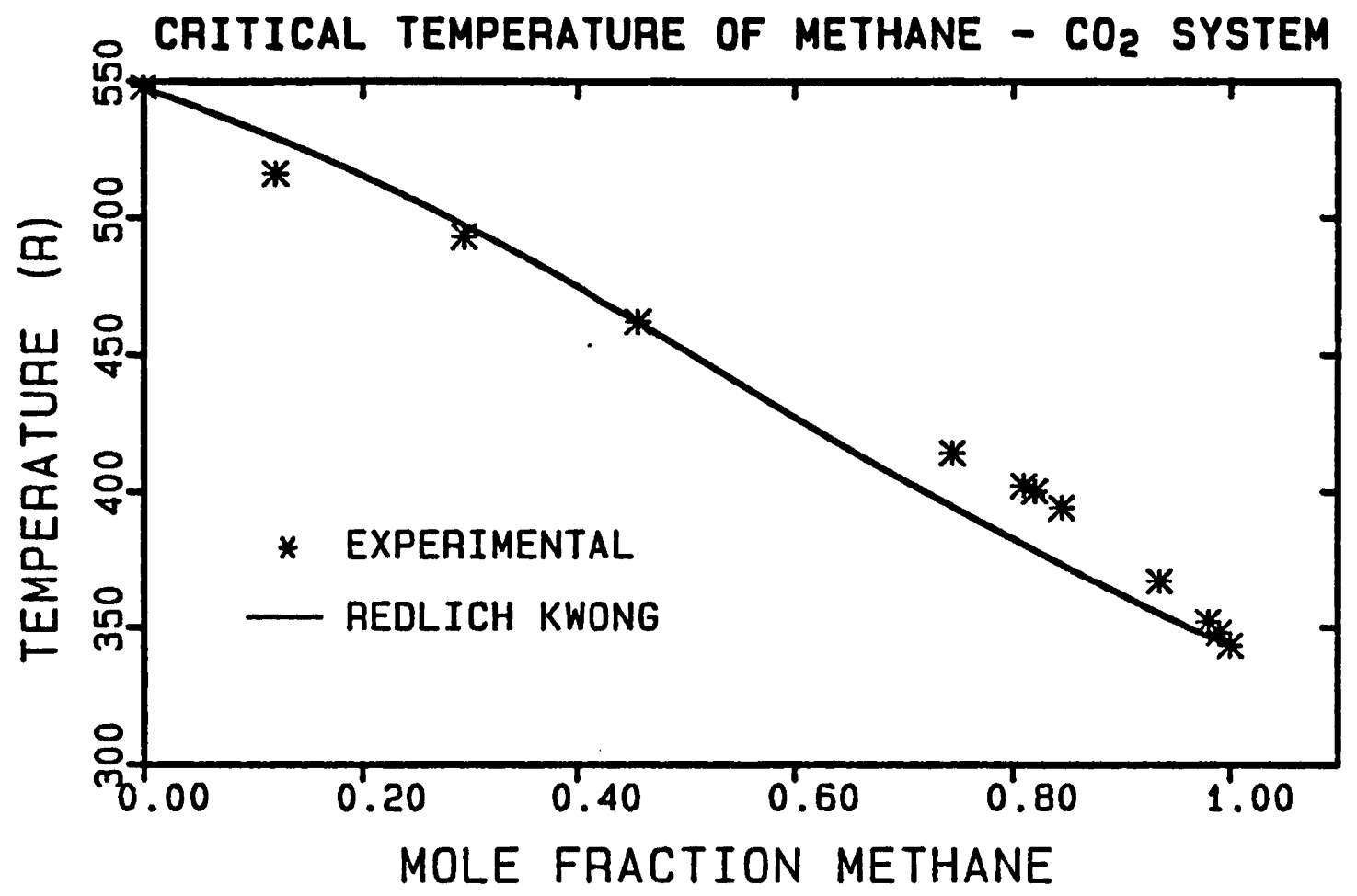

FIGURE 22

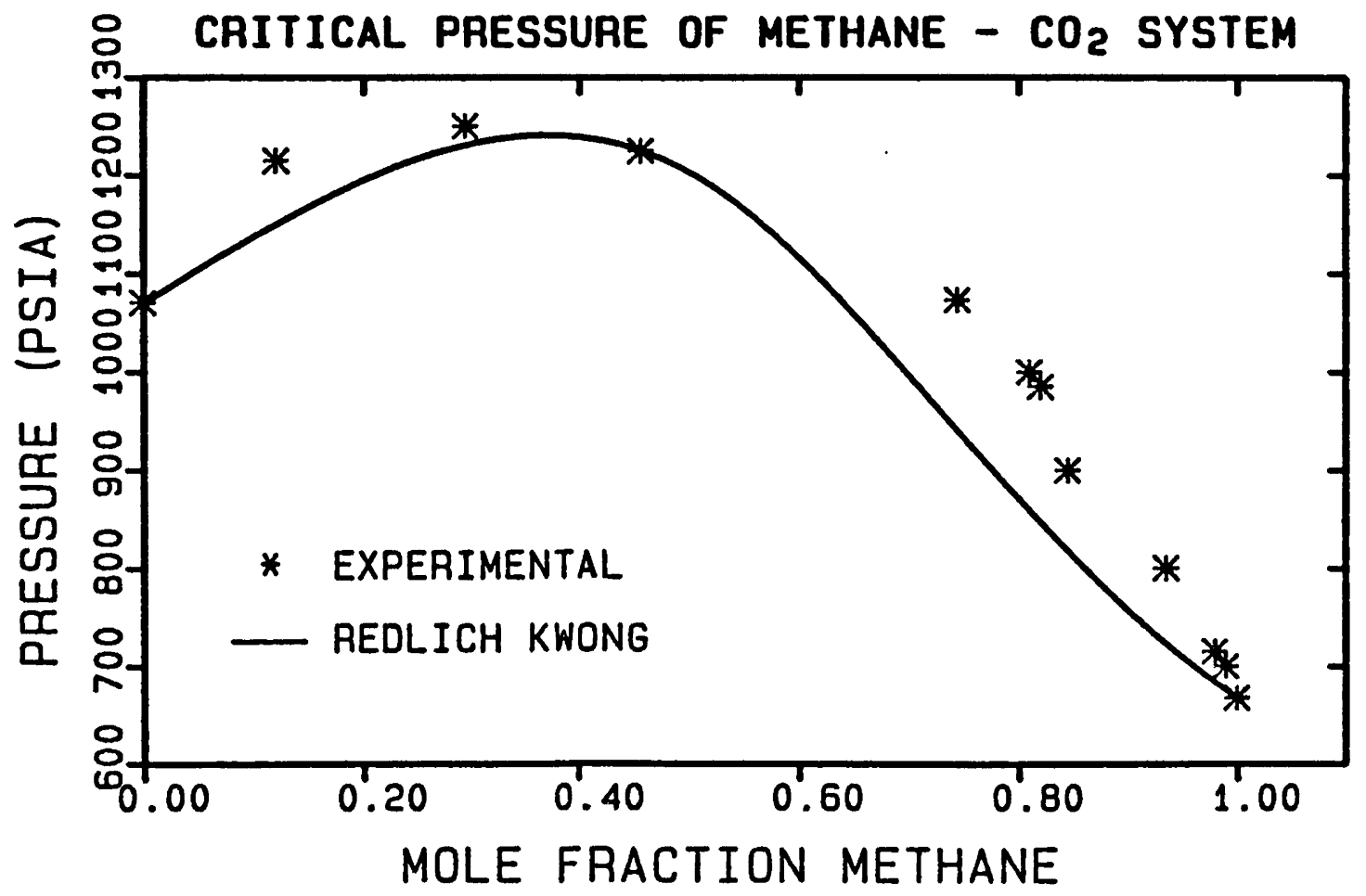


FIGURE 23

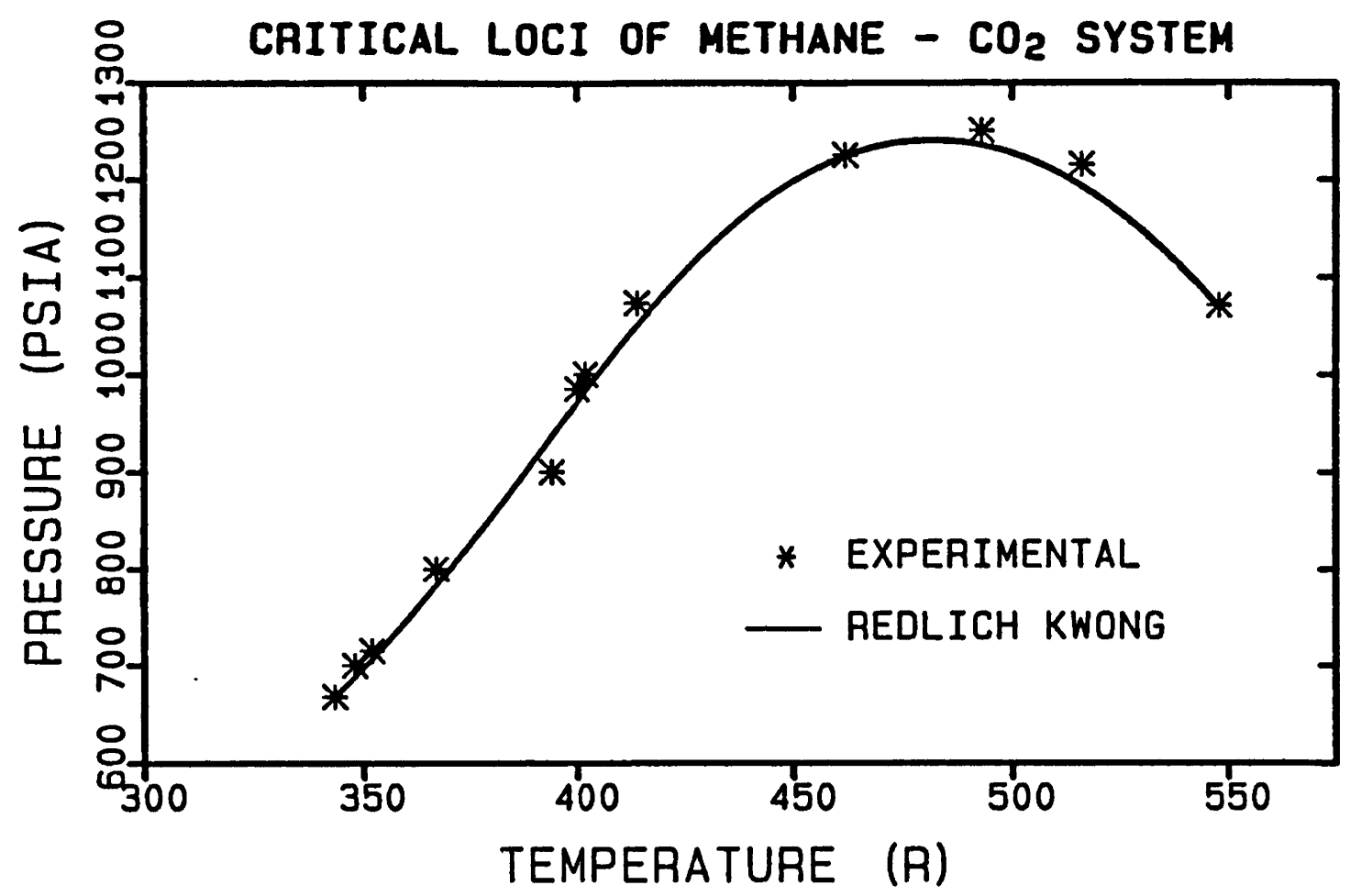

FIGURE 24

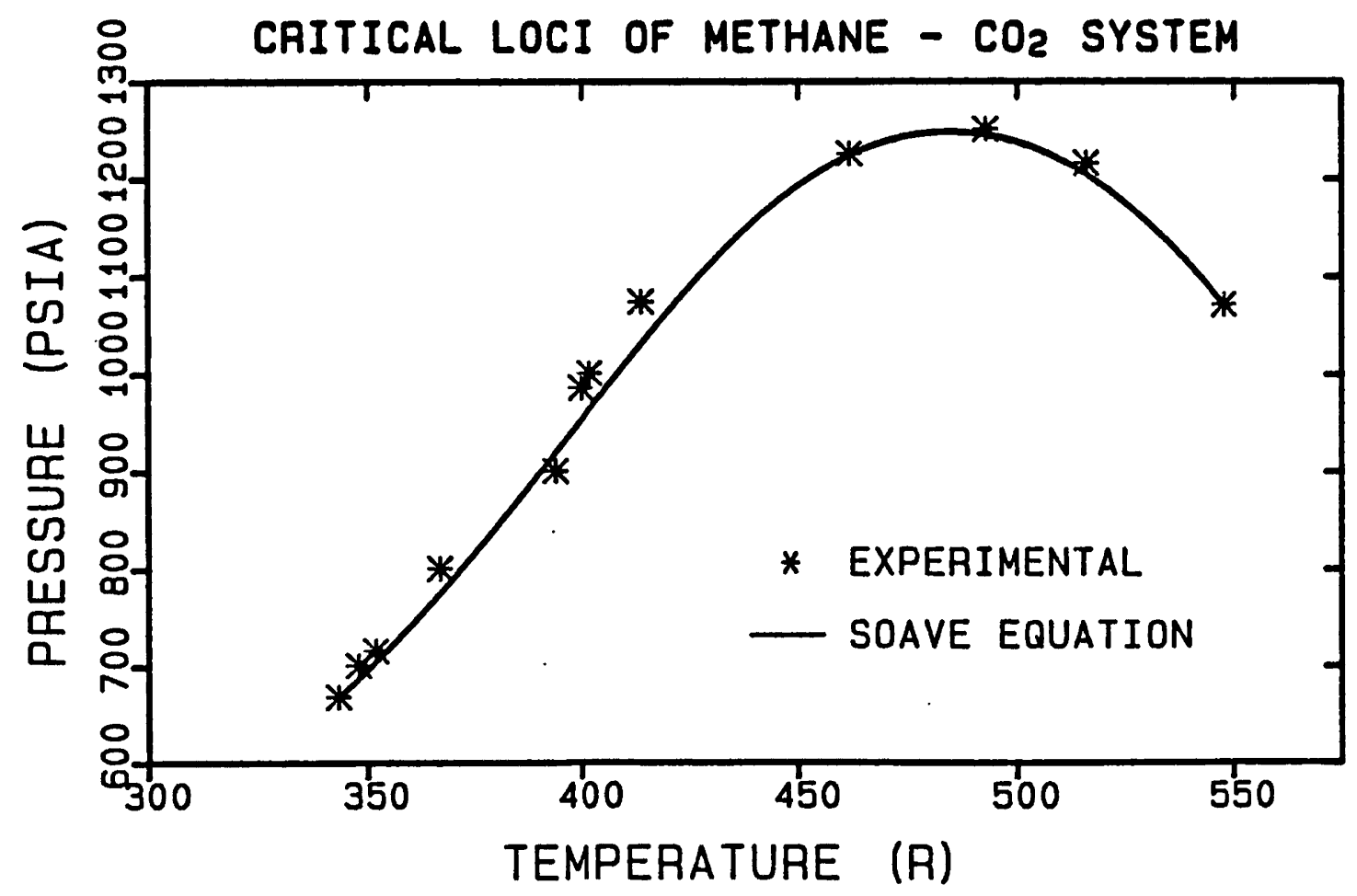


FIGURE 25

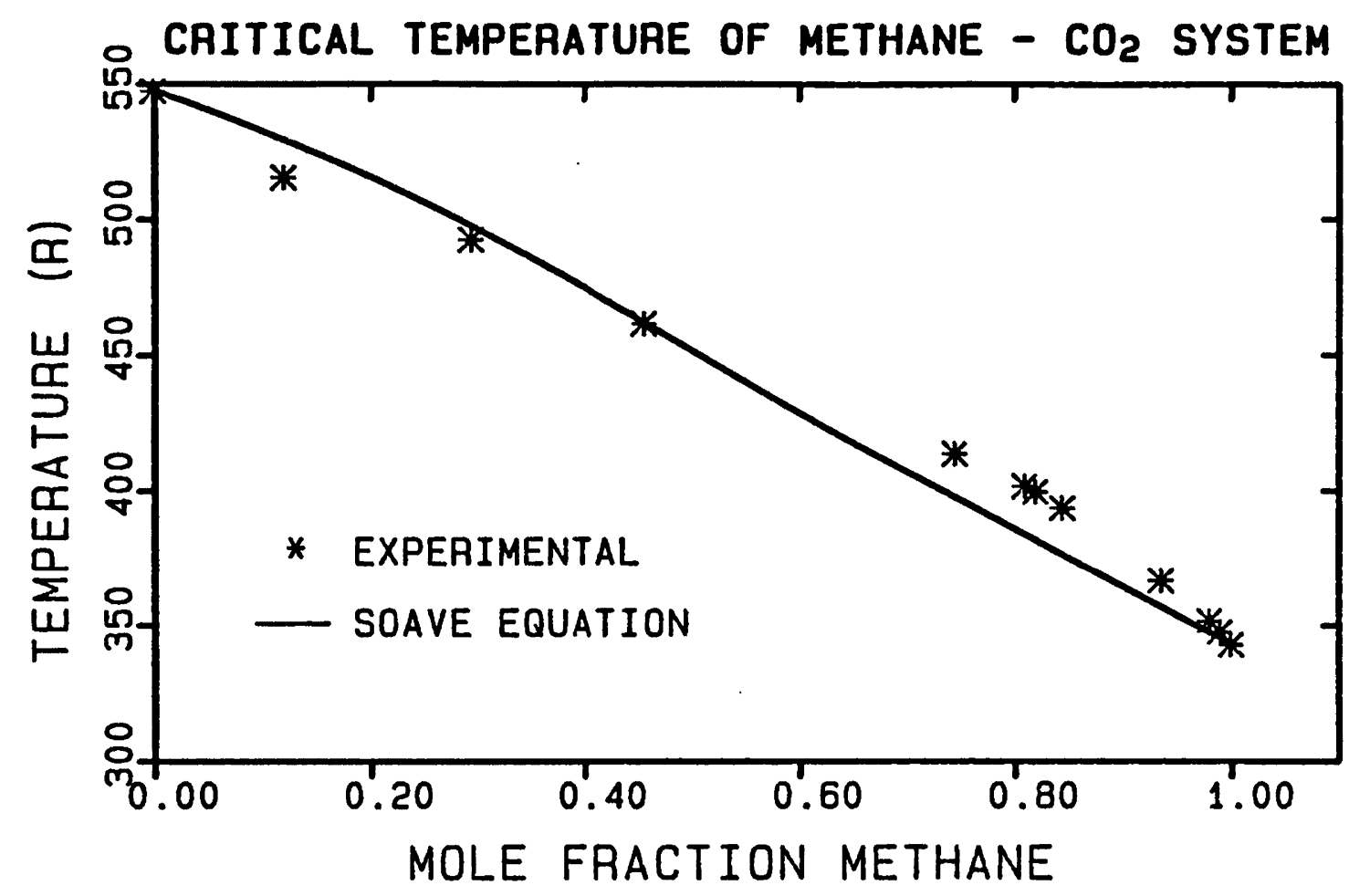

FIGURE 26

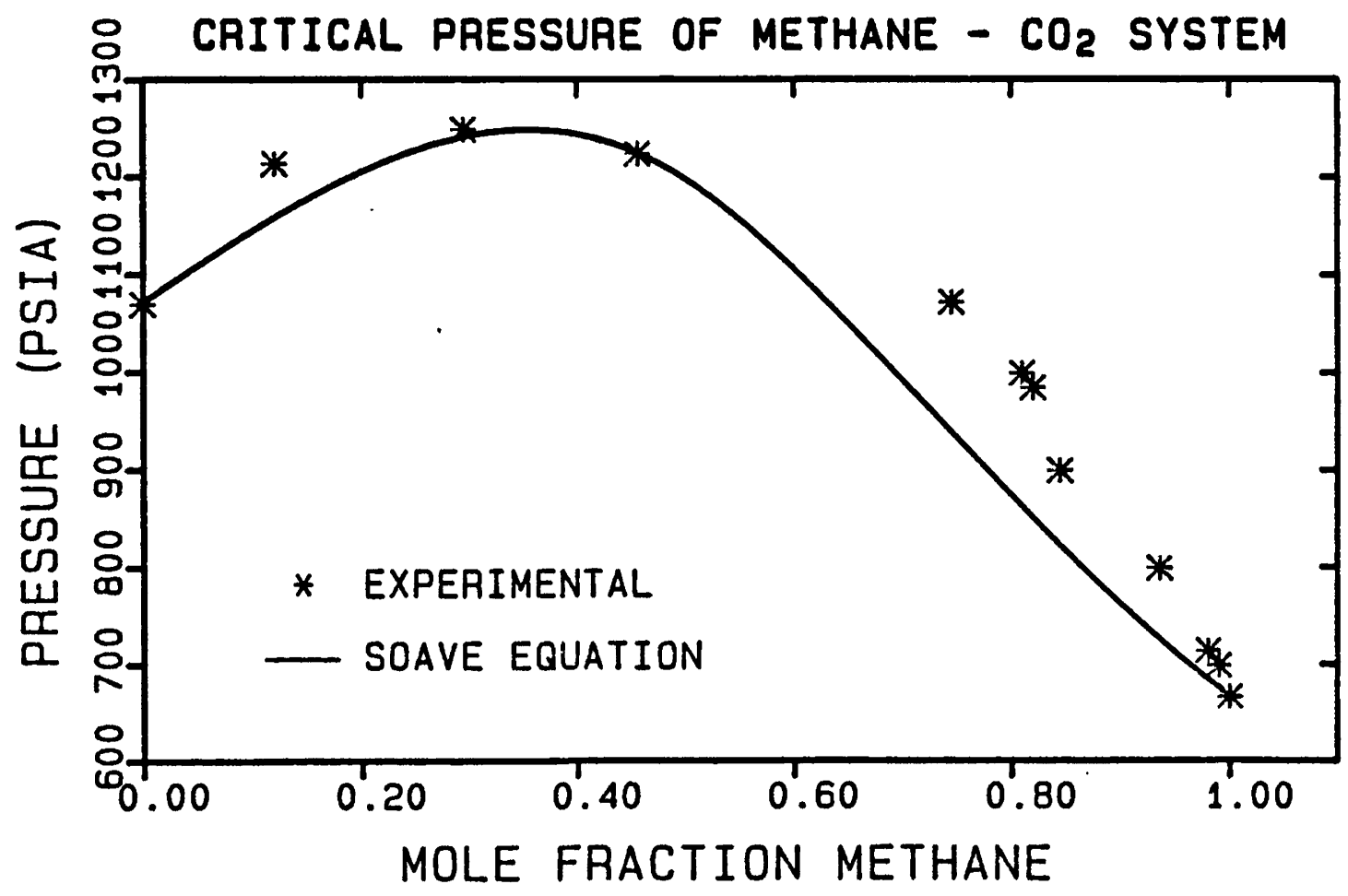


FIGURE 27

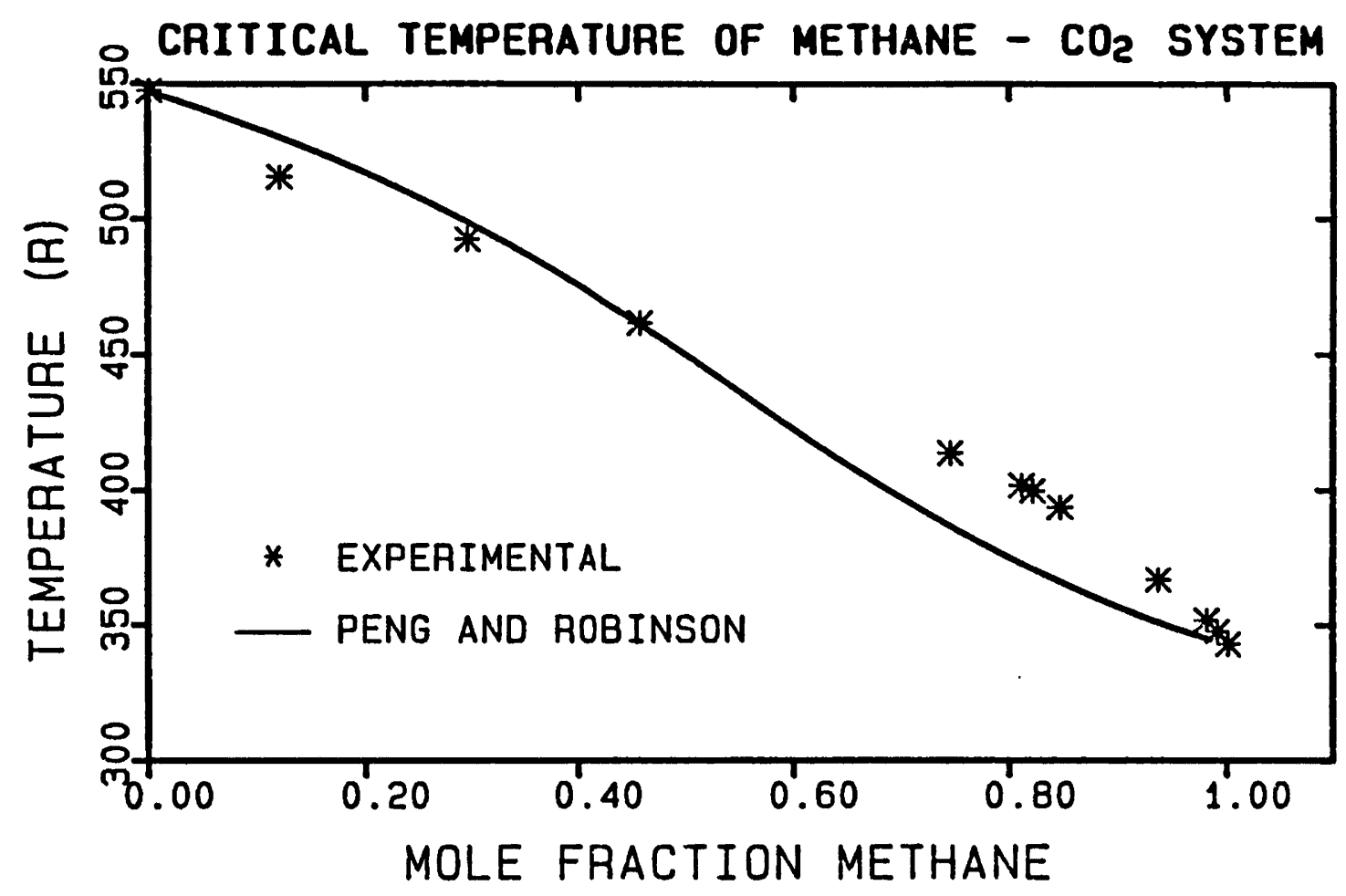

FIGURE 28

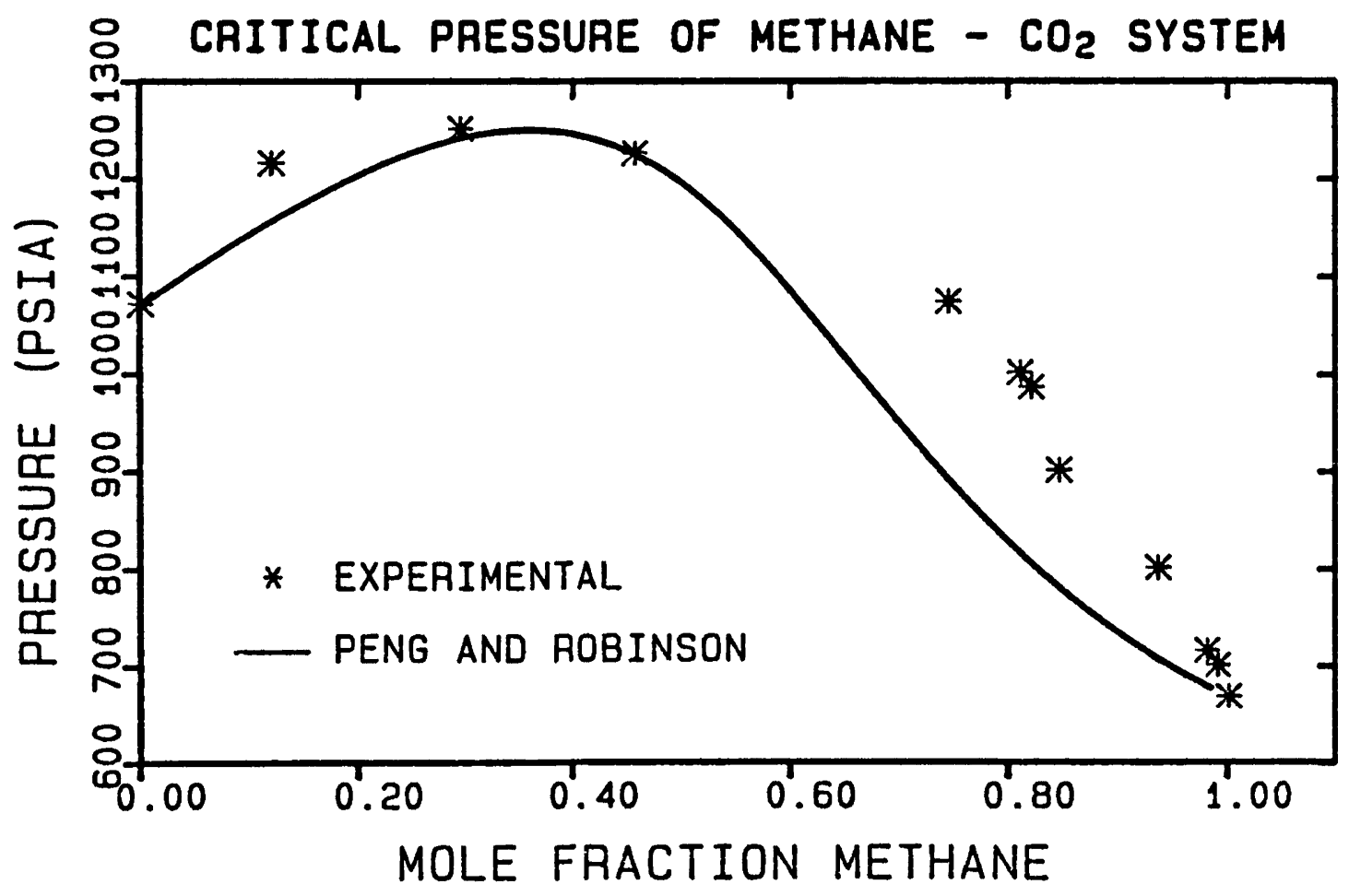


FIGURE 29

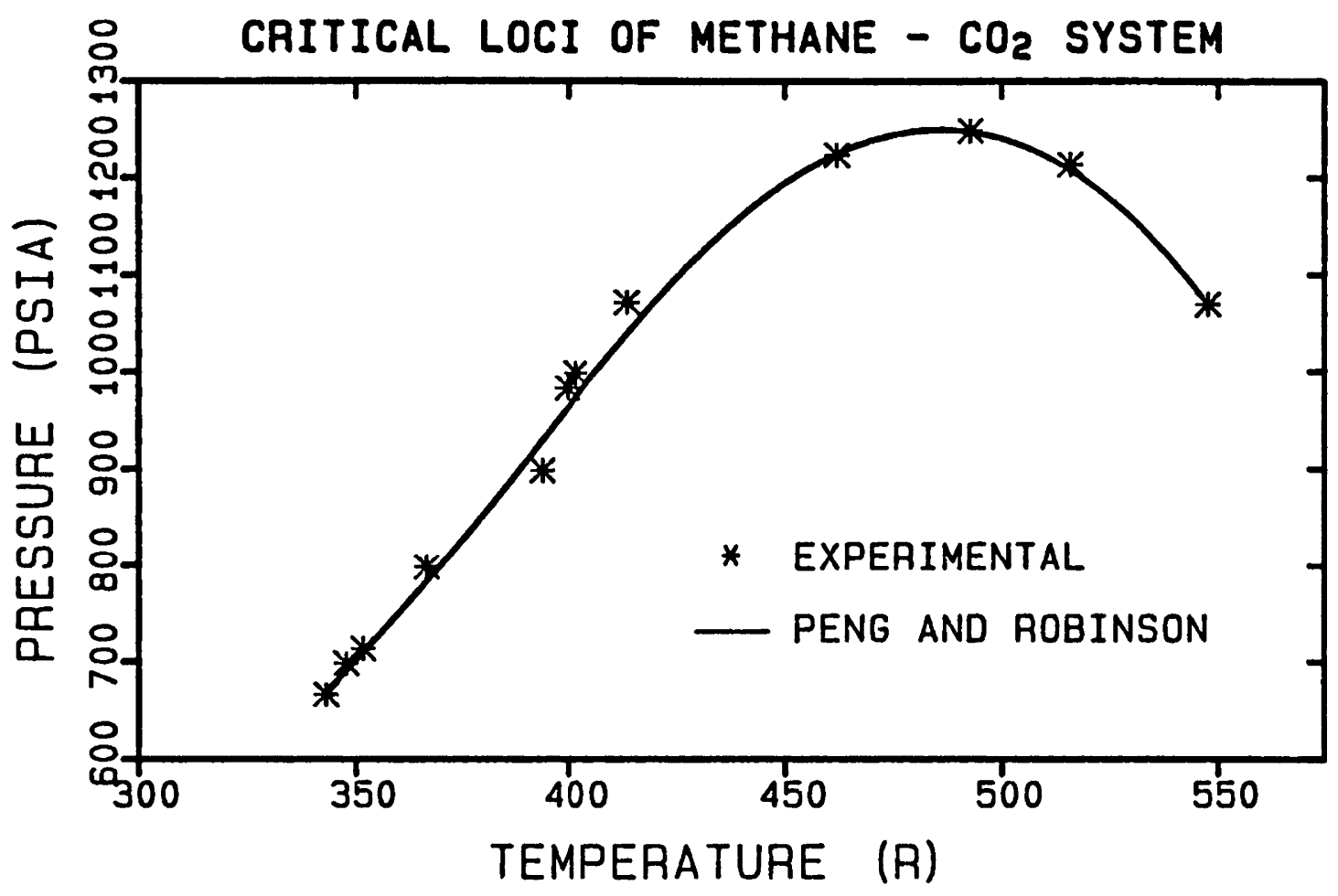

FIGURE 30

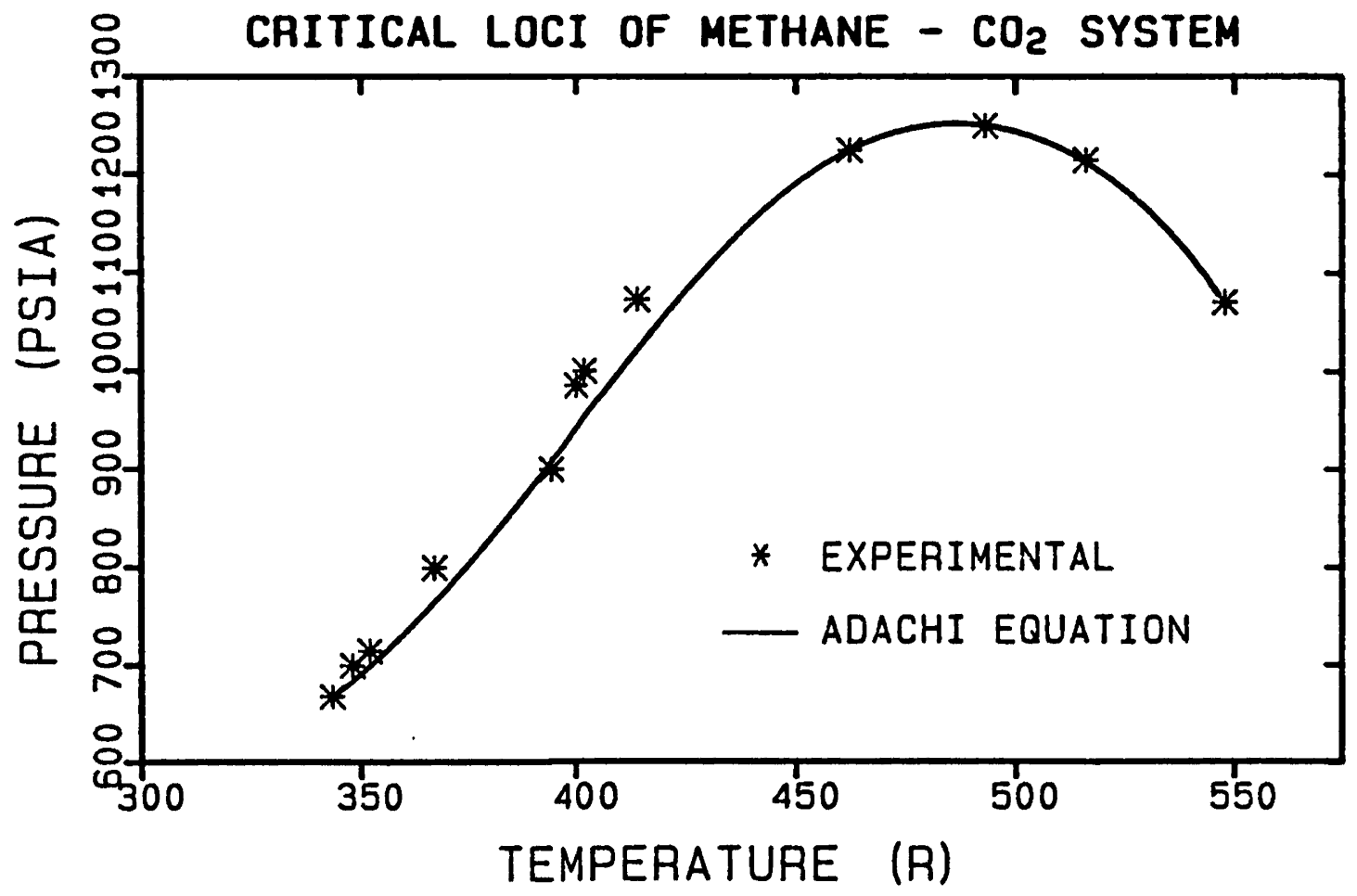


FIGURE 31

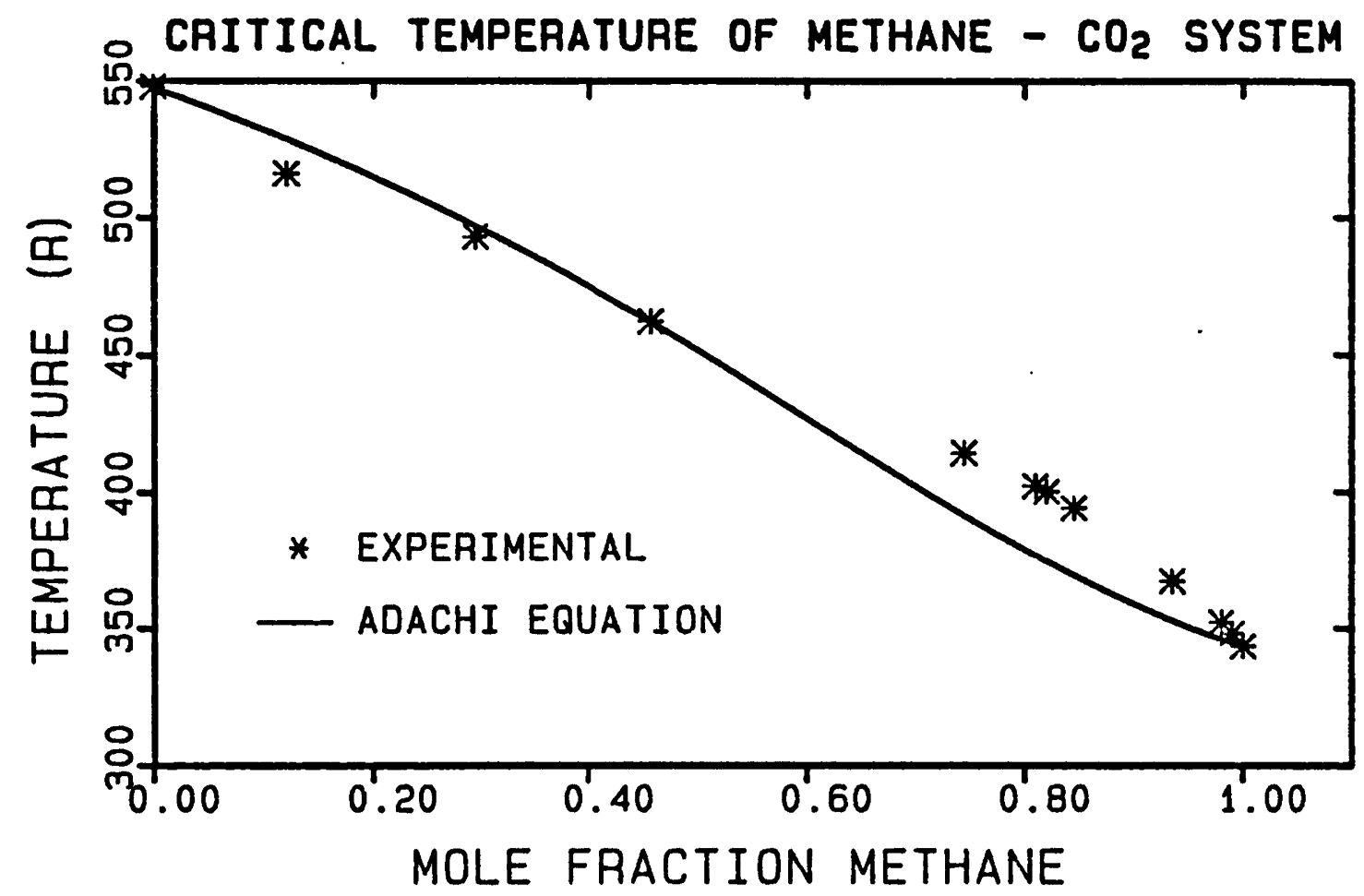

FIGUAE 32

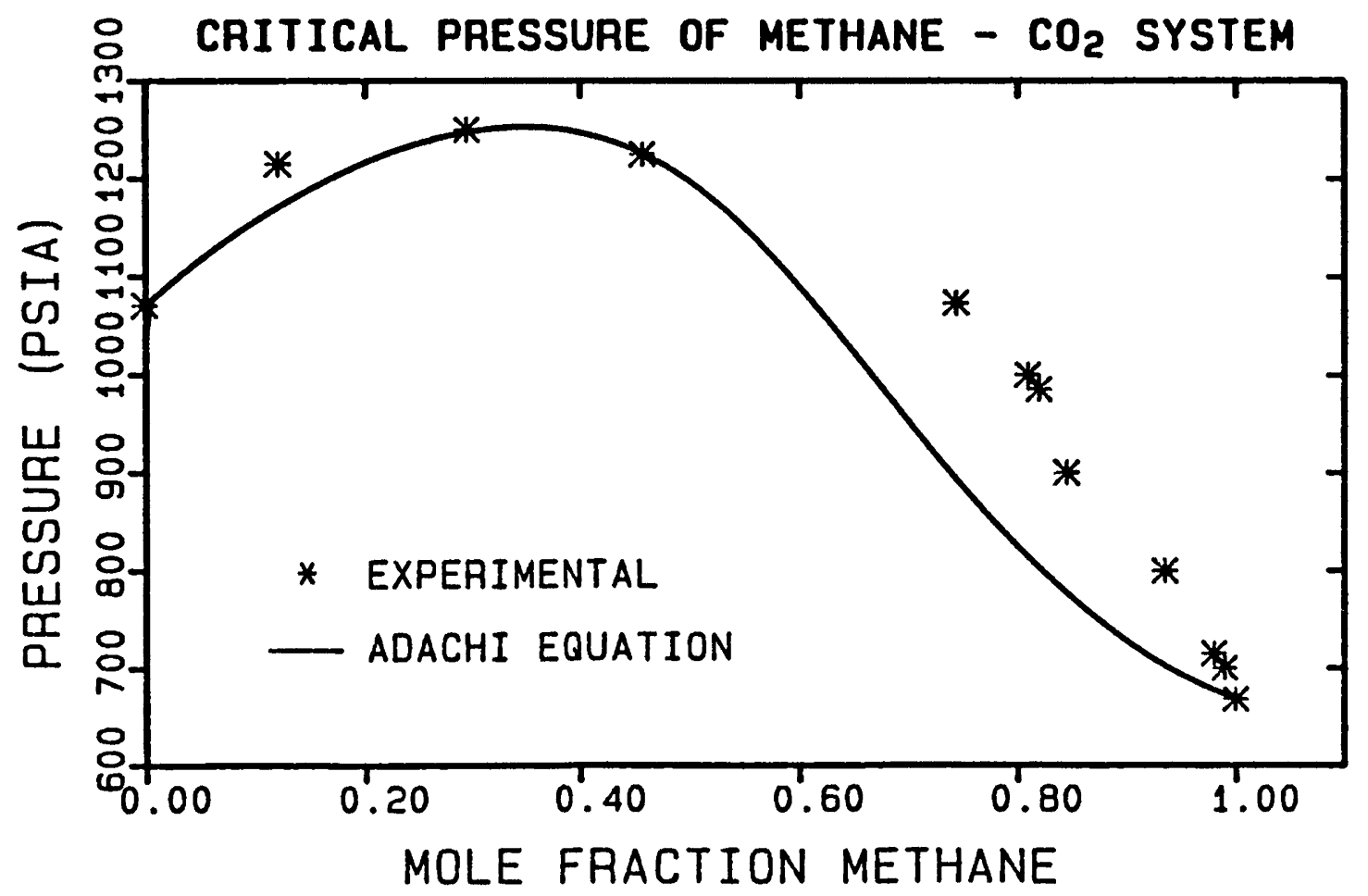


FIGURE 33

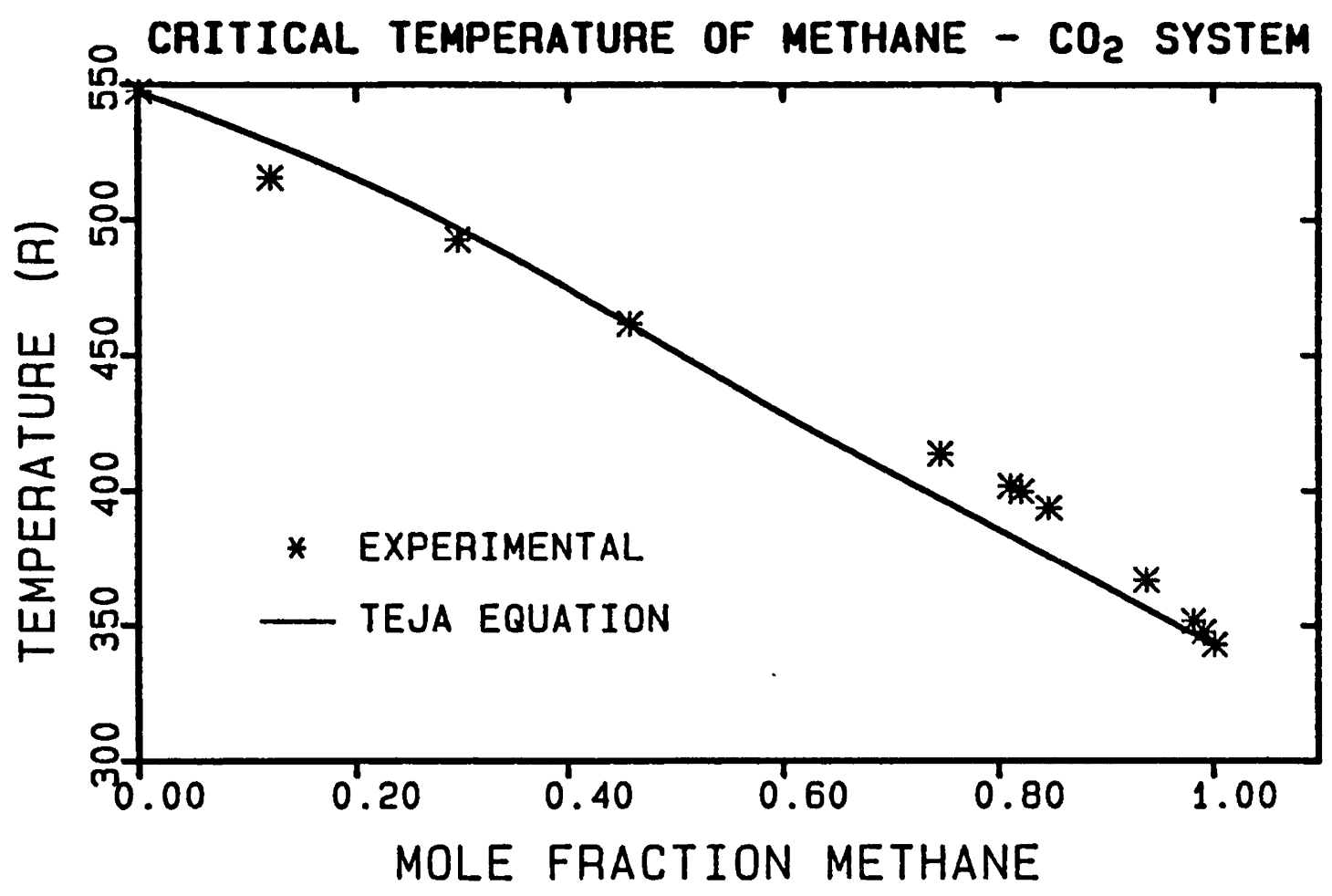

FIGURE 34

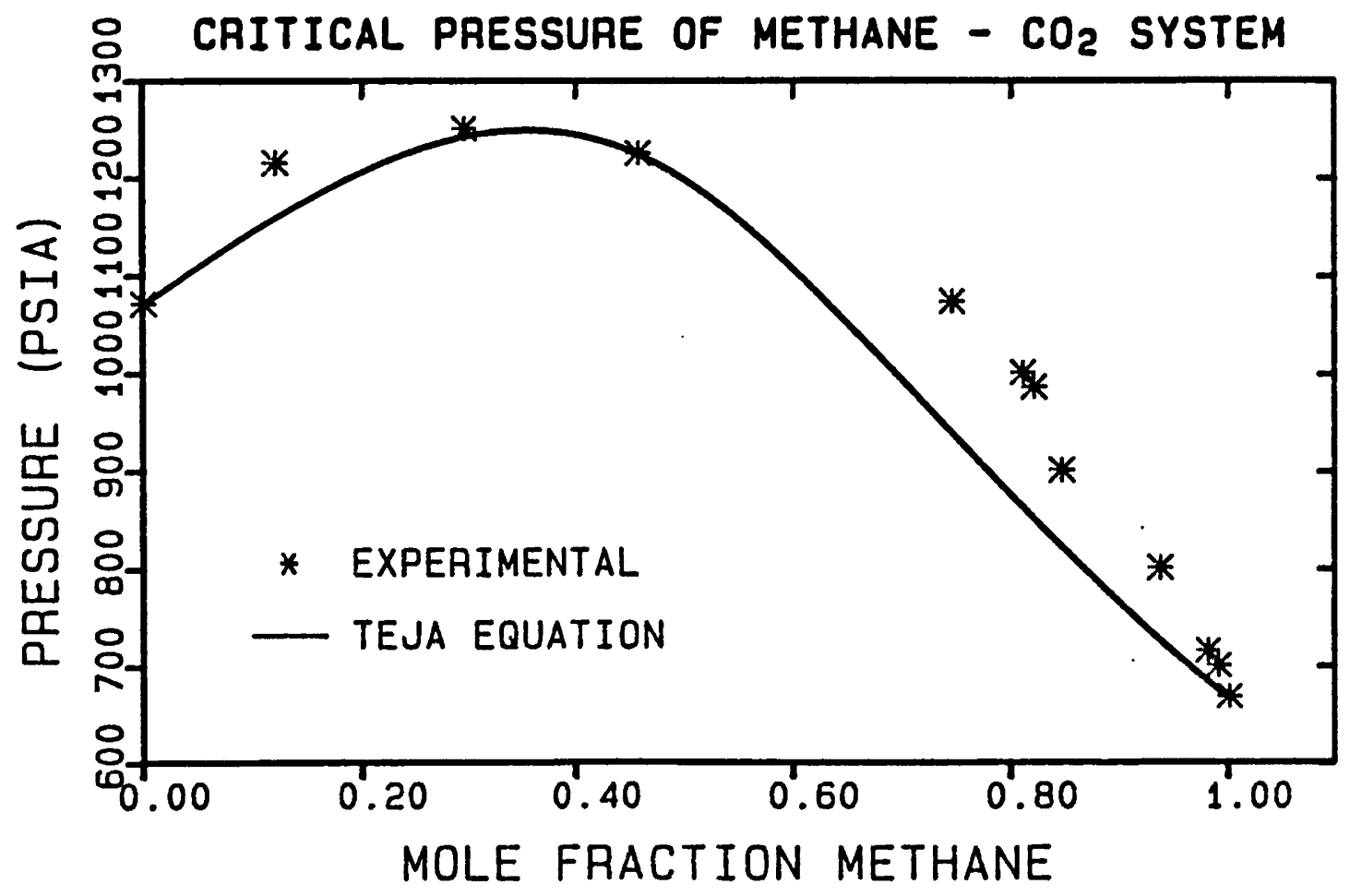


FIGURE 35

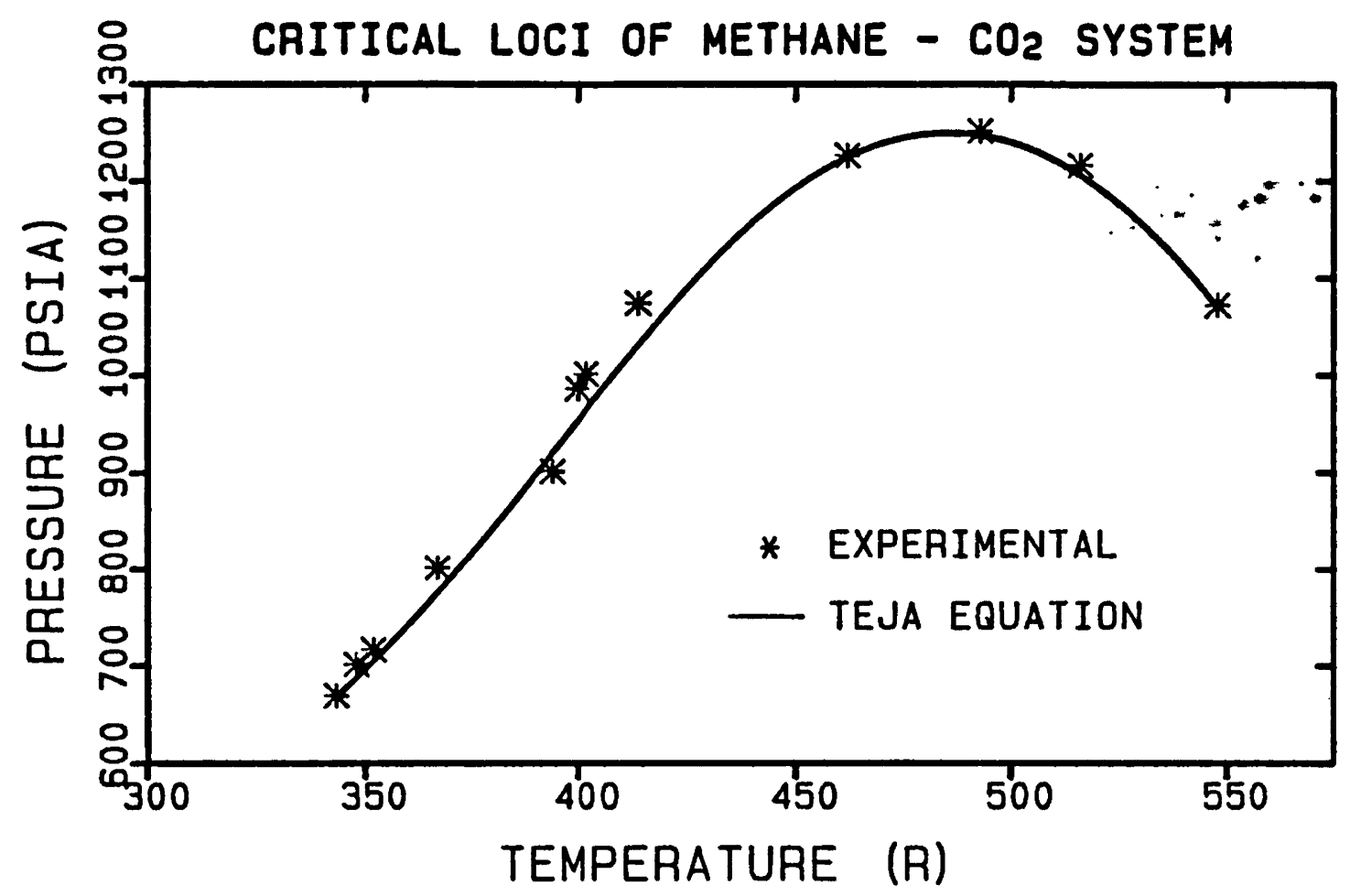




\subsubsection{The Butane - Carbon dioxide System}

Figures 36 - 56 compare the predicted versus experimental critical curves for the butane - carbon dioxide system. The predicted critical pressures and temperatures are considerably better for this system compared to the methane hexane system. However, all of the equations predicted a critical pressure curve with a local minimum that is unsubstantiated by experimental data. This error lies in the values of $\zeta_{12}$ and $\lambda_{12}$ chosen. Figure 56 compares the predicted critical pressure curve obtained when the fitted parameters are set equal to one, with that obtained when the optimum values are used. While the former curve does not contain the erroneous local minimum, the critical pressure prediction suffers considerably. Overall greater accuracy is obtained with the latter curve.

As with the previous systems, the Teja equation was the most accurate with a $0.51 \%$ deviation in predicting the critical temperatures and a $1.56 \%$ deviation in predicting the critical pressures. The Peng and Robinson equation was the poorest in predicting the critical temperatures with a $1.28 \%$ deviation. The Adachi equation was the least accurate in predicting the critical pressures with a $2.96 \%$ overall deviation.

All the equations generated critical volume curves which were greater than experimental data. The Peng and 
Robinson equation was best with a $7.99 \%$ deviation while the Adachi equation of state had a $28.06 \%$ error. 
FIGURE 36

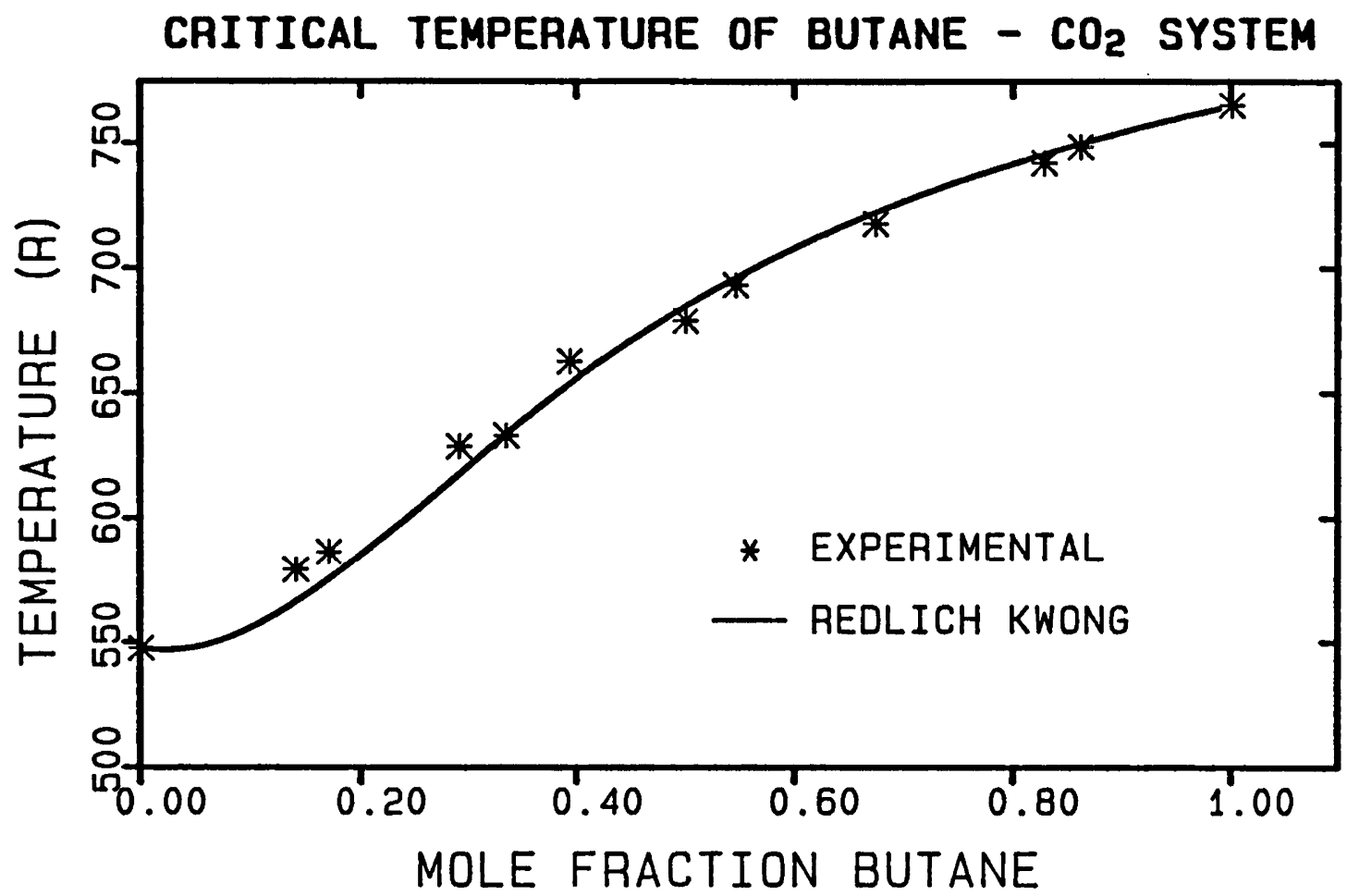

FIGURE 37

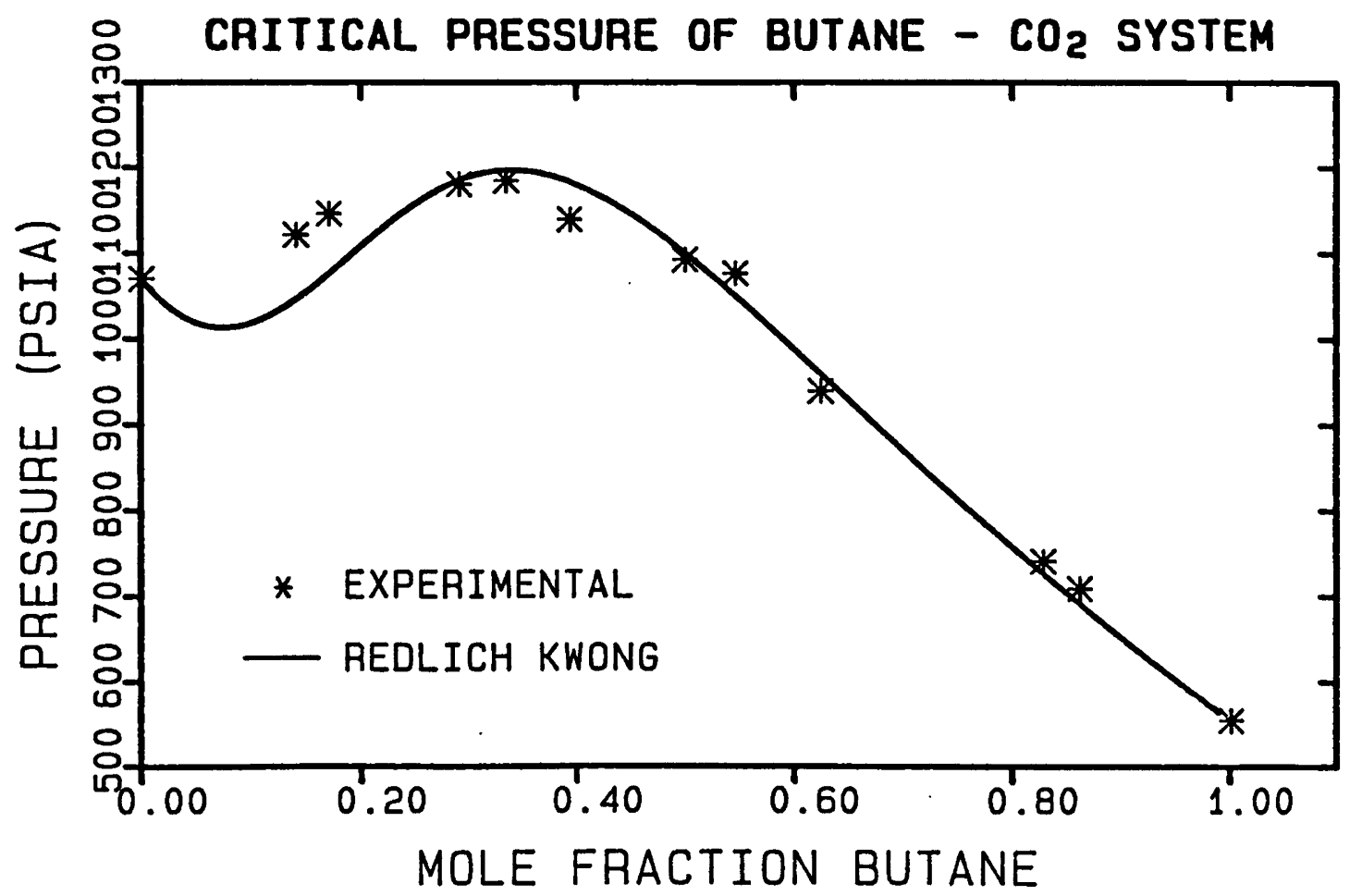


FIGURE 38

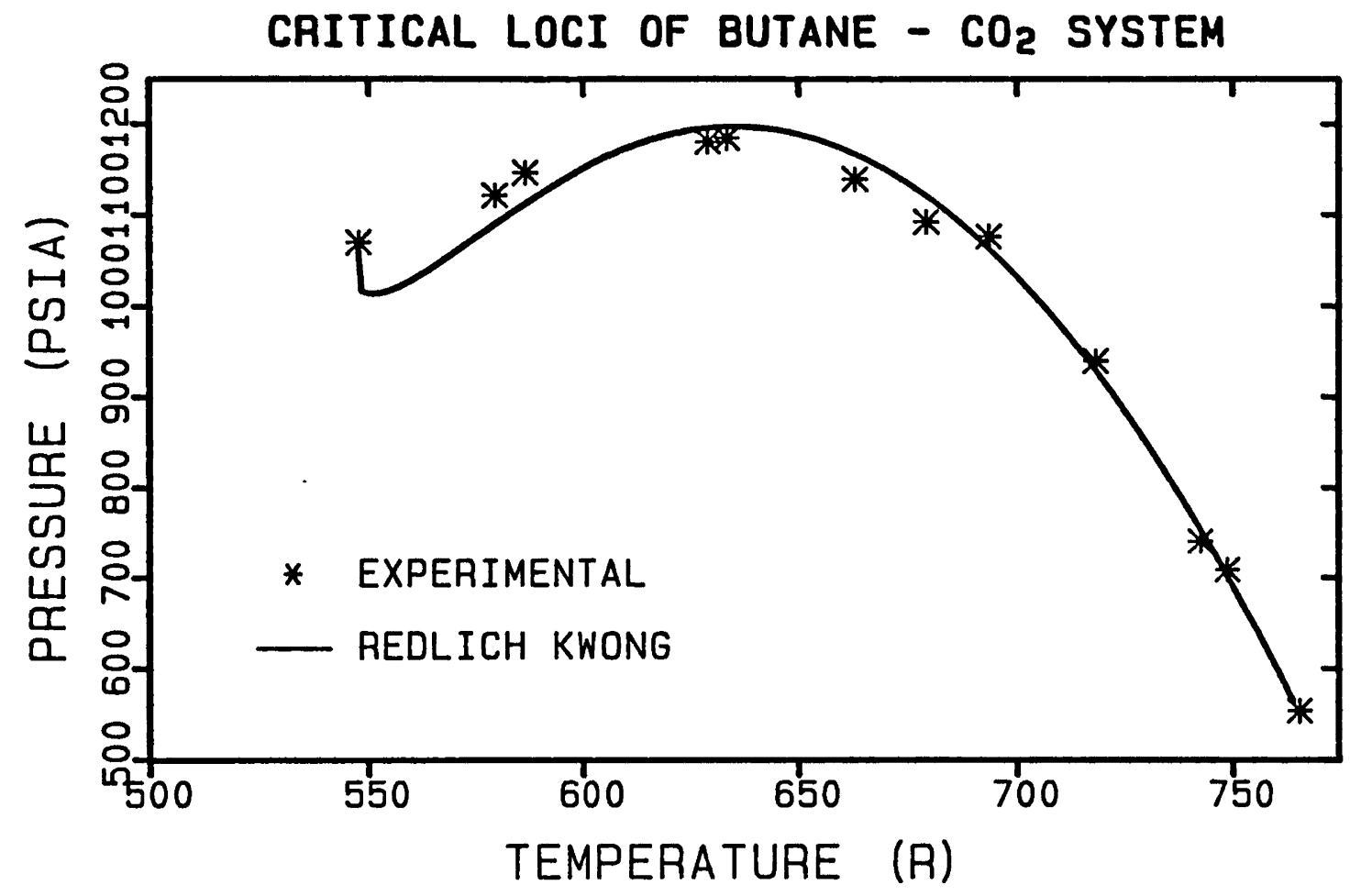

FIGURE 39

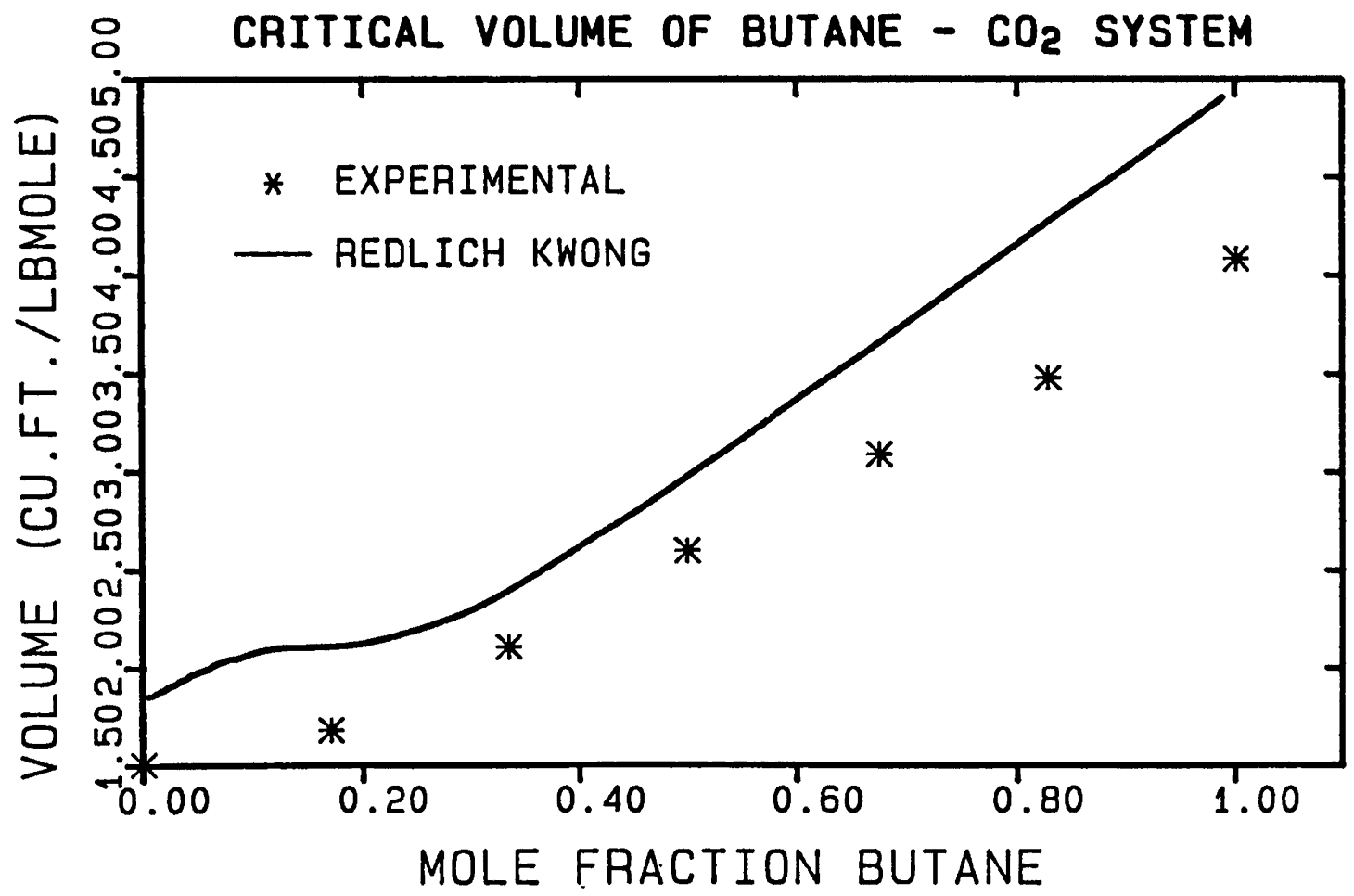


FIGURE 40
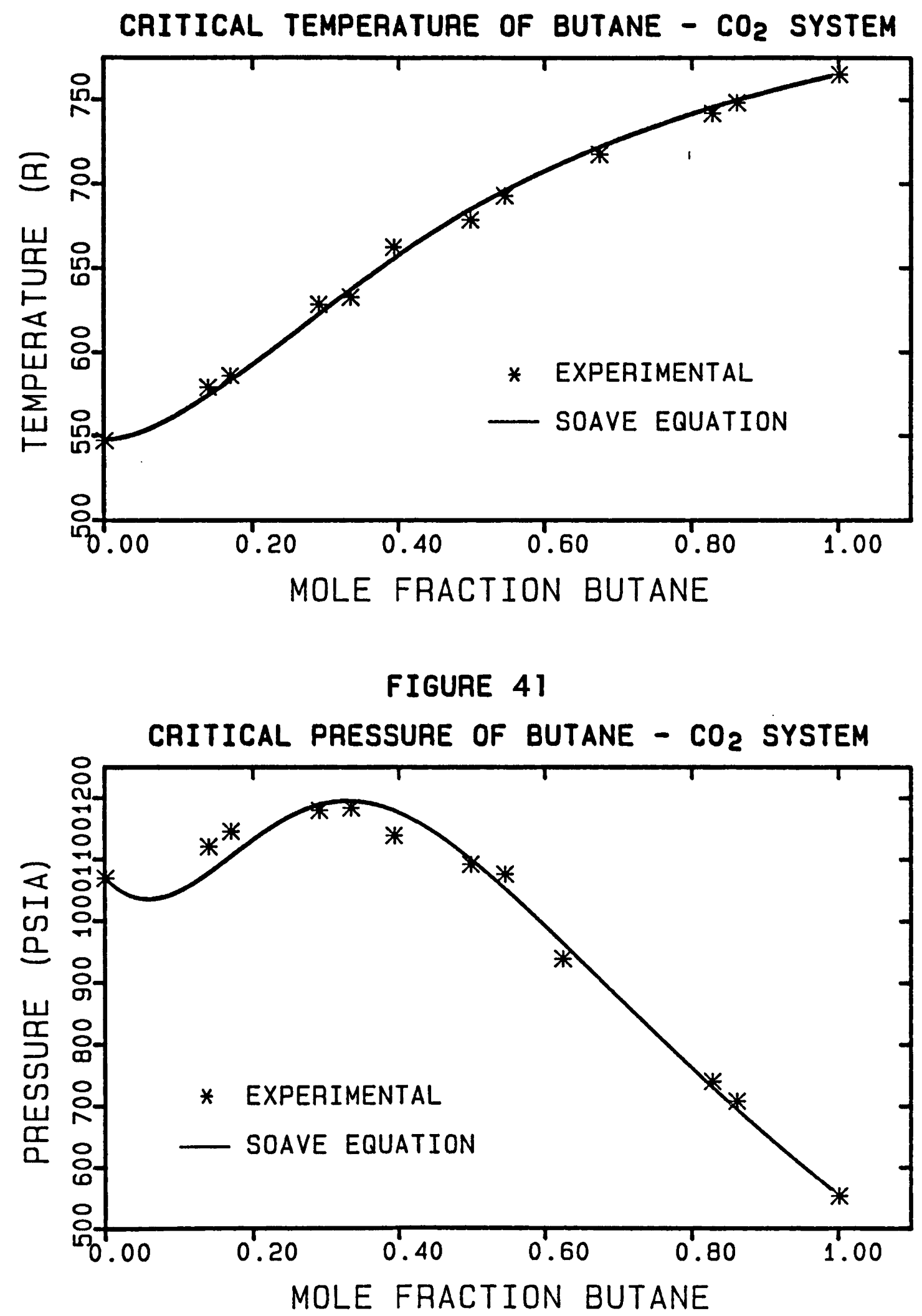
FIGUAE 42

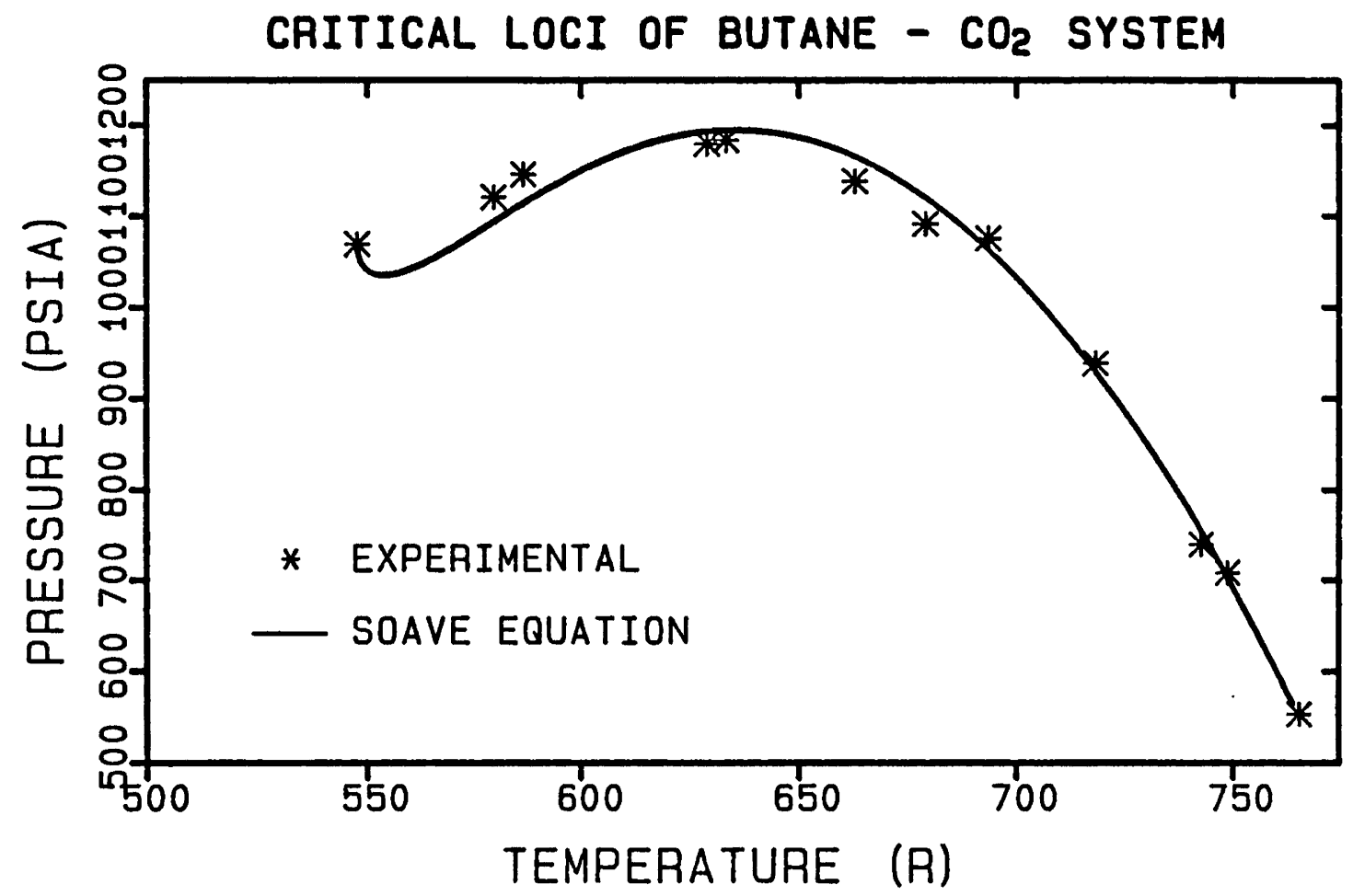

FIGUAE 43

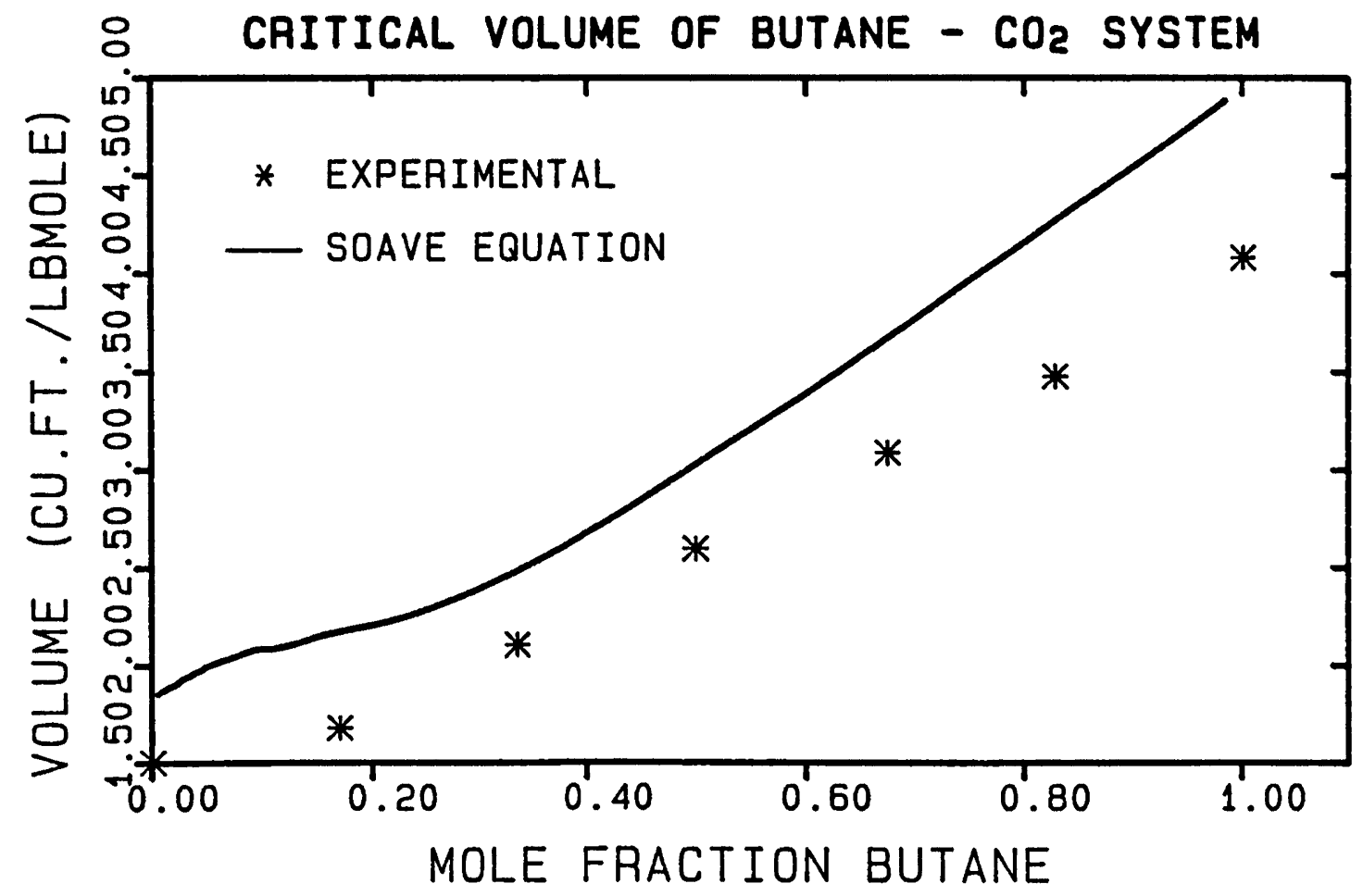


FIGURE 44

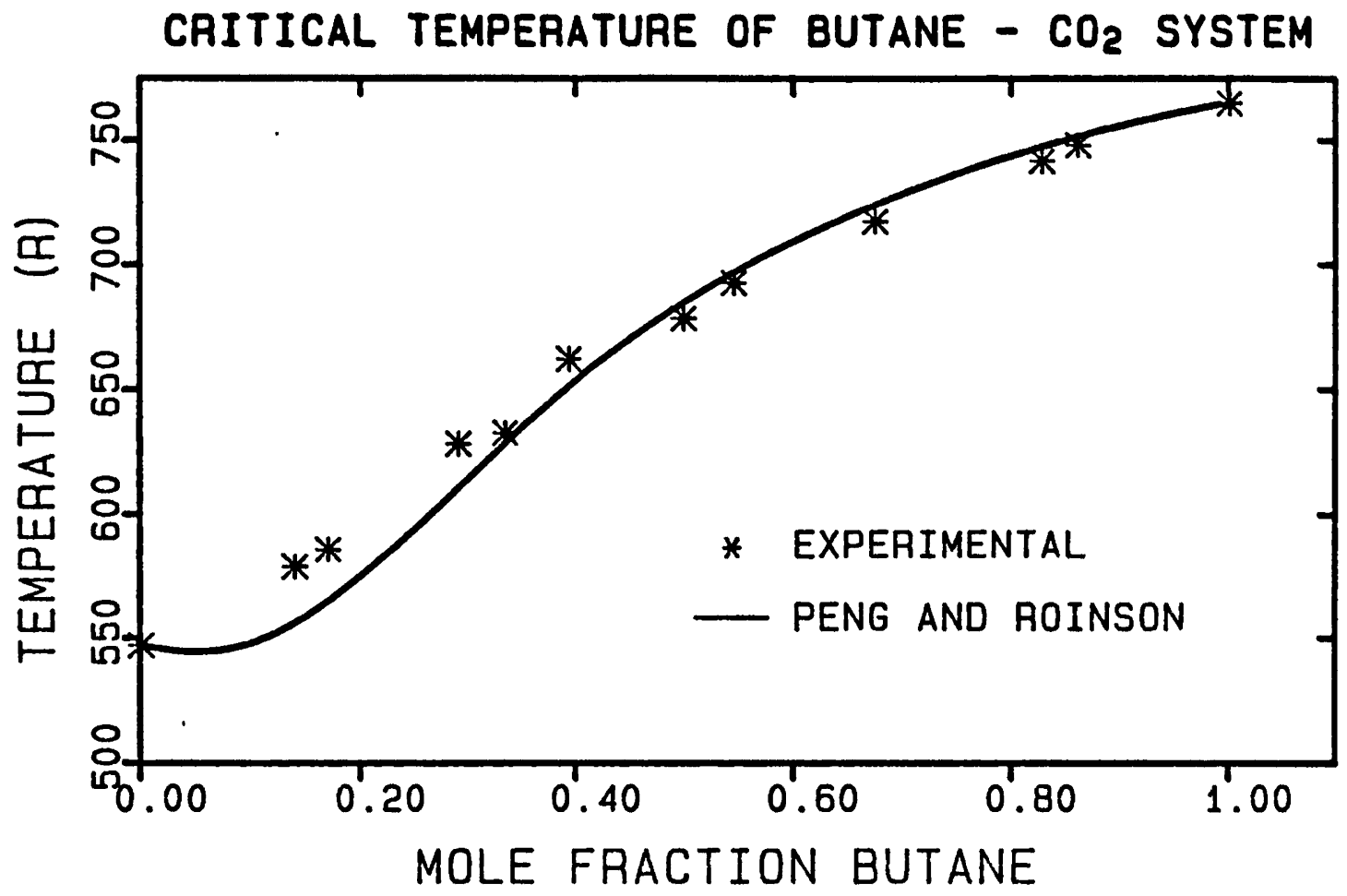

FIGURE 45

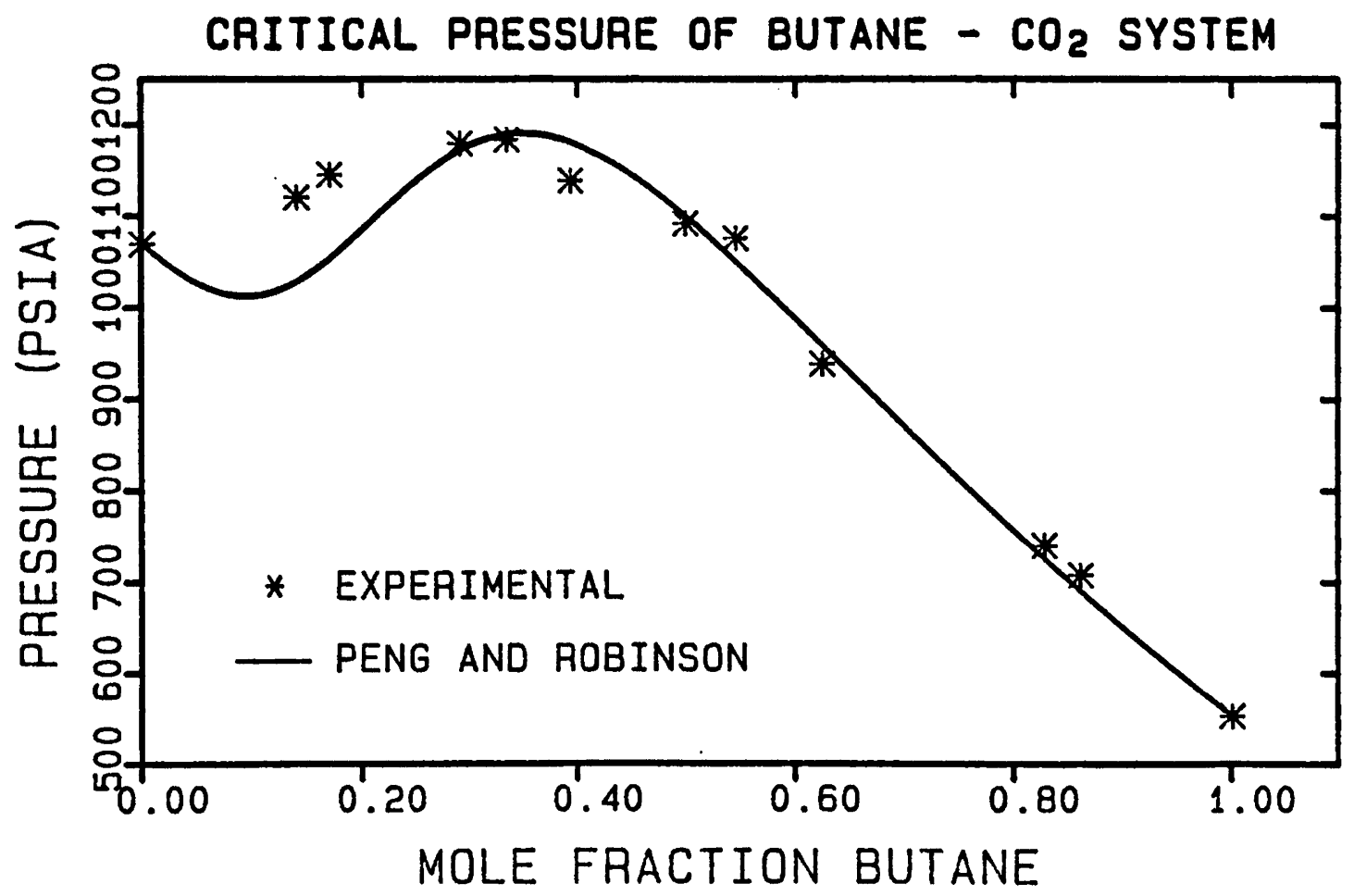


FIGURE 46

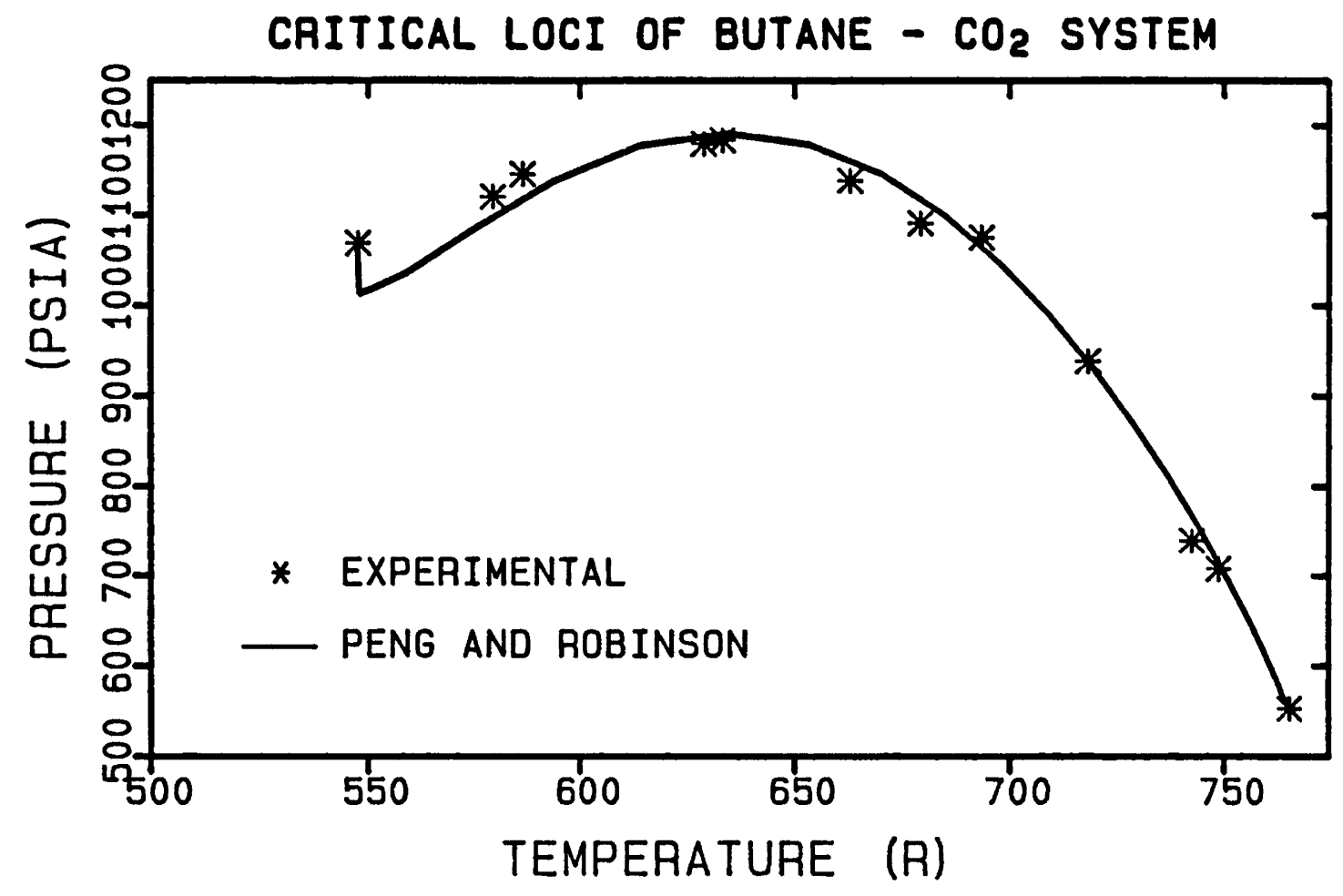

FIGURE 47

CAITICAL VOLUME OF BUTANE - $\mathrm{CO}_{2}$ SYSTEM

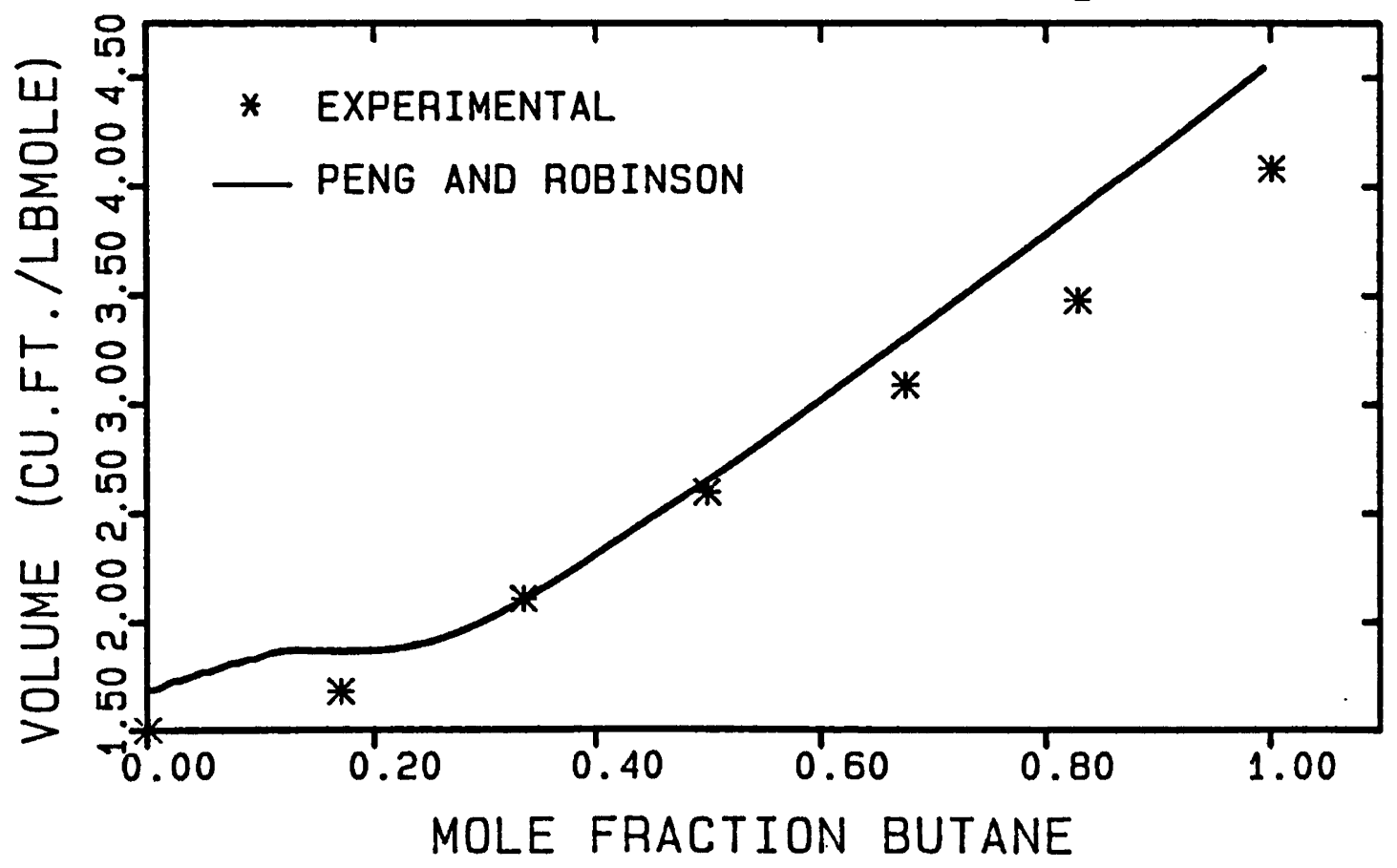


FIGURE 48

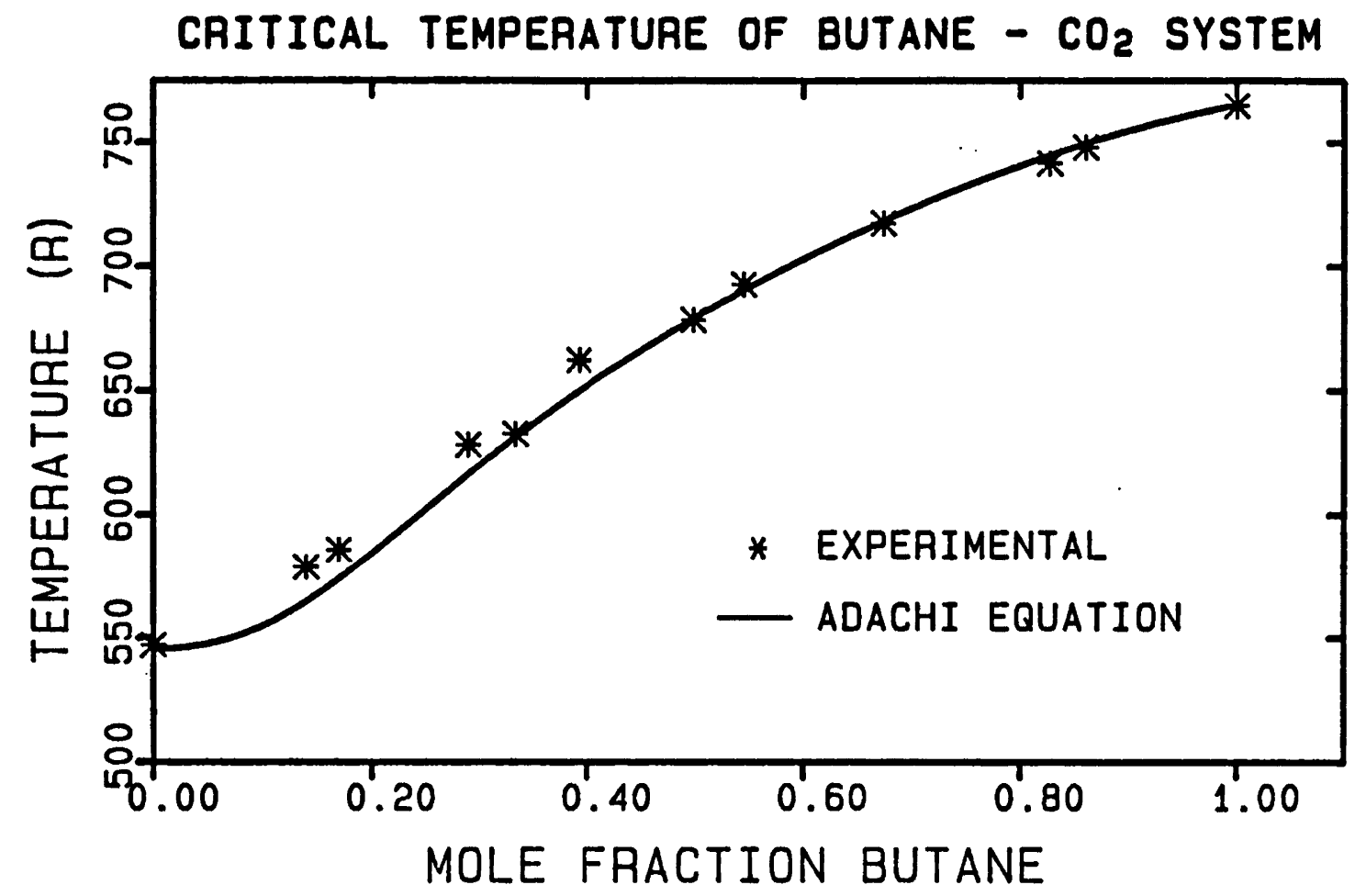

FIGURE 49

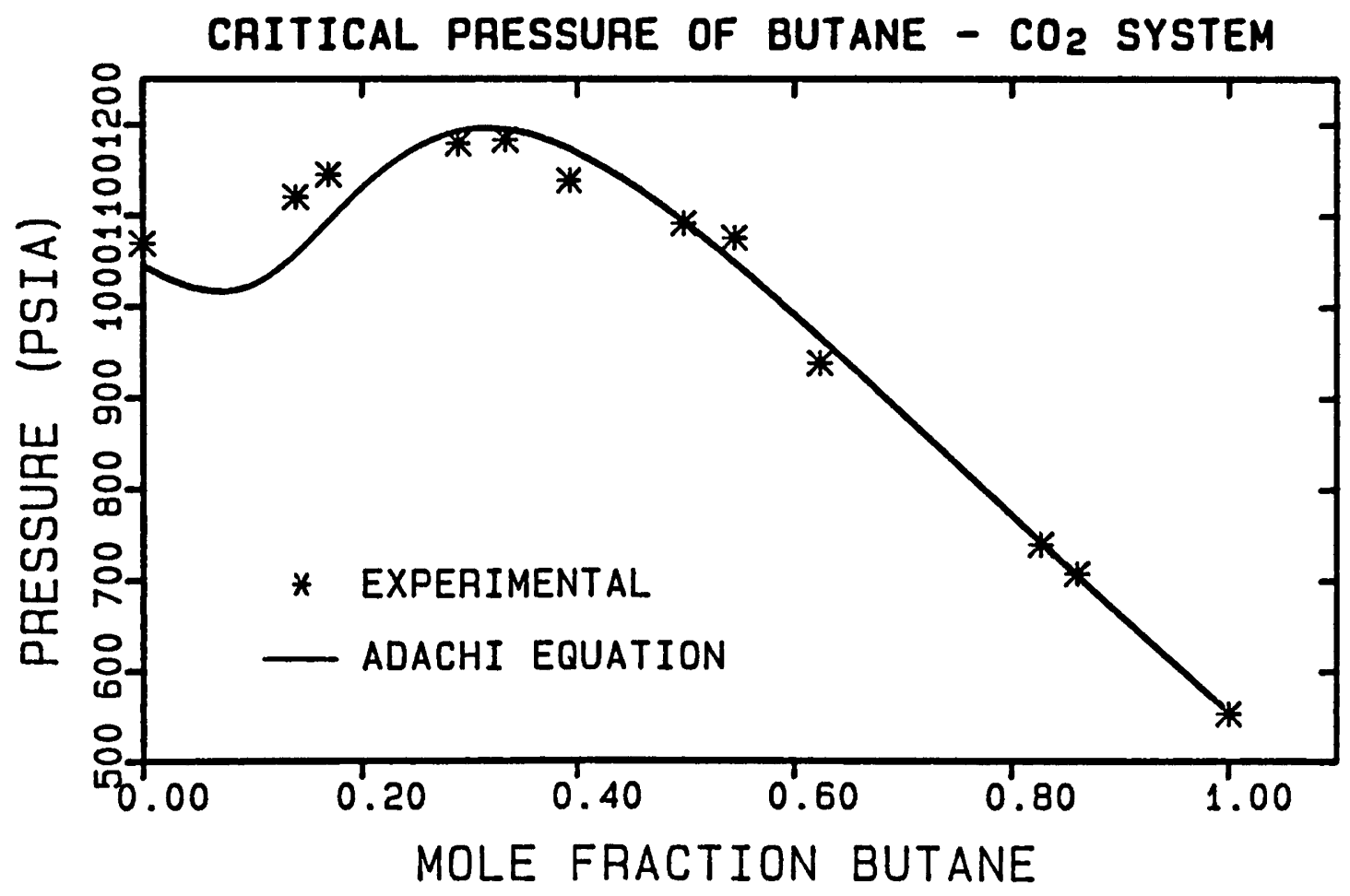


FIGURE 50

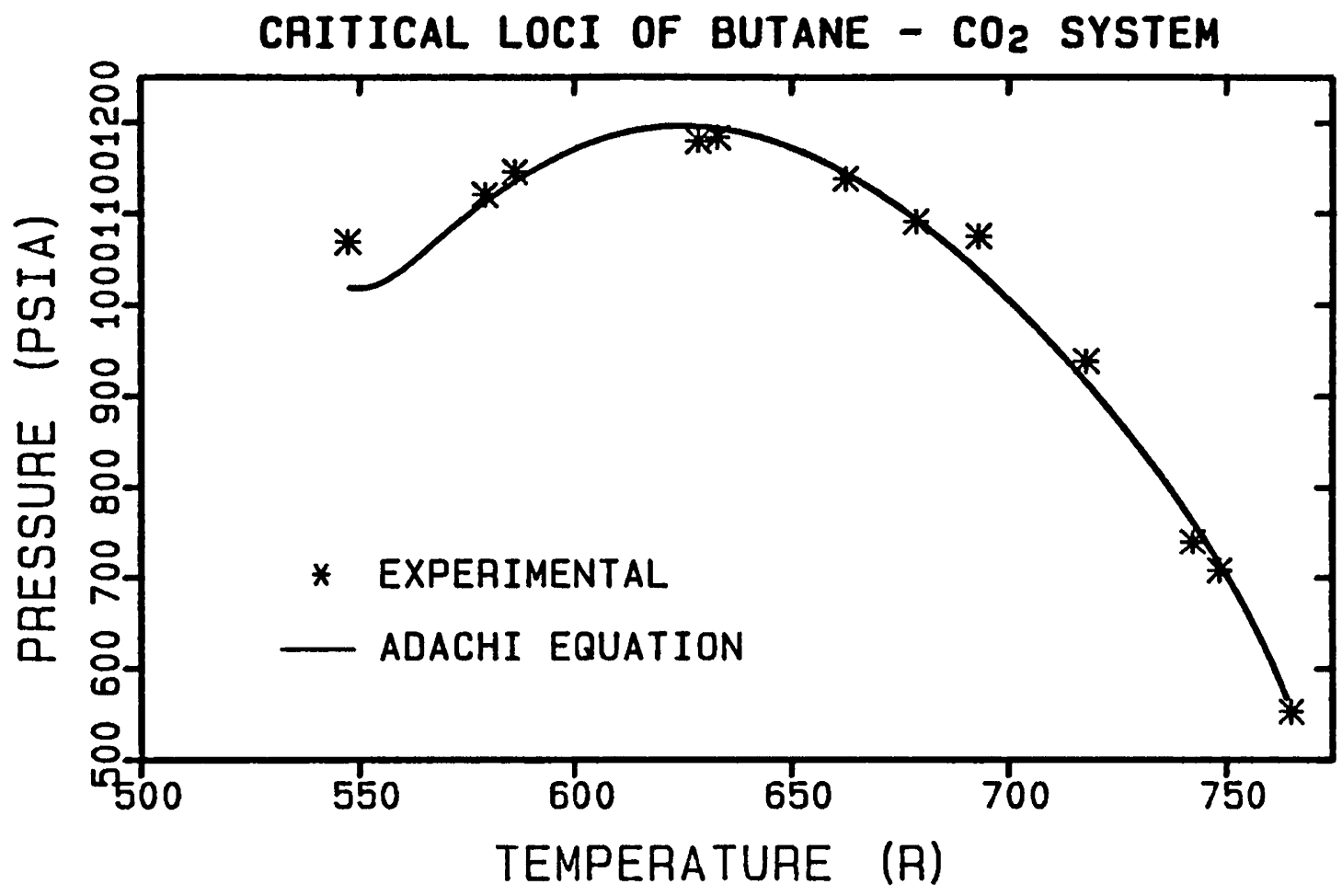

FIGURE 51

은 CRITICAL VOLUME OF BUTANE - $\mathrm{CO}_{2}$ SYSTEM

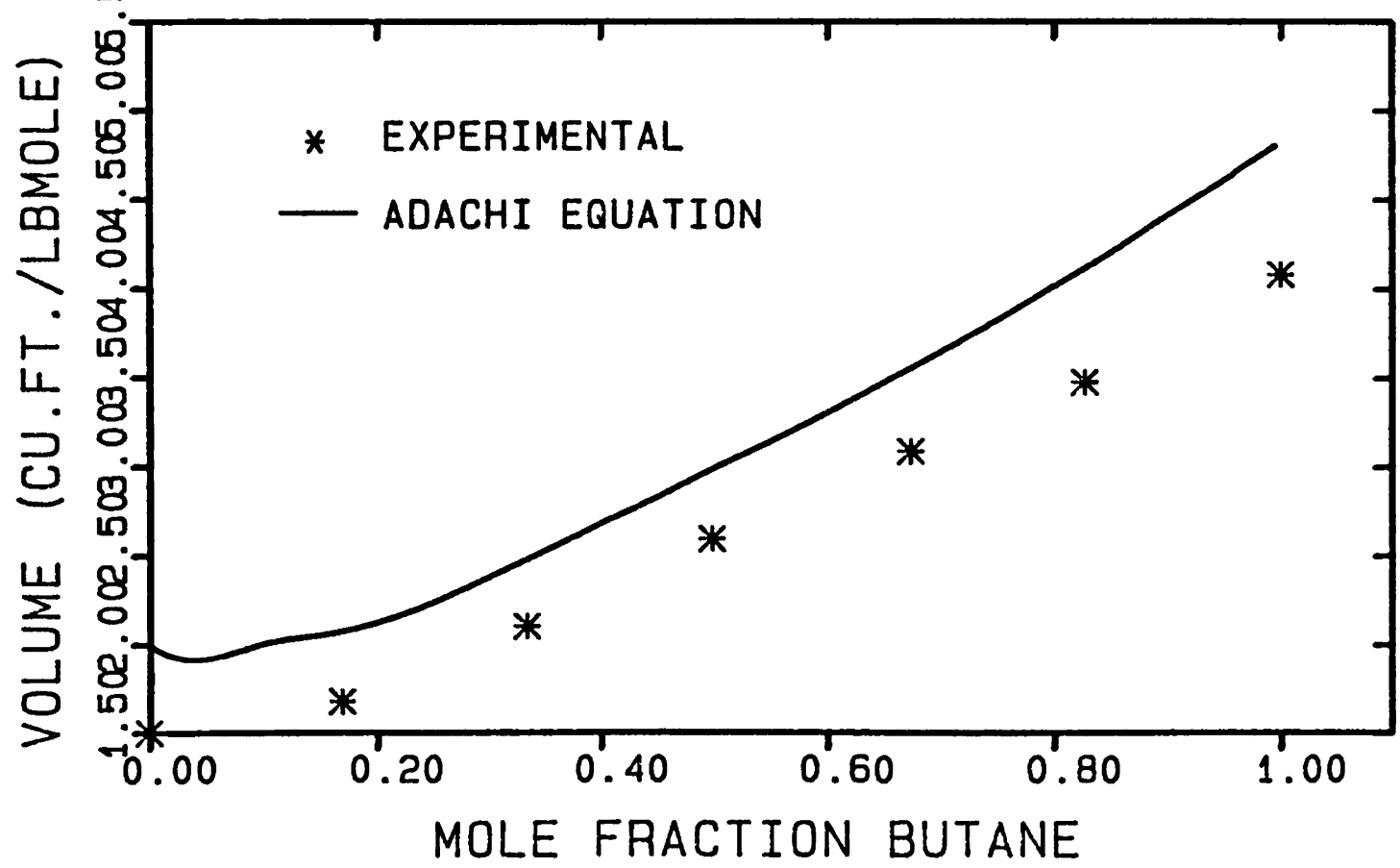


FIGURE 52

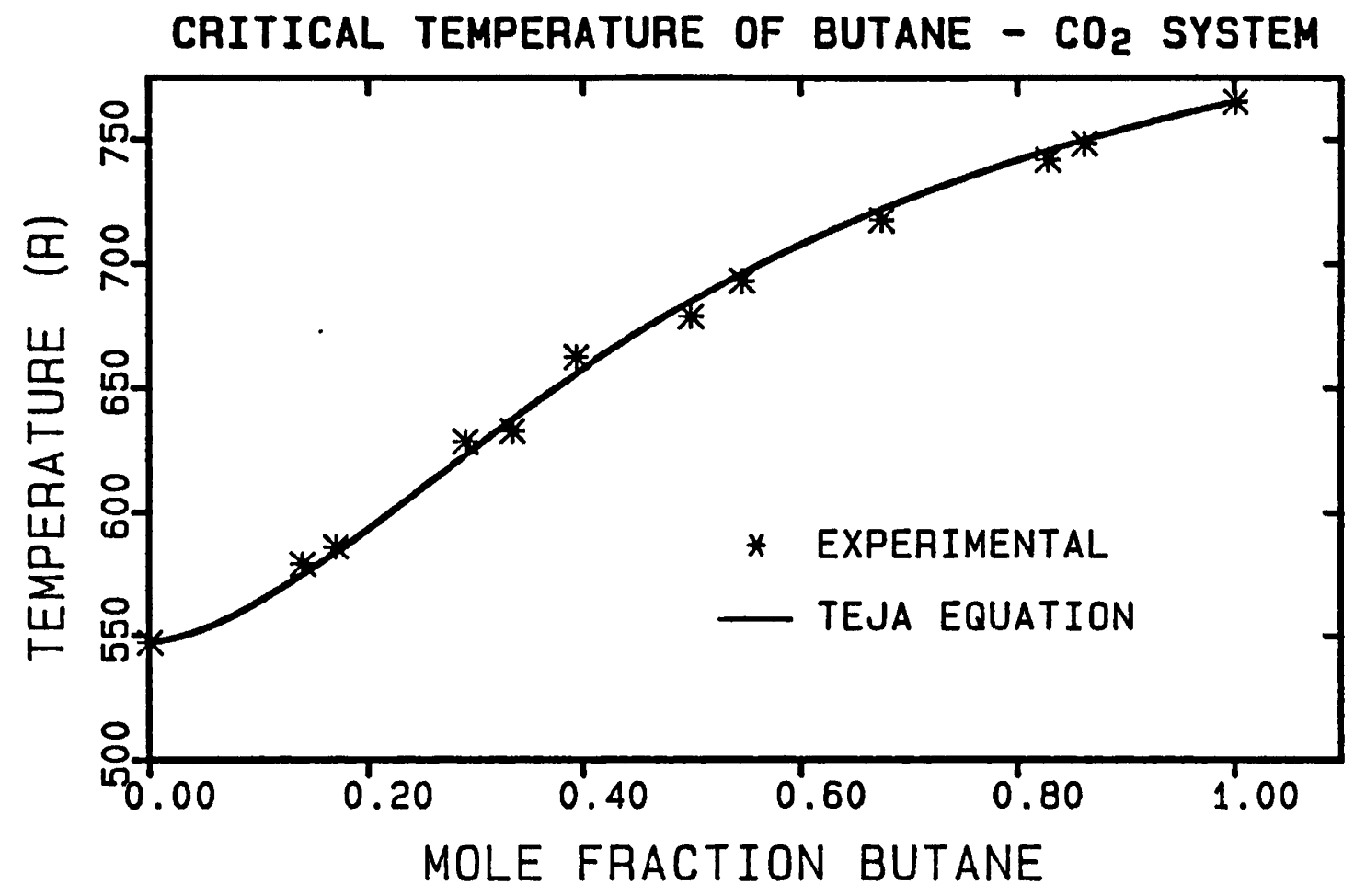

FIGURE 53

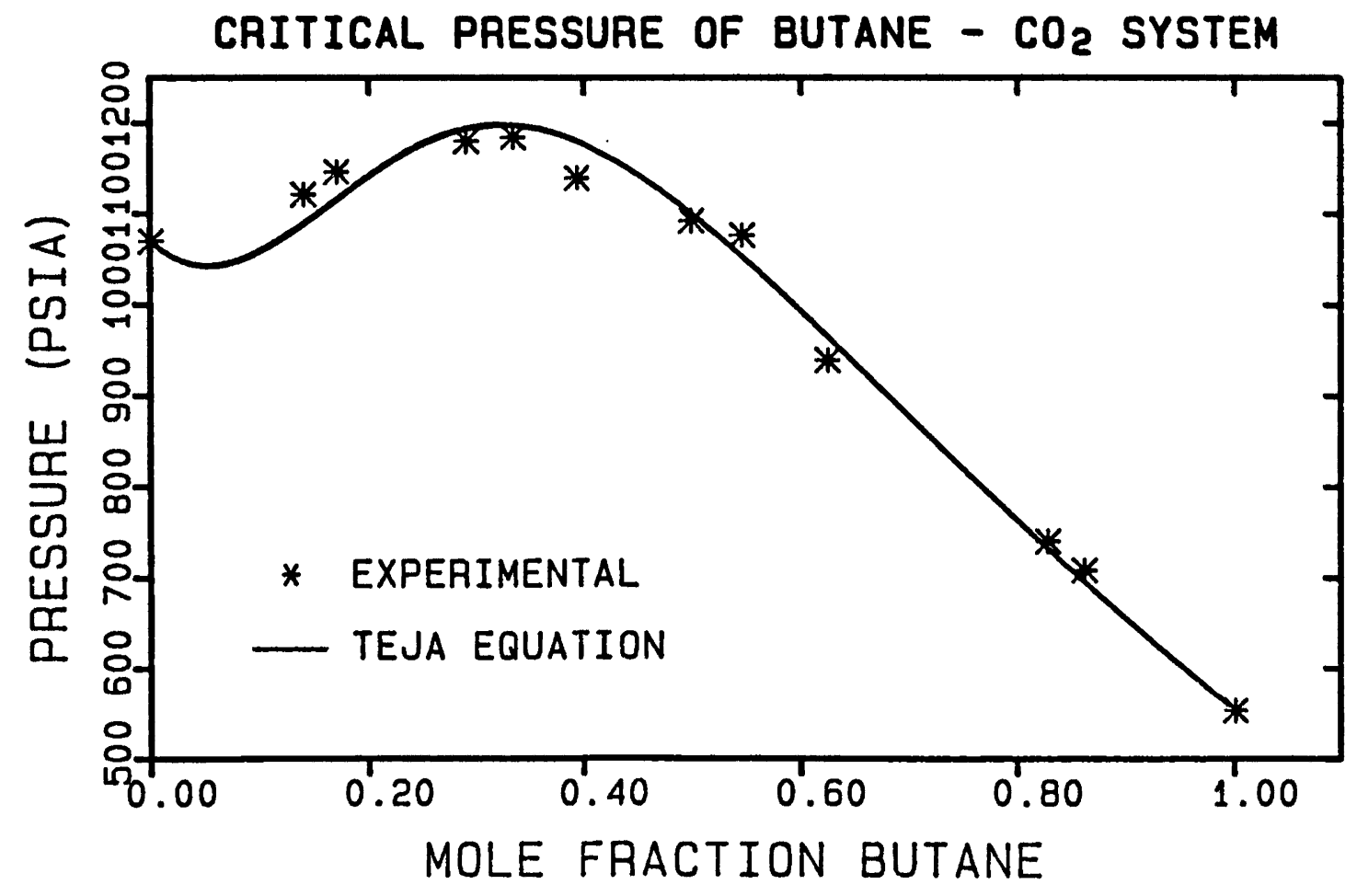


FIGURE 54

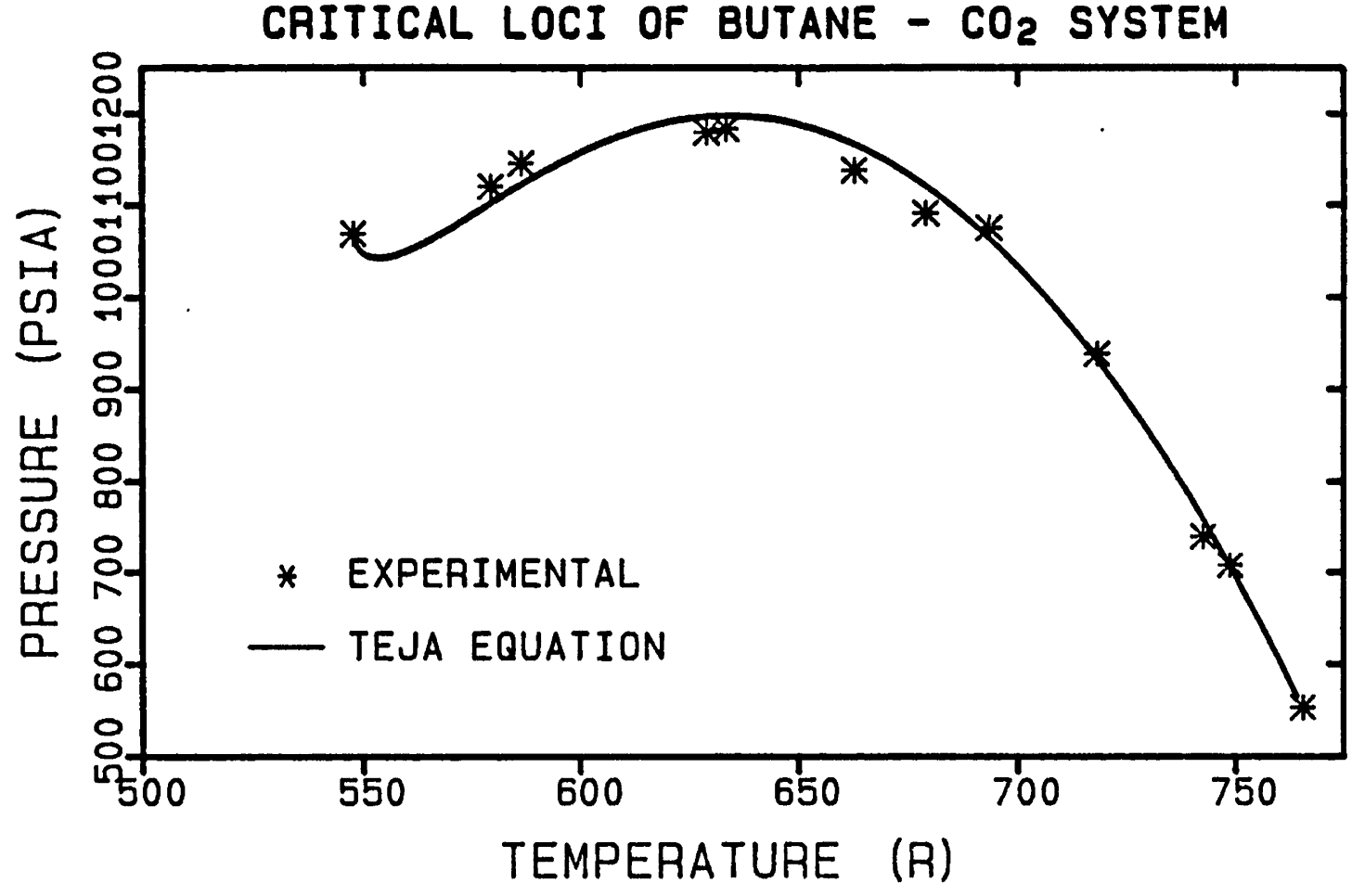

FIGURE 55

CAITICAL VOLUME OF BUTANE - $\mathrm{CO}_{2}$ SYSTEM

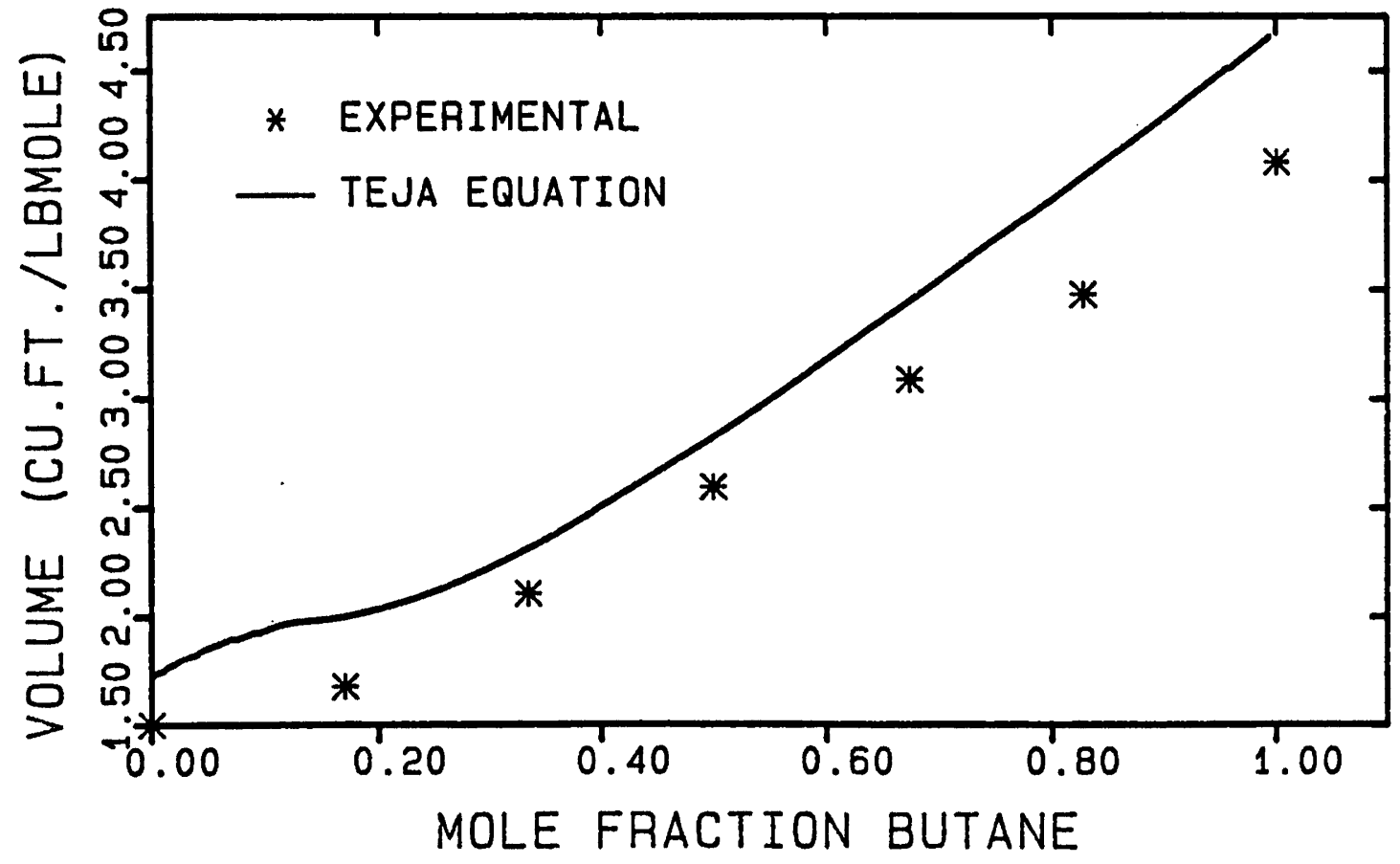




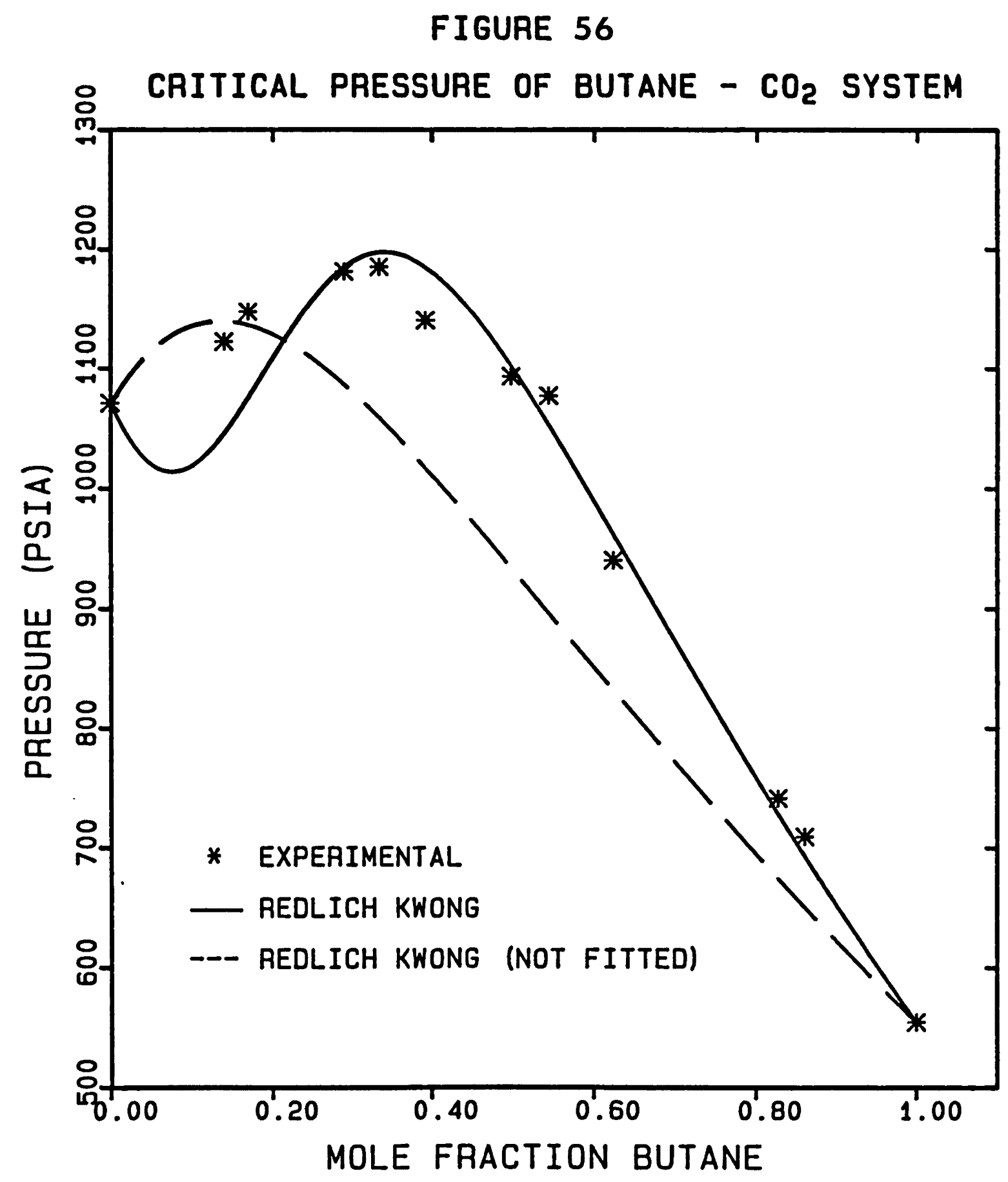




\subsubsection{The Decane - Carbon dioxide System}

Figure 57 compares the predicted versus experimental critical curves for the decane - carbon dioxide system. Unlike the previous type I systems, this mixture displays type II behavior because its pressure - temperature diagram shows two distinct critical lines. The gas-liquid critical curve is parabolic in shape and connects the two pure component critical points. The second critical line is a liquidliquid type and originates at a three - phase LCEP and continues at a steep slope to infinite pressures.

Unlike the type I binary mixtures, none of the equations tested were able to predict the two critical lines characteristic of the type II system, decane and carbon dioxide. Only the Soave equation was able to predict the gas - liquid critical locus with any reasonable accuracy. The critical values were predicted with an average error of $1.67 \%$ for the critical temperatures and $9.61 \%$ for the critical pressures. The Soave equation also failed, however to generate the second liquid - liquid critical curve. 


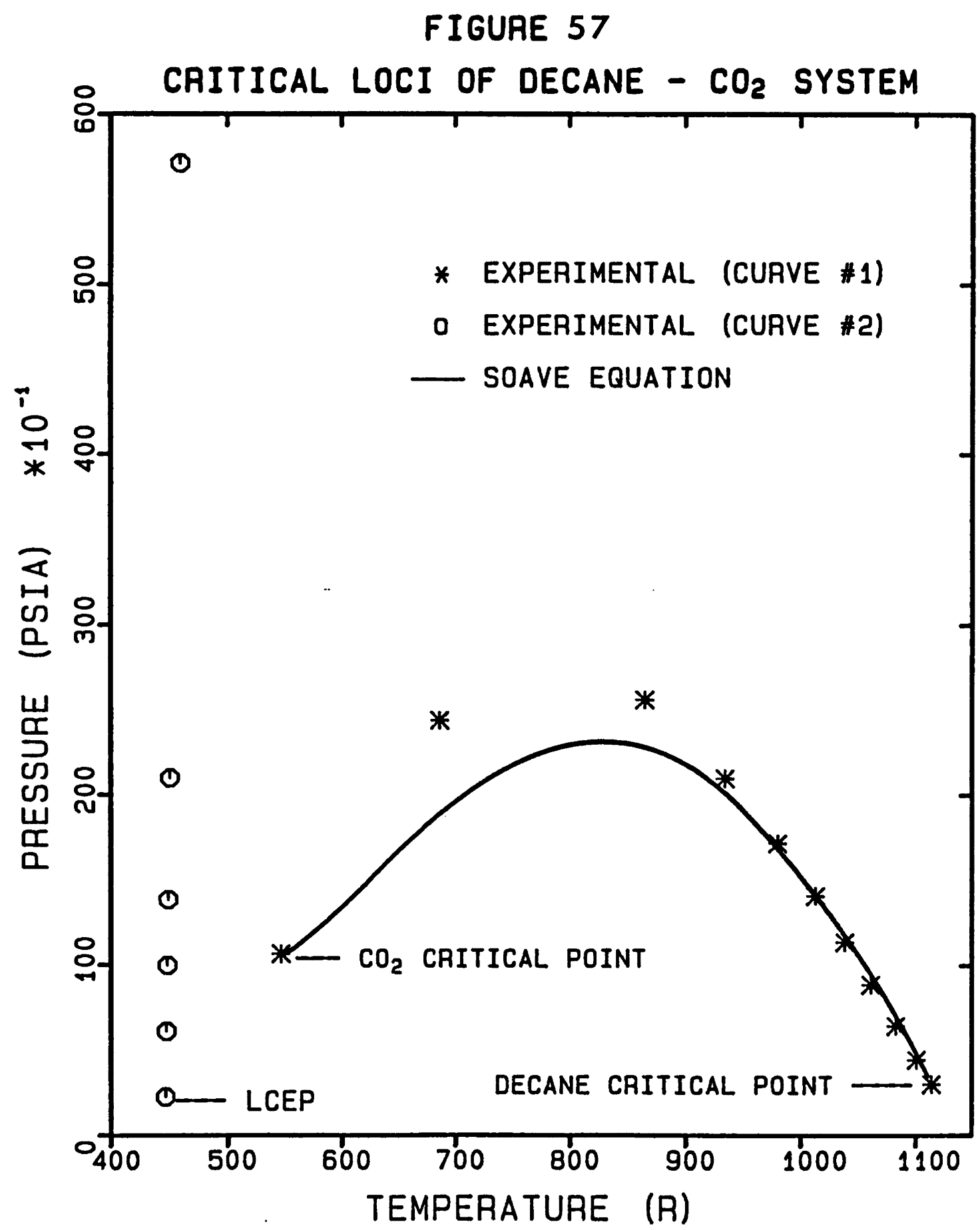




\subsection{CLASS 2 BINARY CRITICAL LOCI}

If the gas-liquid critical temperature of one of the components is of the order of two or more times that of the other component, there is often no continuous critical line joining the two critical points of the pure components. The four class 2 binary mixtures studied are:
(1) benzene - water (Rebert, Schnieder)
(2) carbon dioxide - water (Takenouchi)
(3) methane - hexane (Kohn)
(4) methane - heptane (Chang, Kohn, Reamer)

\subsubsection{The Benzene - water System}

Figures 58 and 59 compare the predicted versus experimental critical curves for the benzene - water system. This mixture is type III-HA $A_{m}$ and exhibits two critical curves on its pressure-temperature graph. The lower branch of the curve, originating at the critical point of benzene, has a negative slope, which is characteristic of type III-HA tems, and terminates at an UCEP. The coordinates of this point are $974.6^{\circ} \mathrm{R}$ and 1364 psia. The upper branch of the 
locus, beginning at the critical point of water, passes through a minimum temperature point, which is represented by the subscript " $m$ " in type III-HA nite pressures. The coordinates of the minimum point are $1154.1^{\circ} \mathrm{R}$ and 2300 psia.

of the five equations tested, only the Redlich-Kwong and Soave equation generated both critical curves with the correct qualitiative shape. Neither equation, however, was quantitatively correct. The Redlich-kwong equation was 'best' with a $1.61 \%$ average deviation in the critical temperatures and an $18.94 \%$ error in the pressures. It predicted an UCEP at $966.4^{\circ} \mathrm{R}$ and 1522 psia and a minimum point for the upper critical curve at $1054.4^{\circ} \mathrm{R}$ and $3727 \mathrm{psia}$. The Soave equation had errors of $2.69 \%$ for the critical temperatures and $30.89 \%$ for the critical pressures. The UCEP was placed at $967.8^{\circ} \mathrm{R}$ and 1440.1 psia while the minimum point had coordinates of $1112.4^{\circ} \mathrm{R}$ and 4157.8 psia. 
FIGURE 58

CRITICAL LOCI OF BENZENE - WATER SYSTEM

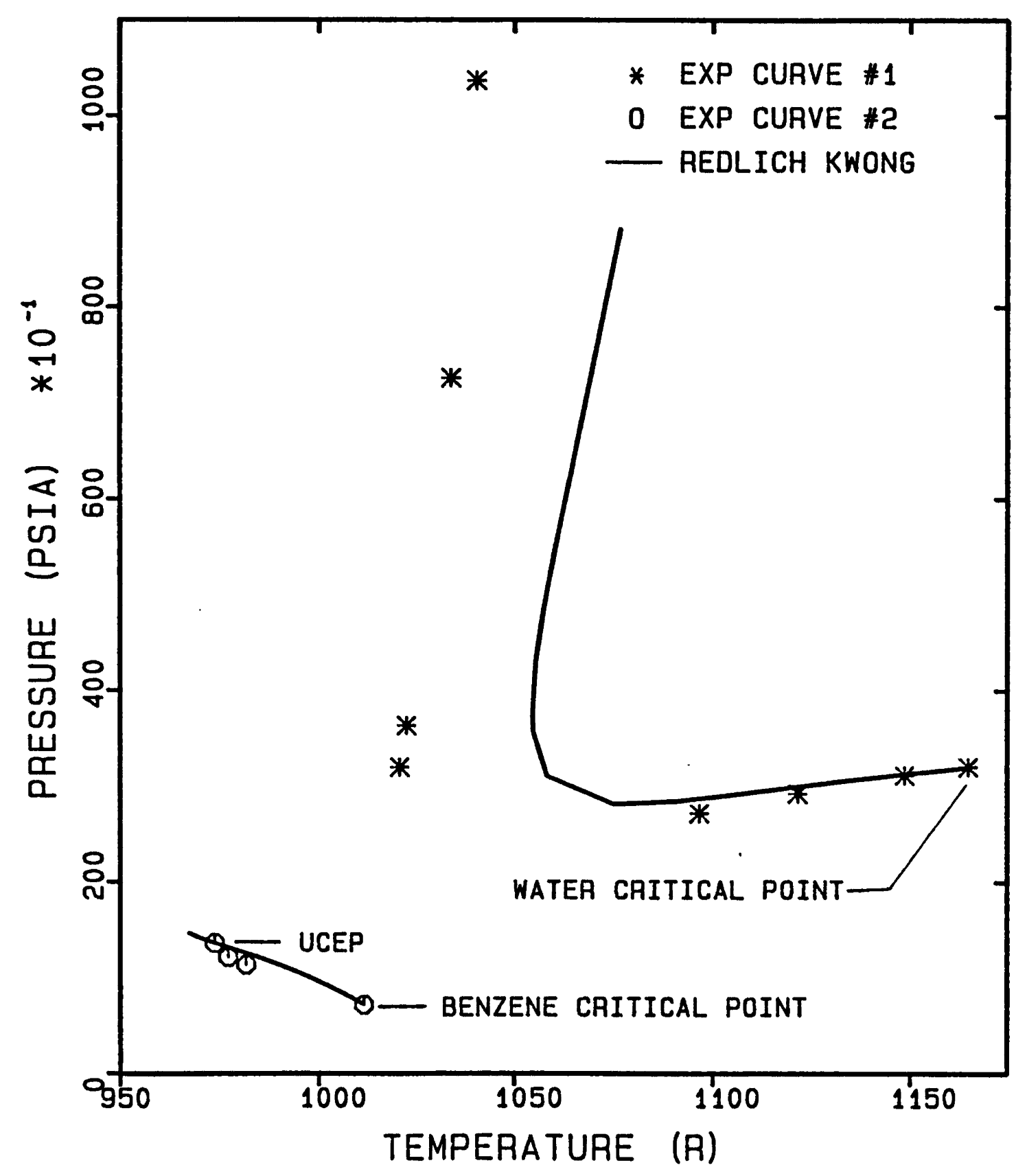


FIGURE 59

CRITICAL LOCI OF BENZENE - WATER SYSTEM

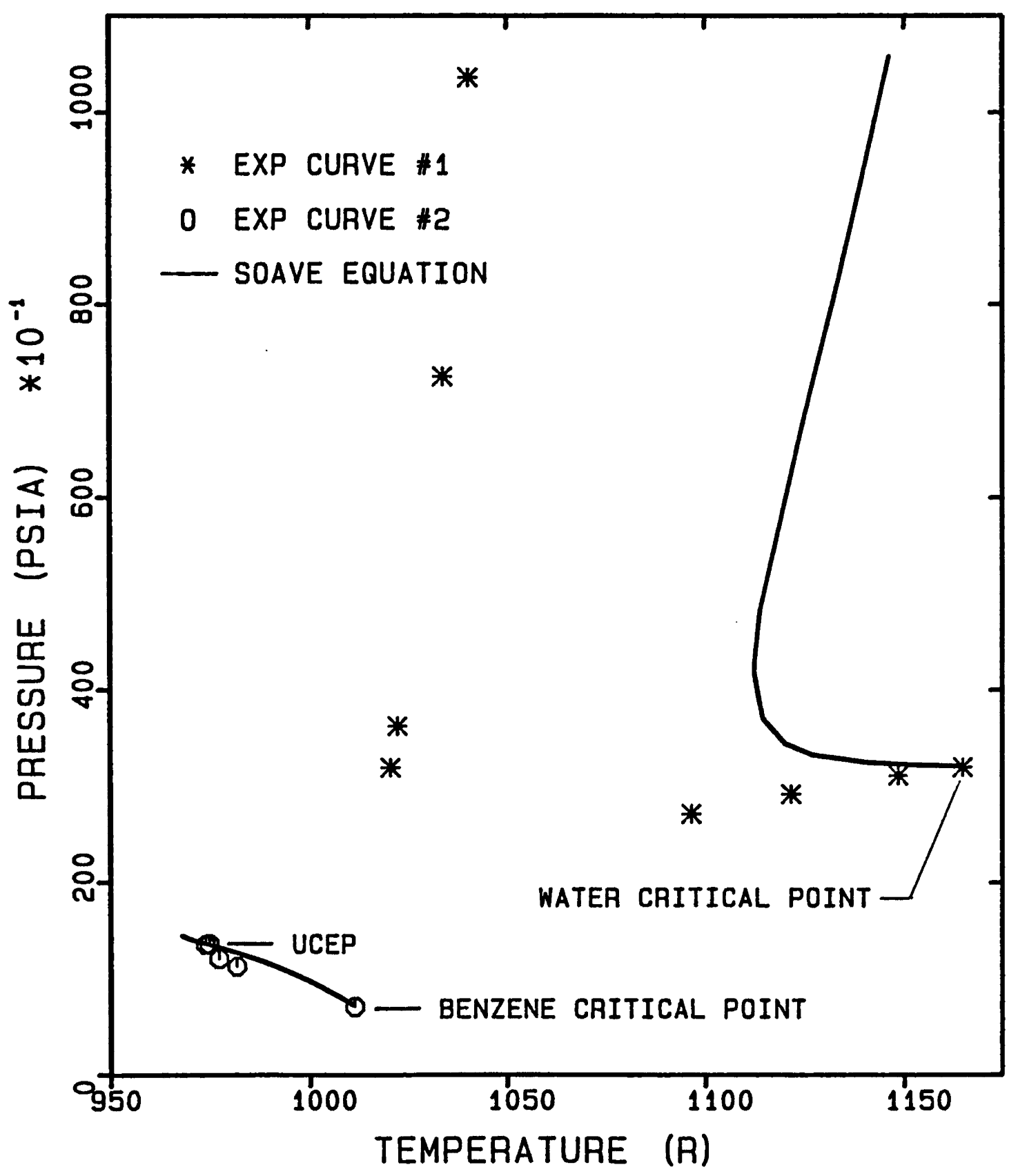




\subsubsection{The Carbon dioxide - water System}

Figures 60 - 62 compare the predicted versus experimental critical curves for the carbon dioxide - water system. This is a type IIIm system. Its two critical curves are similar to those of the benzene - water system except that the lower critical curve, which originates at the critical point of carbon dioxide and terminates at an UCEP, has a positive slope. The coordinates of the UCEP are not available but it is believed to be near the carbon dioxide critical point (Takenouchi). The upper critical line begins at the critical point of water and passes through a minimum temperature point at $968.7^{\circ} \mathrm{R}$ and 30775 psia, before diverging to infinite pressures.

As with the benzene - water system, all of the critical loci predictions were qualitative at best. The Soave equation was most accurate with a $1.41 \%$ deviation in predicting the critical temperatures and a $16.62 \%$ deviation in predicting the critical pressures. This equation generated an UCEP at $586.7^{\circ} \mathrm{R}$ and $1415.8 \mathrm{psia}$ and a minimum temperature point at $967.4^{\circ} \mathrm{R}$ and $19827 \mathrm{psia}$. The Peng and Robinson equation and the Adachi equation failed to predict even qualitatively acceptable critical curves for this system. 
FIGURE 60

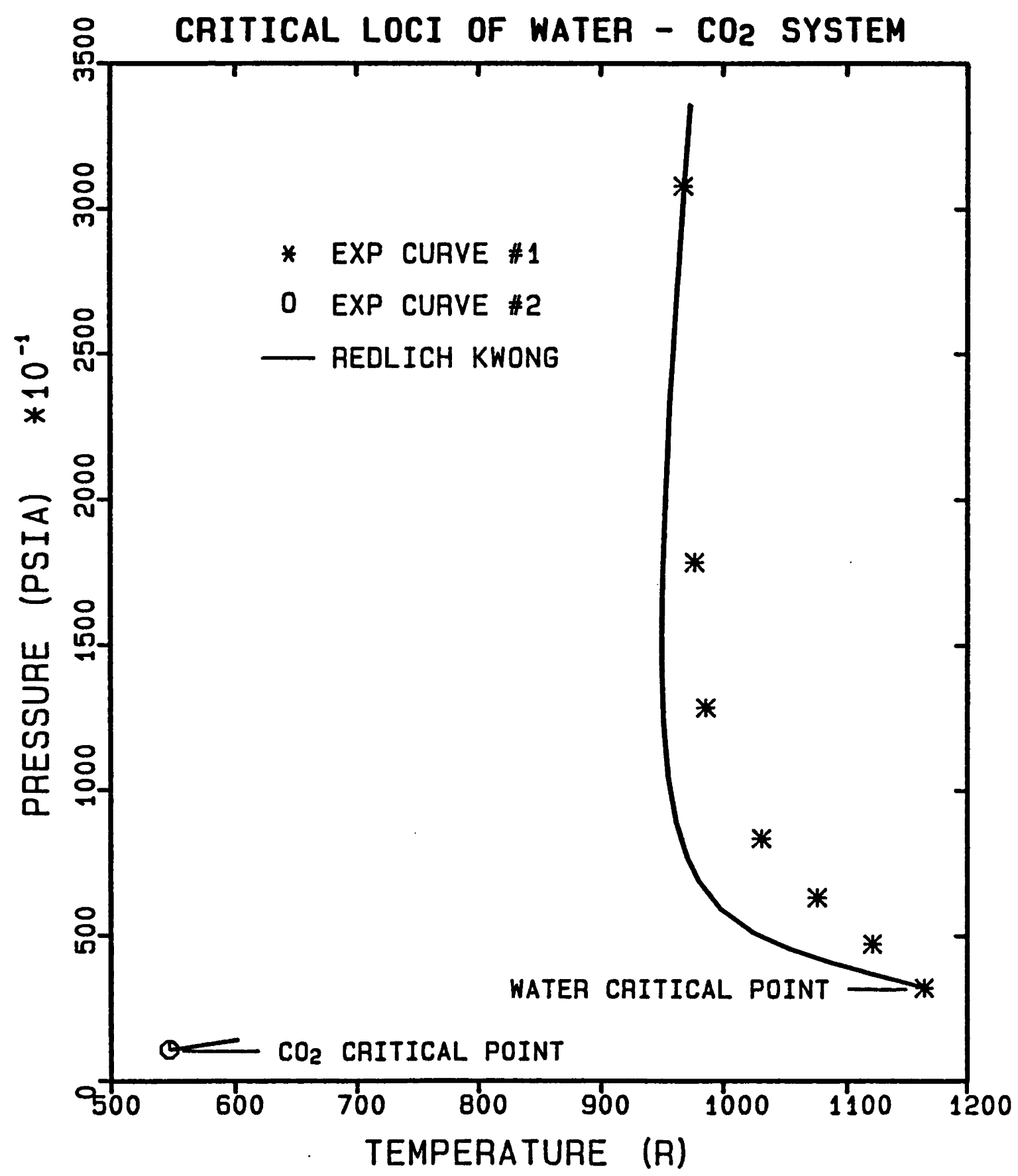


FIGURE 61

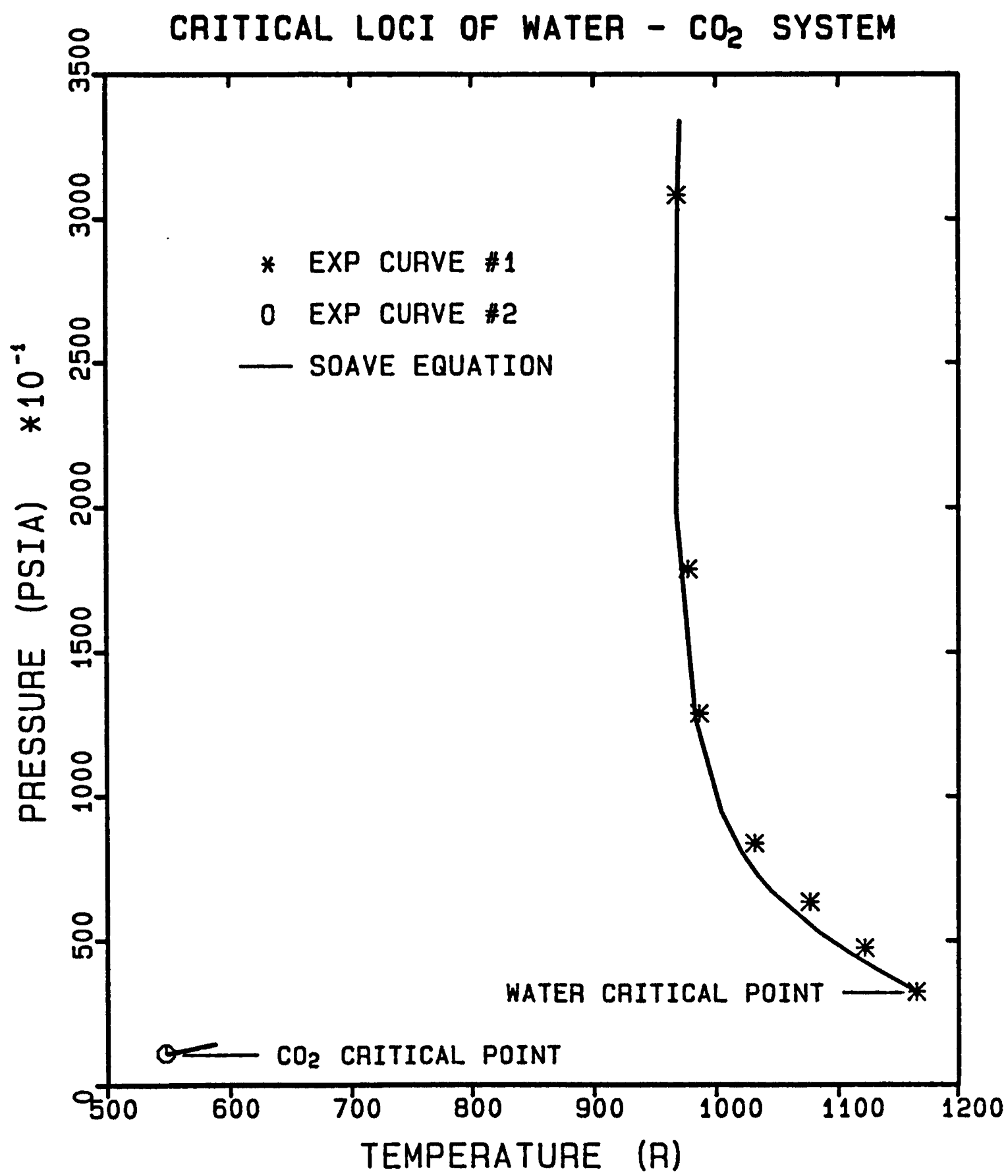


FIGURE 62

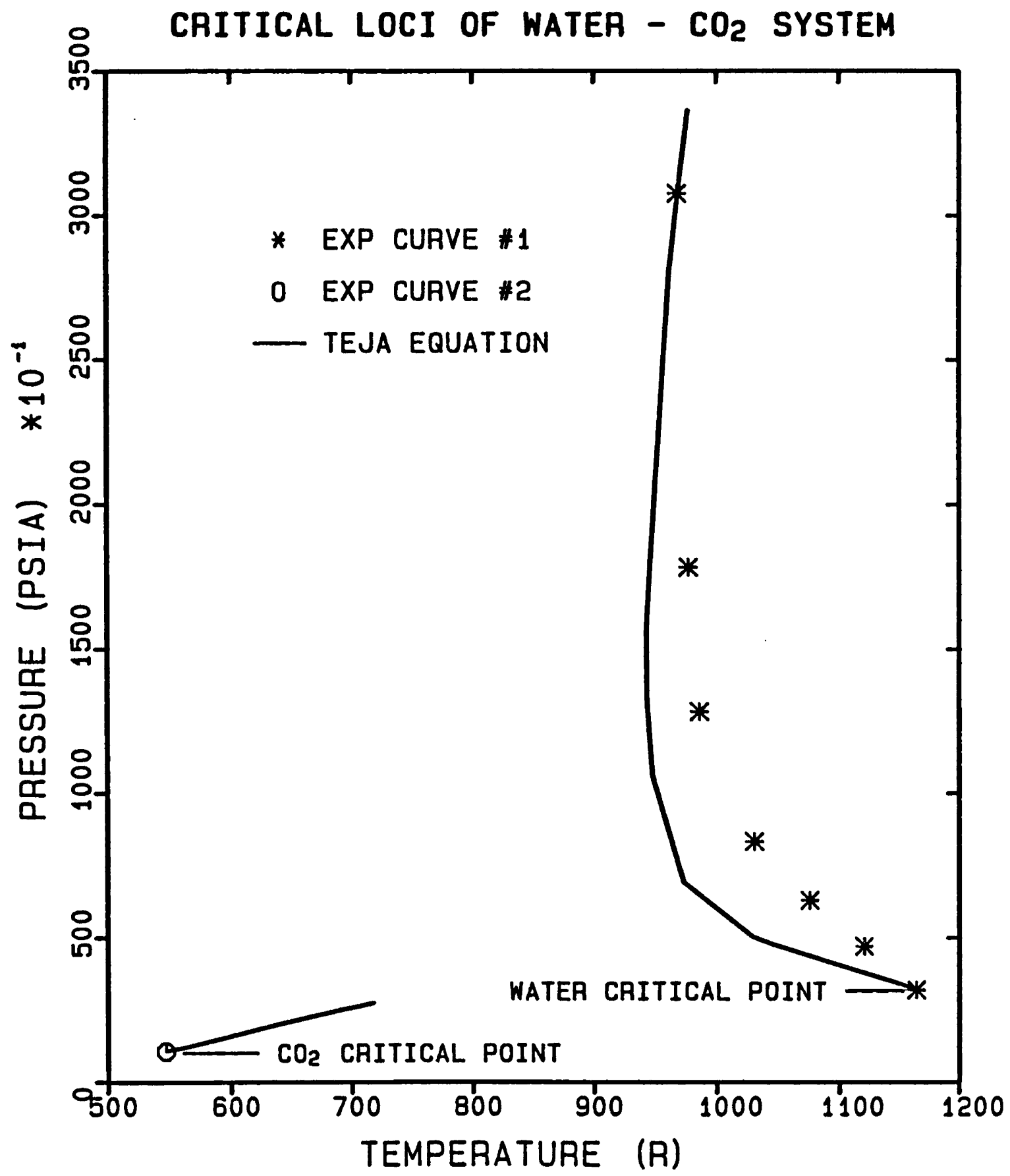




\subsubsection{The Methane - Hexane System}

Figures 63 and 64 compare the predicted versus experimental critical curves for the Methane - Hexane system. This system is classified as a type $V$ mixture. The upper critical curve begins at the critical point of hexane and passes through a maximum pressure point instead of diverging to infinite pressures as with the previous class 2 systems. It then terminates at a LCEP where three phases are present. The coordinates of the maximum point are $536.7^{\circ} \mathrm{R}$ and 2845 psia while the LCEP lies at $327^{\circ} \mathrm{R}$ and 495 psia. The lower critical curve is a gas-liquid type and begins at the critical point of methane and ends at an UCEP. The latter point is at $352^{\circ} \mathrm{R}$ and 760 psia.

None of the five equations tested were able to correctly predict the two critical curves of this system. However, two of the equations, Soave and Teja predicted a single critical curve which originated at the critical point of hexane. But instead of terminating at a LCEP, the curve ended at the critical point of methane. The equations were not acurate enough to predict the two critical endpoints. This may be due to the proximity of the LCEP and UCEP with the critical point of methane (only 25 degrees Rankine separate the three points). 
FIGURE 63

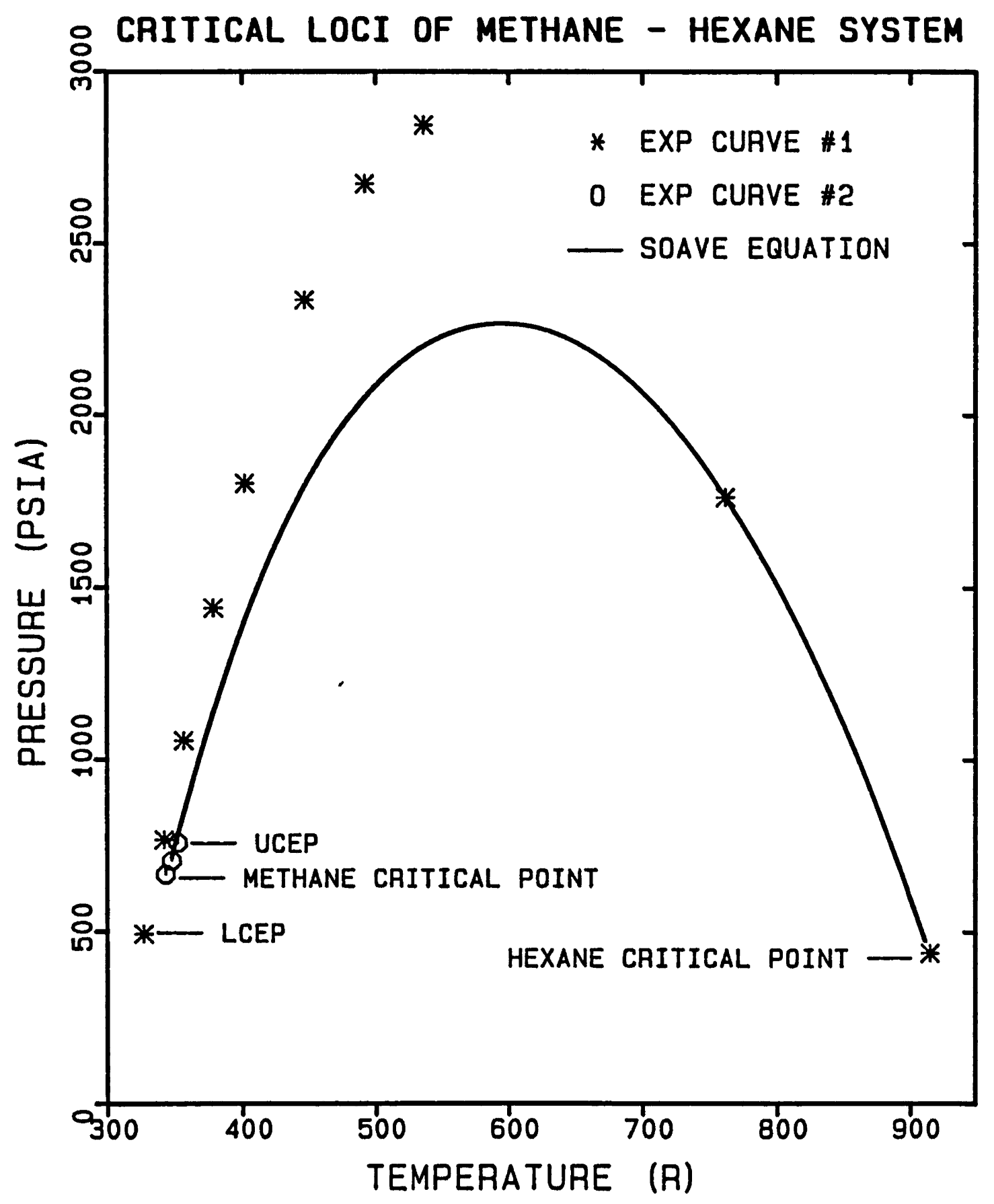


FIGURE 64

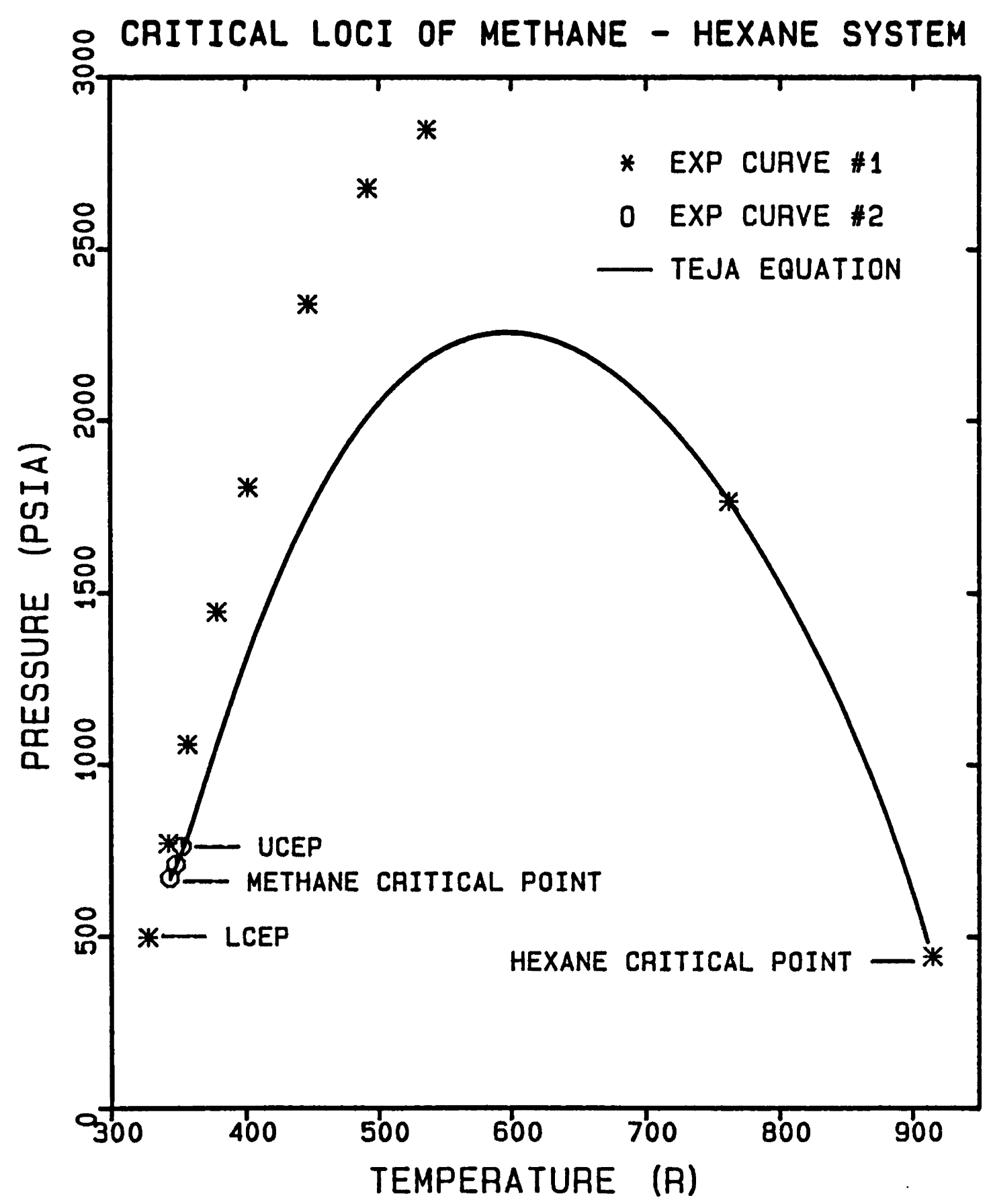




\subsubsection{The Methane - Heptane System}

Figures 65 - 68 compare the predicted versus experimental critical curves for the methane - heptane system. Like the methane - hexane system, this mixture is also type $V$. The lower critical curve begins at the methane critical point and ends at an UCEP with coordinates $345^{\circ} \mathrm{R}$ and 694 psia. The upper critical curve originates from the heptane critical point and passes through a maximum pressure point. Instead of ending at a LCEP, as with methane and hexane, a solid heptane phase appears and terminates the critical curve. Presumably the UCEP would have appeared if not for the relatively high freezing point of heptane (Scott).

For this system, only the Soave and Teja equation, generated both critical curves. The Soave equation had a $2.43 \%$ average deviation in predicting the critical temperatures and a $3.39 \%$ error for the critical pressures. It placed the UCEP at $348^{\circ} \mathrm{R}$ and 715 psia. The corresponding errors for the Teja equation where $4.9 \%$ and $8.3 \%$. It predicted the UCEP at $350.9^{\circ} \mathrm{R}$ and $733 \mathrm{psia}$.

For this equation critical volume data were also avaiable so a comparison could be made. Both the Soave and the Teja equation did poorly however, with average deviations of $18.89 \%$ and $22.23 \%$ respectively. 
FIGURE 65

CRITICAL LOCI OF METHANE - HEPTANE SYSTEM

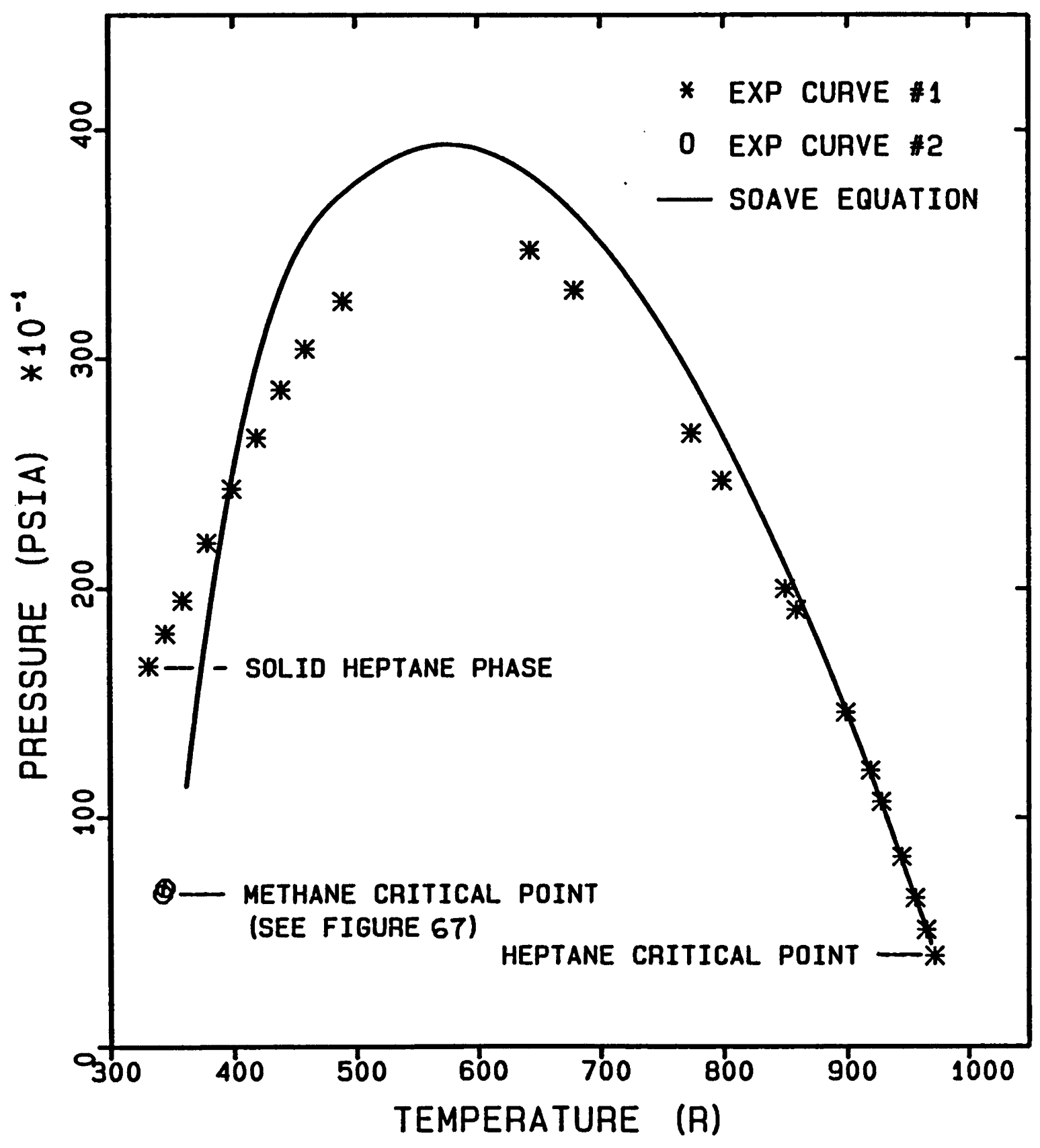




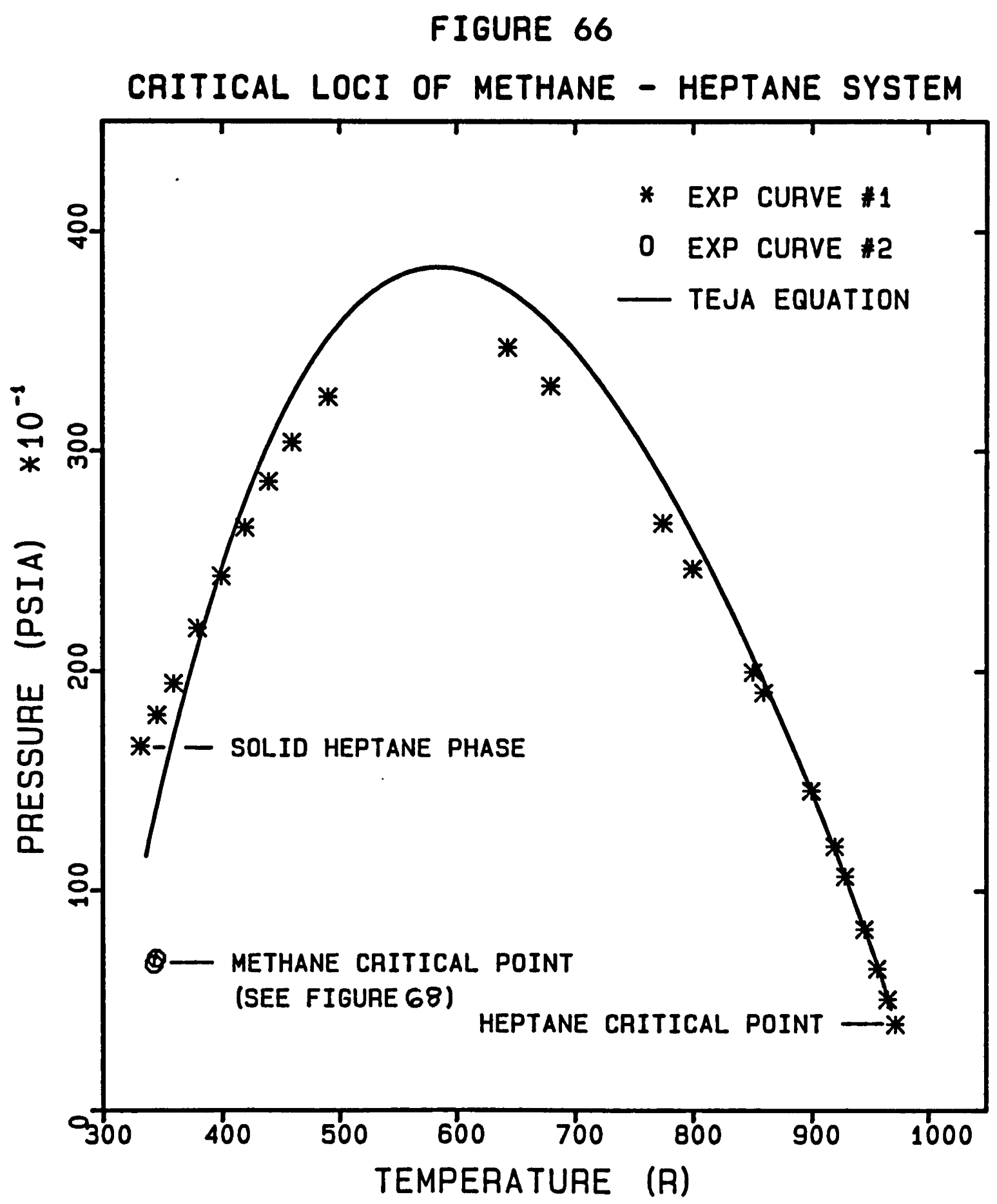


FIGURE 67. CRITICAL LOCI OF METHANE - HEPTANE

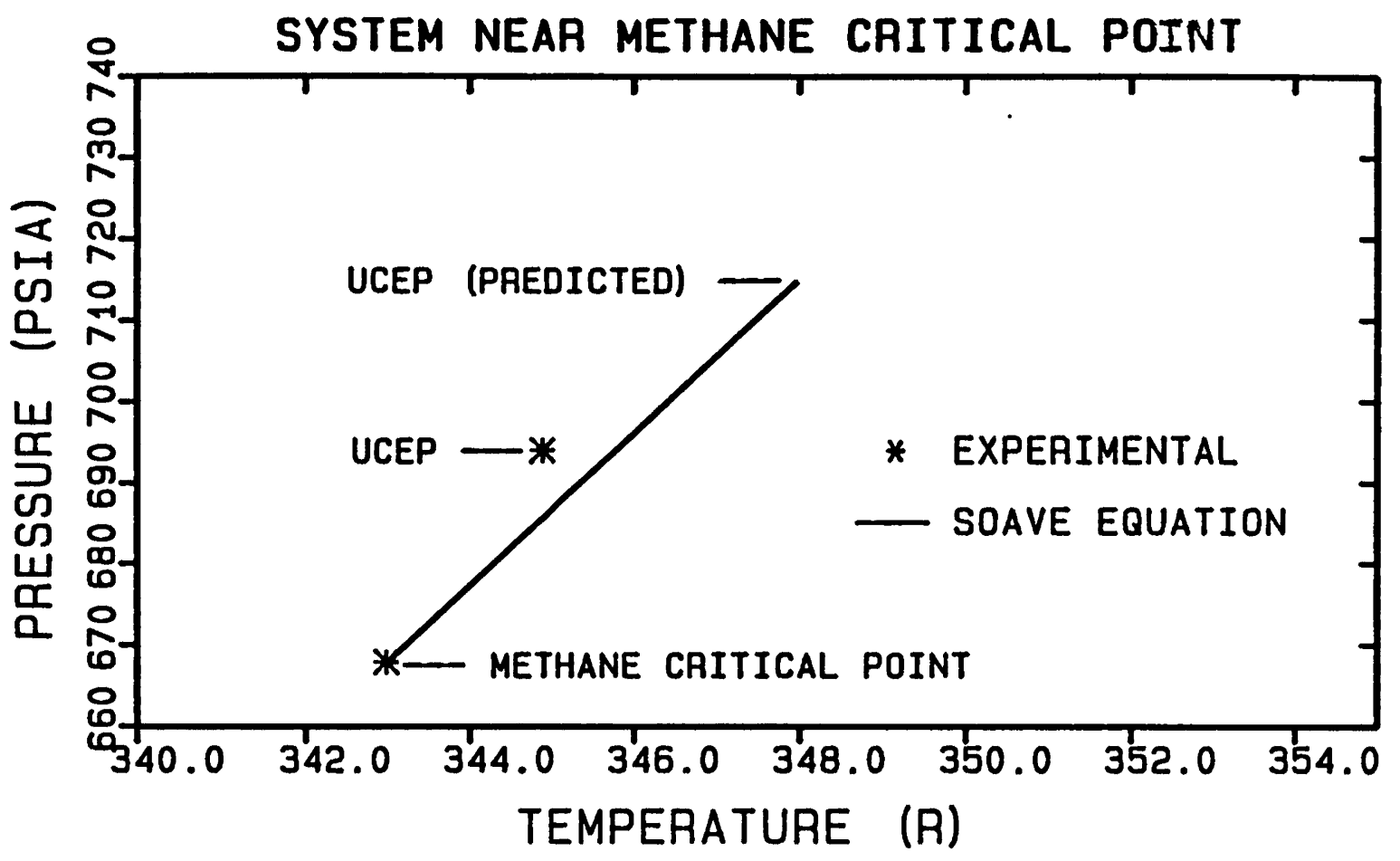

FIGURE 68. CRITICAL LOCI OF METHANE - HEPTANE

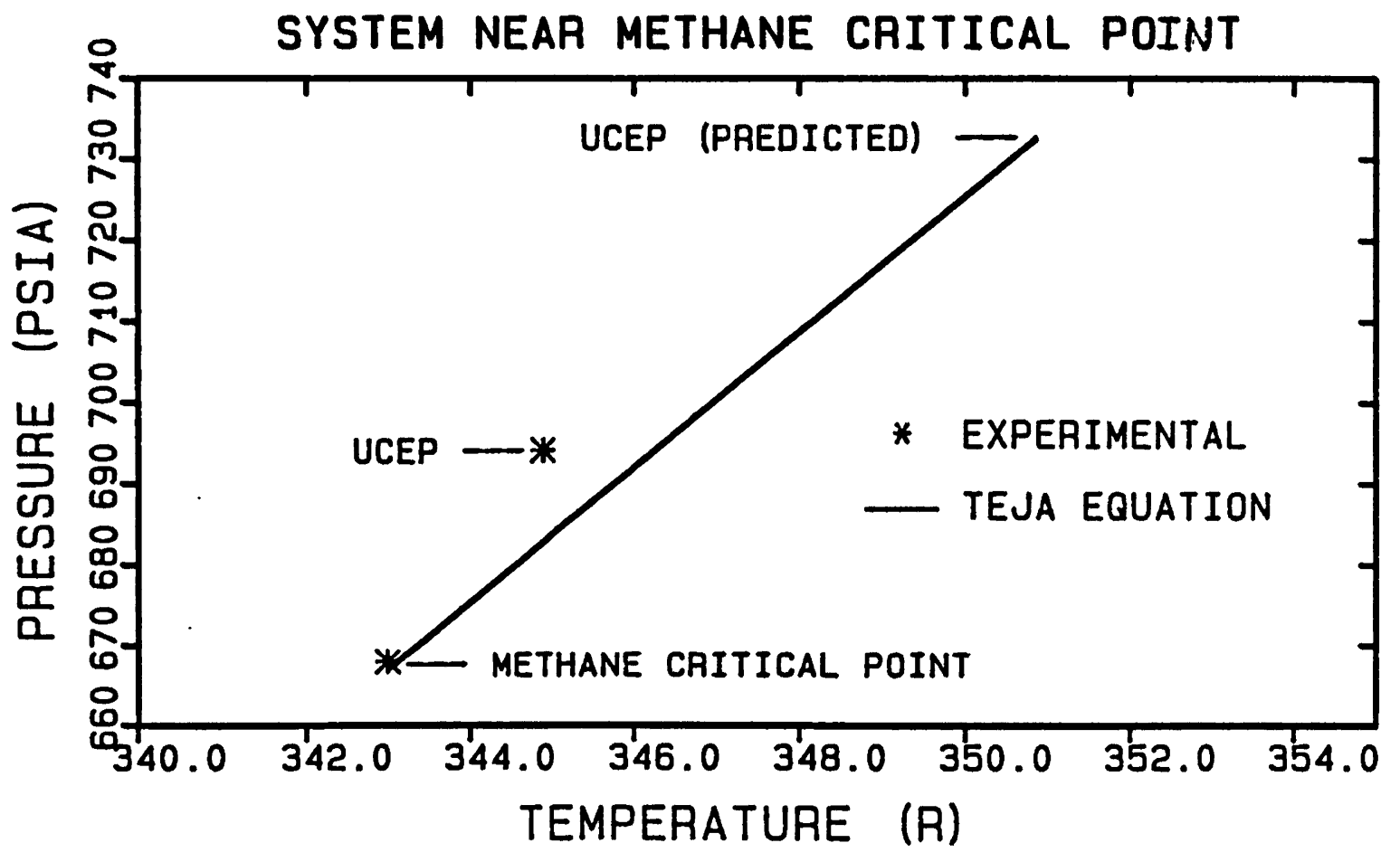




\subsection{CRITICAL VOLUME PREDICTION}

As mentioned earlier, none of the equations was able to satisfactorily predict the critical volumes of the mixtures tested. Most of the deviations were greater than $10 \%$.

Figure 69 shows that the critical volumes of the propane - hexane system could be predicted much more accurately by using the following equation:

$$
\mathrm{Vc} c_{\mathrm{m}}=\mathrm{V} c_{1} \cdot \mathrm{x}_{1}+\mathrm{V} c_{2} \cdot \mathrm{x}_{2}
$$

The above equation simply uses a mole fraction average of the pure component critical volumes to calculate the critical volume fo the mixture. This conclusion was also obtained with two other systems for which critical volume data was available (1) methane - carbon dioxide and (2) methane - heptane. Table 4 summarizes the results.

The reason for the poor critical volume prediction by the equations of state is due to the relatively high pure component critical compressibility generated by these equations. The Redlich kwong equation predicts the highest value of 0.333 . The corresponding value for the Peng and Robinson equation is 0.307 . The equation by Teja is unique in that it contains a variable compressibility. Its average value of 0.31 however, was still higher than the experimental values which lie between 0.25 and 0.30 . 
FIGURE 69

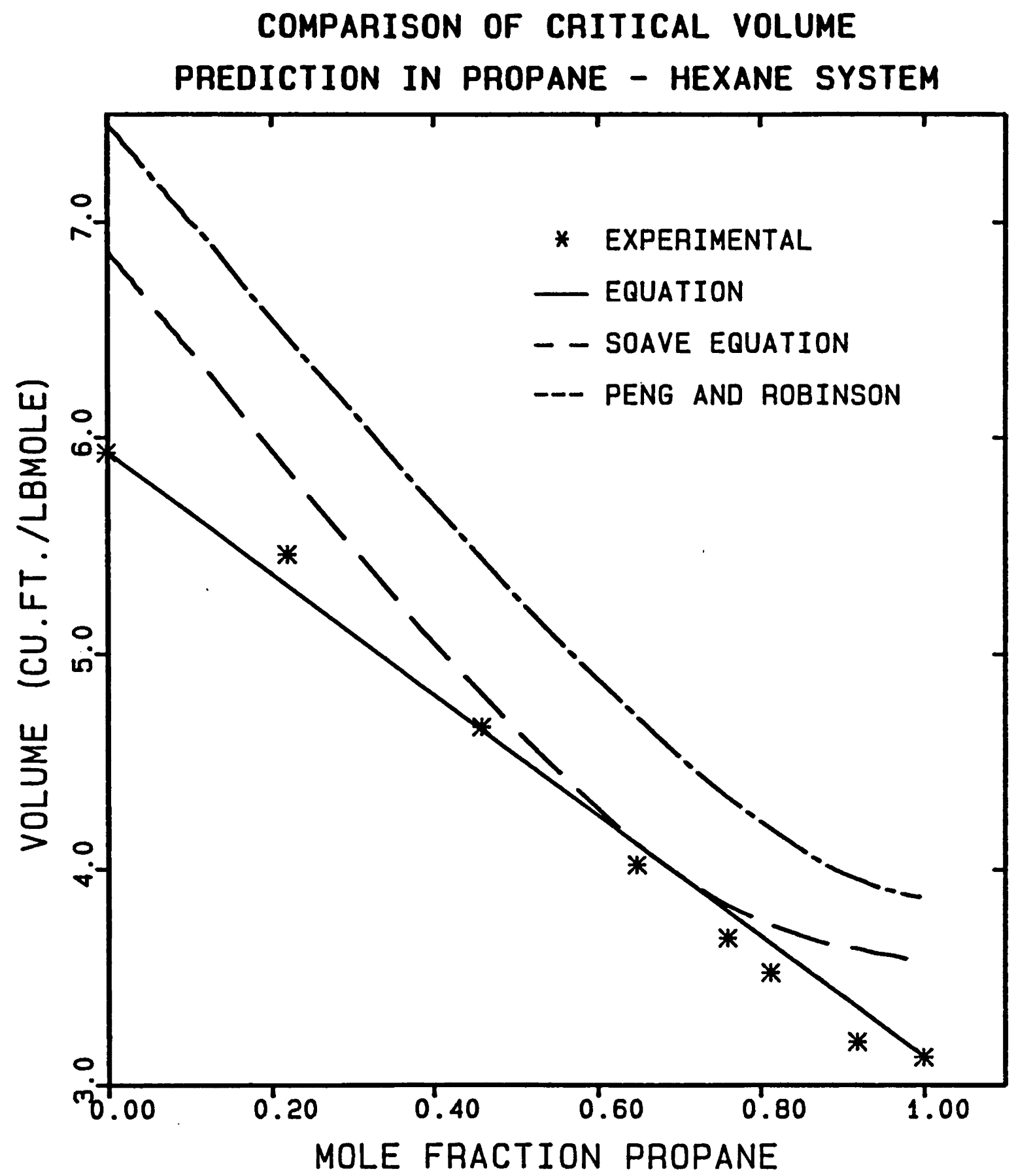


Table 4

Comparison of Methods for Predicting

Critical Volumes

\begin{tabular}{|c|c|c|c|c|c|c|}
\hline system & & $\begin{array}{l}\text { Redlich } \\
\text { Kwong }\end{array}$ & Soave & Adachi & $\begin{array}{l}\text { Peng and } \\
\text { Robinson }\end{array}$ & Teja \\
\hline $\begin{array}{l}\text { propane/ } \\
\text { hexane }\end{array}$ & $\begin{array}{l}(1) \\
(2)\end{array}$ & $\begin{array}{r}18.31 \\
3.56\end{array}$ & $\begin{array}{r}19.51 \\
3.56\end{array}$ & $\begin{array}{r}16.78 \\
3.56\end{array}$ & $\begin{array}{l}7.70 \\
3.56\end{array}$ & $\begin{array}{r}11.61 \\
3.56\end{array}$ \\
\hline $\begin{array}{l}\text { butane/ } \\
\mathrm{CO}_{2}\end{array}$ & & $\begin{array}{r}17.00 \\
6.50\end{array}$ & $\begin{array}{r}20.95 \\
6.50\end{array}$ & $\begin{array}{r}28.06 \\
6.50\end{array}$ & $\begin{array}{l}7.99 \\
6.50\end{array}$ & $\begin{array}{r}13.38 \\
6.50\end{array}$ \\
\hline $\begin{array}{l}\text { methane/ } \\
\text { heptane }\end{array}$ & & - & $\begin{array}{l}18.89 \\
21.75\end{array}$ & - & - & $\begin{array}{l}22.23 \\
21.75\end{array}$ \\
\hline
\end{tabular}

percent error critical volume prediction by:

(1) equation of state

(2) equation 44 


\section{Chapter V \\ CONCLUSION}

The critical loci of eight binary hydrocarbon and nonhydrocarbon mixtures have been predicted with five cubic equations of state. These mixtures correspond to four class 1 and four class 2 critical loci as catagorized by van Konynenburg. The predictions have been compared with experimental data to determine the most accurate equation.

No single equation was the most accurate for all types of mixtures tested. For calculating the critical pressures and temperatures of hydrocarbon mixtures the Teja equation of state was the best. The average deviation from experimental results was well within the experimental error for this equation. For more complex binary mixtures, such as benzene and water, the predictions were qualitative at best. The Soave equation was the only equation able to generate the critical curves of all the mixtures tested. However, its predictions for the class 2 systems were also only qualitatively accurate.

It appears that the common cubic equations of state are incapable of modeling the critical loci of class 2 mixtures, due to the complex molecular interactions that occur in 
these systems. Because these types of mixtures are encountered in supercritical extraction (Paulaitis, Schneider), future work should concentrate on improving the critical loci prediction of these systems.

Unlike the critical temperatures and pressures, the critical volume predictions were inaccurate even in the case of simple class 1 binary systems. Most of the predictions had errors of at least ten percent. 


\section{References}

Chang, H. L., Hurt, L. J., and Kobayashi, R., AIChE J., Vol. 12, No. 6, p. 1212, (1966).

Chang, R. F., Morrison G., and Sengers, J. M. H., J. Phys. Chem., Vol. 88, No. 16, p. 3389, (1984).

Donnelly, H. G., and Katz, D. L., Ind. Eng. Chem., Vol. 46, No. 3, p. 511, (1954).

Gibbs, J.W., "Collected Works", Vol. 1, pp. 129-134, Longmans, Green, and Company, New York, (1928).

Hissong, D. W. and Kay, W. B., AIChE J., Vol. 16, No. 4, p. $580,(1970)$ ?

Joffe, J., and Zudkevitch, D., Chem. Eng. Prog. Symp. S., vol. 63, p. 43 .

Kay, W. B., J. Chem. Eng. Data, Vol. 16, No. 2, p. 137, (1971).

Kohn, J. P., AIChE J., Vol. 7, No. 3, p. 514, (1961).

Paulaitis, M. E., Penninger, J. M. L., and Gary, R.D., "Chemical Engineering at Supercritical Fluid Conditions", Ann Arbor Science, 1983.

Peng, Ding-Yu, and Robinson, Donald B., Ind. Eng. Chem. Fund., Vol. 15, No. 1, p. 59, (1976).

Rebert, C. J., and Kay, w. B., AIChE. J., Vol. 5, No. 3, p. 285, (1963).

Reamer, H. H., and Sage, B. H., J. Chem. Eng. Data, Vol. 8, No. 4, p. 508, (1963).

Reamer, H. H., Sage, B. H., and Lacey, W. N., Chem. Eng. Data S., Vol. 1, No. 1, p. 29, (1956).

Redlich, O., and Kister H., and Lacey, w. N., Ind. Eng. Chem., No. 841 , No. 3, p. 475, (1949).

Redlich, O., and Kwong, J. N. S., Chem. Rev., Vol. 44, p. 233, (1949).

Reid, C. R., Prausnitz, J. M., and Sherwood, T. K., "The Properties of Gases and Liquids", 3rd ed., MCGraw-Hill Book Co., (1977). 
Robert, M., and Tavan, P., J. Chem. Phys., Vol. 78, No. 5, p. 2557, (1983).

Rowlinson, J. S., Physik. Chem. B.G., Vol. 76, No. 3, p. 282, (1972).

Schneider, G.M., Physik. Chem. B.G., Vol. 76, No. 3, p. 325, $(1972)$.

Schneider, G. M., Stahl, E., and Wilke, G., "Extraction with Supercritical Gases", Verlag Chemie, Weinheim, 1980.

Scott, Robert L., Physik. Chem. B.G., Vol. 76, No. 3, p. 296, (1972).

Scott, R. L., and van Konynenburg, P. H. , Phil. Trans. Roy. Soc. Lond., Vol. 298, No. 1442, p. 495, (1980).

Sengers, J. M. H., Morrison, G., and Chang, R. F., Fluid Phase Equilibria, Vol. 14, p. 19, (1983).

Shim, J., and Kohn, J. P., J. Chem. Eng. Data, Vol. 7, No. 1. p. 3, (1962).

Spear, R. R., Robinson, R. L. Jr., and Chao, K. C., I\&EC Fund., Vol. 8, No. 1, p. 2, (1969).

Soave, G., Chem. Eng. Sci., Vol. 27, p. 1197, (1972).

Takenouchi, S., and Kennedy, G. C., Am. J. Sci., Vol. 262, p. $1055,(1964)$.

Teja, Amyn S., and Patel, Navin C., Chem. Eng. Sci., Vol. 37, No. 3, p. 463, (1982).

Teja, Amyn S., and Rowlinson, J. S., Chem. Eng. Sci., Vol. 28, p. 529, (1972).

van Konynenburg, P. H., "Critical Lines and Phase Equilibria in Binary Mixtures", Ph.D. Thesis, UCLA, 1968. 


\section{Appendix A}

\section{DERIVATION OF FREE ENERGY EQUATIONS IN TERMS OF $P, V$, AND $X$}

Note: The equations derived below are analogous to the Helmholtz free energy equations as stated in Rowlinson.

At the critical point of a binary mixture:

$$
\begin{aligned}
& \left(\frac{\partial^{2} G}{\partial x_{1}^{2}}\right)_{p, t}=0 \\
& \left(\frac{\partial^{3} G}{\partial x_{1}^{3}}\right)_{p, t}=0
\end{aligned}
$$

On a molar basis at constant temperature and pressure, the chemical potential can be written as:

$$
\mu_{1}=\left(\frac{\partial G}{\partial x_{1}}\right)_{p, t}
$$

Written in terms of the chemical potential, equations A.l and A. 2 become:

$$
\left(\frac{\partial \mu_{1}}{\partial x_{1}}\right)_{p, t}=0
$$




$$
\left(\frac{\partial^{2} \mu_{1}}{\partial x_{1}^{2}}\right)_{p, t}=0
$$

Using the definition of the fugacity at constant $t$ and $p$ :

$$
\partial \mu_{1}=R T \partial \ln \left(f_{1}\right)
$$

The critical point equations become (for constant $t$ and $p$ :

$$
\begin{aligned}
& \frac{\partial}{\partial x_{1}} \ln \left(f_{1}\right)=0 \\
& \frac{\partial^{2}}{\partial x_{1}{ }^{2}} \ln \left(f_{1}\right)=0
\end{aligned}
$$

Substituting the definition of the fugacity coefficient:

$$
\Phi_{1} X_{1} P=f_{1}
$$

gives:

$$
\begin{aligned}
& \frac{\partial}{\partial x_{1}} \ln \left(\Phi_{1} x_{1} P\right)=0 \\
& \frac{\partial^{2}}{\partial x_{1}^{2}} \ln \left(\Phi_{1} x_{1} P\right)=0
\end{aligned}
$$

The above equations are at constant $t$ and $p$. Because $\partial x_{1}=$ $-\partial \mathrm{X}_{2}$ equations $\mathrm{A} .10$ and $\mathrm{A} .11$ can also be written in terms of component 2 as: 


$$
\begin{aligned}
& \frac{\partial}{\partial X_{1}} \ln \left(\Phi_{2} X_{2} P\right)=0 \\
& \frac{\partial^{2}}{\partial X_{1}^{2}} \ln \left(\Phi_{2} X_{2} P\right)=0
\end{aligned}
$$

Subtracting equation A.12 from A.10 and A.13 from A.11 gives:

$$
\begin{aligned}
& \frac{\partial}{\partial \mathrm{X}_{1}} \ln \left(\frac{\Phi_{1} \mathrm{X}_{1}}{\Phi_{2} \mathrm{X}_{2}}\right)=0 \\
& \frac{\partial^{2}}{\partial \mathrm{X}_{1}{ }^{2}} \ln \left(\frac{\Phi_{1} \mathrm{X}_{1}}{\Phi_{2} \mathrm{X}_{2}}\right)=0
\end{aligned}
$$

Performing the indicated differentiation (at constant $t$ and p) gives:

$$
\begin{aligned}
& \frac{\partial}{\partial \mathrm{x}_{1}} \ln \left(\frac{\Phi_{1}}{\Phi_{2}}\right)=\frac{-1}{\mathrm{x}_{1} \mathrm{x}_{2}} \\
& \frac{\partial^{2}}{\partial \mathrm{x}_{1}{ }^{2}} \ln \left(\frac{\Phi_{1}}{\Phi_{2}}\right)=\frac{\mathrm{x}_{2}-\mathrm{x}_{1}}{\mathrm{x}_{1}{ }^{2} \mathrm{x}_{2}{ }^{2}}
\end{aligned}
$$

Thermodynamics gives the following equations:

$$
\ln \left(\Phi_{1}\right)=\int_{0}^{p}\left(v_{1} / R T-1 / P\right) d p
$$




$$
\left(\frac{\partial V}{\partial x_{1}}\right)_{p, t}=\left(\frac{\partial P}{\partial x_{1}}\right)_{V, t}\left(\frac{\partial V}{\partial P}\right)_{x, t}
$$

Using equations $A .17$ and $A .18$, the ratio of the fugacity coefficients can be calculated as:

$$
\ln \left(\frac{\Phi_{1}}{\Phi_{2}}\right)=-\int_{\infty}^{V}\left(\frac{\partial P}{\partial X_{1}}\right)_{v, t} d V / R T
$$

Substituting A.20 into equations A.16 and A.17, performing the indicated differentiation (the integral can be differentiated with Leibnitz' formula), and using the following relations:

$$
\left(\frac{\partial V}{\partial x_{1}}\right)_{p, t}=-\left(\frac{\partial V}{\partial P}\right)_{x, t}\left(\frac{\partial P}{\partial x_{1}}\right)_{V, t}
$$

$$
\begin{aligned}
\left(\frac{\partial^{2} V}{\partial X_{1}^{2}}\right)_{p, t} & =-\left(\frac{\partial^{2} V}{\partial P \partial X_{I}}\right)_{t}\left(\frac{\partial P}{\partial X_{I}}\right)_{V, t} \\
& -\left(\frac{\partial V}{\partial P}\right)_{x, t}\left(\frac{\partial^{2} P}{\partial x_{1}^{2}}\right)_{V, t} \\
& -\left(\frac{\partial V}{\partial P}\right)_{x, t}\left(\frac{\partial V}{\partial X_{I}}\right)_{p, t}\left(\frac{\partial^{2} P}{\partial V \partial X_{I}}\right)_{t}
\end{aligned}
$$


Gives the final form of the equations for calculating the critical loci of binary mixtures using an equation of state:

$$
\begin{gathered}
\int_{\infty}^{v}\left(\frac{\partial^{2} P}{\partial x_{1}^{2}}\right)_{v, t} d v-\left(\frac{\partial P}{\partial x_{1}}\right)_{v, t}^{2}\left(\frac{\partial V}{\partial P}\right)_{x, t} \\
=\frac{R T}{x_{1} x_{2}}
\end{gathered}
$$

$$
\begin{aligned}
& \int_{\infty}^{v}\left(\frac{\partial^{3} P}{\partial x_{1}^{3}}\right)_{v, t} d v-2\left(\frac{\partial^{2} P}{\partial x_{1}^{2}}\right)_{v, t}\left(\frac{\partial P}{\partial x_{1}}\right)_{v, t}\left(\frac{\partial v}{\partial P}\right)_{x, t} \\
& +\left(\frac{\partial^{2} P}{\partial X_{1} \partial V}\right)_{T}\left(\frac{\partial V}{\partial P}\right)_{x, t}^{2}\left(\frac{\partial P}{\partial X_{1}}\right)_{V, t}^{2} \\
& -\left(\frac{\partial V}{\partial P}\right)_{x, t}\left[\frac{\partial}{\partial x_{I}}\left(\frac{\partial P}{\partial x_{1}}\right)_{V, t}\right]_{p, t}\left(\frac{\partial P}{\partial x_{1}}\right)_{v, t} \\
& +\left(\frac{\partial V}{\partial P}\right)_{x, t}^{2}\left(\frac{\partial P}{\partial X_{1}}\right)_{V, t}^{2}\left[\frac{\partial}{\partial X_{1}}\left(\frac{\partial P}{\partial V}\right)_{x, t}\right]_{p, t} \\
& =\frac{\operatorname{RT}\left(x_{1}-x_{2}\right)}{x_{1}^{2} x_{2}^{2}}
\end{aligned}
$$

